\title{
MECHANISM OF HYDRODENITROGENATION
}

FINAL REPORT

Period of Performance: Sep. 1, 1989-Aug. 31, 1992

Raul Miranda

Deparment of Chemical Engineering

University of Louisville

Louisville, KY 40292, USA 
Table of Contents

Summary

Introduction

Pan 1: Preparation and characterization of acidic aupports

Abarnet

Experimental

Reoults and Discussion

Coaclusions

References

Tables

Figures

Pant 2: Piperidine denitrogemation over silica-aluminas

Abstract

Introduction

Experimeneal

Recults and Diecuscion

Conclusions

References

Tables

Figures

Part 3: Preparation and characterization

of acidic molybdene catalyes

Abruract

Introduction

Experimental

Remuth and Discuscion

Conclusions

Figures

Pan 4: Infrared apectroscopy of acidic

molybdena catalyes:

Abunct

Introduction

Experimental

Reauts and Diecussion

Conclusion:

References

Figures

Pan 5: X-Ray diffraction of molybdenum

catalyas

Abaract

Ineroduction

Experimental

Rexulu and Diecussion

Conclusions

References

Figures

Pan 6: Hydrodenitrogenation of pyridine over

acidic molybdenum catalyats

Abaract

Introduction

Experimental

Results and Discussion

Conclusions

References

Tables

Figures
Pan 7: Low temperature oxygen chemisomption over acidic molybdenum caulyats

Abatract

Introduction

Experimeneal

Reauls and Discustion

Conclusions

References:

Figures

Pan 8: H2-D2 exchange in non-acidic and acidic supports

Abstract

Introduction

Experimental

Results and Discussion

Conclusions

References

Figures

Pant 9: H2-D2 exchange in reduced molybdenum calalyas

Absuract

Introduction

Experimental

Reaults and Discuscion

Conclusions

References

Figures

Pan 10: Adeorption of piperidine on reduced molybdenum caulyou

Abrencet

Introduction

Experimental

Reaulus and Discussion

Conclusion

References

Figures

Part 11: Beta-Hydrogen elimination

Abatract

Introduction

Experimenual

Results and Diecussion

Conclutions

References

Figures

Part 12. Preparation of supported $R u$ calalysts

Abstract

Introduction

Experimental

Results and Discussion

References

85

85

85

85

86

87

Acknowledgements $\quad 119$

$\begin{array}{ll}\text { Publications } & 119\end{array}$

Personnel 
Report DOE/PC/89771-13

\section{SUMMARY}

In this project it was proposed that the selectivity of the HDN reaction can be affected by an alteration of the catalyst acidity since it is possible that an acidic Hofmann-like deamination pathway operates in parallel with the hydrogenolysis of saturated C--N--C bonds. Such a possibility was verified in this work by studying the denitrogenation of piperidine over acidic catalysts, and it was demonstrated that Bronsted acid sites are active for the denitrogenation of $\mathrm{N}$ heterocycles, whereas Lewis sites are not.

To better understand the role of acidic sites in the presence of hydrogenation and hydrogenolysis sites, molybdena was supported on a series of acidic aluminas, and the resulting new acidity and molybdic phases were characterized. The oxidized catalysts supported on silica-aluminas showed increases from 3 to $150 \%$ of weak, medium and strong acid sites, which were produced by the molybdena phases.

The new acidity was both of Lewis and Bronsted type, the predominance of one over the other depending upon support composition, as well as on loading and state of oxidation of Mo. Highalumina supports and low Mo loading favor dispersed Mo species, in particular bidentate and monodentate di-oxo Mo species. The latter is responsible for the nev Bronsted acidity. Coordinative unsaturation of polymolybdates is responsible for the new Lewis acidity, which is increased upon reduction of Mo. High-silica supports favor monodentate species (high Bronsted acidity) up to $4 \mathrm{wt} \% \mathrm{MoO}_{3}$. Beyond that polymolybdate species and Lewis acidity predominate.

The nature of the reduced molybdena phases is obviously affected by support composition. The silica-rich supports favor more reducible phases, including a segregated $\mathrm{Al}_{2}\left(\mathrm{MoO}_{4}\right)_{3}$ phase, and the alumina-rich supports favor less reducible phases. It must be noticed that pure gamma-alumina does not lead to the formation of $\mathrm{Al}_{2}\left(\mathrm{MoO}_{4}\right)_{3}$. This is only formed upon calcination of Mo oxides over silica-rich silica-aluminas, and is highly reducible. Pure silica favor the agglomeration of a phase of $\mathrm{MoO}_{3}$, which is also highly reducible. In these complex catalysts, a varying number of hydrogenolysis sites are accompanied by a varying number of acidic sites, and their combined roles affect the activity and selectivity for HDN.

The HDN reaction of pyridine was utilized to assess the variation in activity and selectivity produced by the nature of the support. The results revealed that for silica-alumina supports (>50 $\mathrm{wt} \%$ silica) the optimum loading of molybdena is $4 \mathrm{wt} \%$. At this low loading the activity and selectivity towards HDN were at a maximum. The main parameters affecting the activity and selectivity are here postulated to be Mo reduction state and surface acidity. Thus low-temperature oxygen chemisorption was utilized to investigate the surface reducibility of near-surface Mo, and the effect of catalyst loading and support composition on such reducibility. It was determined that for supports with compositions under $50 \%$ silica, the optimum loading producing maximum surface reducibility is $8 \mathrm{wt} \% \mathrm{MoO}_{3}$, while for supports with more than $50 \%$ silica, the optimum loading is $4 \mathrm{wt} \% \mathrm{MoO}_{3}$. At this loading, a substantial portion of the support (containing acidic sites) is also exposed. The role of Lewis sites produced on the molybdena surface by coordinative unsaturation is the strong adsorption of aromatic or unsaturated amines, and the destabilization of $\mathrm{C}-\mathrm{C}$ and $\mathrm{C}-\mathrm{N}$ bonds. Hydrogenation and hydrogenolysis can then occur by $\mathrm{H}$ addition. The highly acidic Bronsted sites, present on the support as well as on the molybdena, strongly chemisorb the 
hydrogenated amines. The acidic sites probably contribute to the denitrogenation, as shown by the abundance of unsaturated hydrocarbons produced, and are also active for cracking and cyclization, as shown by the selectivity towards methane and cyclopentene.

The mechanism postulated for this acid-catalyzed denitrogenation must involve the Bronsted acid sites present on the support and molybdena-support interface, since strong Bronsted sites on the molybdena phase itself are unlikely to be formed. The approach taken in this work to show the participation of Bronsted acid sites in the mechanism of HDN of pyridine involved the exchange of surface hydroxyl hydrogen with deuterium followed by the chemisorption of piperidine on those sites. Work was done to demonstrate that it is possible to exchange deuterium with surface $\mathrm{OH}$ in silica, alumina and silica-alumina, at temperatures under $400^{\circ} \mathrm{C}$, and using $\mathrm{D}_{2} \mathrm{O}$ and $\mathrm{D}_{2}$ as deuterium sources. It was also demonstrated that exchangeability is maintained after suporting and reducing those supports with molybdena. The study of piperidine adsorption demonstrated that the silanol groups on pure silica do not interact strongly with piperidine, as shown by their inability to promote the exchange of deuterium from OD with hydrogen from piperidine. After supporting molybdena on such silica, however, the silanol groups associated with interfacial sites become more acidic and are able to exchange $\mathrm{D}$ with piperidine, which is also adsorbed more strongly. The $\mathrm{OH}$ groups on pure alumina do not interact with adsorbed piperidine because of their high basicity. Upon supporting molybdena, however, new acidity and probably new $\mathrm{OH}$ groups are generated that interact and exchange $\mathrm{D}$ with piperidine. Adsorbed piperidine was then thermally desorbed and the products of desorption were followed by mass spectrometry. It was possible to conclude that piperidine exchanges only the beta-H of its molecule with surface OD. The lability of such hydrogen and its degree of interaction with surface sites are strong evidence that on acidic catalysts piperidine may undergo Hofmann elimination during the hydrodenitrogenation reaction.

In order to better understand the role of hydrogenolysis functionalities in the HDN mechanism, a series of $\mathrm{Ru}$ oxide catalysts was prepared and partially characterized. Starting from $\mathrm{Ru}(\mathrm{NO})\left(\mathrm{NO}_{3}\right)_{3}$ to avoid residual $\mathrm{Cl}$ in the catalysts, $\mathrm{Ru}+3$ oxides were prepared in loadings of 1,4 and $8 w t \%$, over silica, gamma-alumina and silica-aluminas of controlled acidity. 


\section{INTRODUCTION}

Hydrocarbon feedstocks for energy production are currently obtained mainly from heavy petroleum crudes. To a lesser extent today, but of greater ir portance in the future, are fuels obtained from coal liquids, shale oils and tar sand oils. A common denominator to all of these feedstocks is the high content of S-(primarily in petroleums), $\mathrm{N}$-(primarily in coal liquids and heavy oils) and O-heterocyclic aromatics. Those heteroaromatics must be decomposed, and S, N and $\mathrm{O}$ compounds must be removed from feedstocks for various reasons: they poison the reforming catalysts used in refineries, they induce polymerization of unsaturated compounds and form gums during combustion, they produce corroders in combustion engines, and they form environmental pollutants. Thus major effort has been allocated to the development of catalysts that selectively desulfurize, denitrogenate and deoxygenate fuel feedstocks.

Following the demand for high-octane gasolines manufactured from light crude oils, the catalysts that have received the greatest attention are those utilized in hydrotreatment at medium pressure and high temperature (ca. 20 atm and $450^{\circ} \mathrm{C}$ ). In particular, the so-called Comolybdate/alumina catalyst has been highly developed for hydrodesulfurization (HDS) of light naphthas and gas-oils. An extensive industrial and academic literature has already built up on such catalyst. Less abundant is the literature on the HDS, HDN and HDO of heavy crude oils and coalderived oils. From the available information it is apparent that the catalyst requirements for the HDN process are different from those for the HDS process. Patents of catalysts for HDN and HDO have only recently been published.

One feature of modern HDN catalysts for heavy oil fractions is the use of strongly acidic supports, combined with an active hydrogenation function. For example, most catalysts are sulfided "molybdates" of $\mathrm{Co}$ and preferably $\mathrm{Ni}$, supported on mixed alumina-zeolites. Some industrial catalysts may also be based in the near future on Ru metal and sulfides, which are highly active for hydrogenation of aromatics. The hydrogenation function is needed for HDN (although not essential for HDS) because the scission of the C--N--C bonds is more facile when they are saturated than when they are aromatic. Obviously, this restriction will apply until catalysts are developed that selectively open $\mathrm{N}$-heteroaromatic rings. In the meantime, HDN catalysts will continue to rely on a strong hydrogenating agent to saturate the hetero-aromatics before ring opening. After saturation of the ring, the rate-limiting ring opening step proceeds according to a hydrogenolysis mechanism, which involves adsorption of the heterocycle on a coordinatively unsaturated site, and hydrogenation of the C--N--C bonds. Subsequent deamination of the linear amine moiety is facile. In this widely accepted mechanism, the role played by the acidic support has not been addressed so far.

In this project the acidic function of modern HDN catalysts is studied in detail. In particular, it is of interest to prove or disprove a bifunctional mechanism in which the acidic functionality catalyzes a Hofmann-like elimination step; to quantify the effect of acidity on surface structures; and to investigate whether the only function of acidity is to catalyze secondary reactions. Understanding such functionality in terms of the mechanism of HDN will provide information to develop better catalysts. In the process of studying the role of acidity, the overall mechanism of HDN on "molybdate" catalysts will be better documented than heretofore. Kinetic information derived from the well-characterized catalysts made for this project may be utilized as a reference for further catalyst or process development. 
The study will be presented in twelve parts that will contain details of support and catalyst preparation, characterization, and testing with various reactions. This first part will consider the preparation and characteristics of a series of silica-aluminas with well-known acidic properties.

\title{
Part 1: PREPARATION AND CHARACTERIZATION OF ACIDIC SUPPORTS
}

\begin{abstract}
A method was developed to prepare silica, $\gamma$-alumina, and amorphous silica-aluminas of compositions varying from $10 \mathrm{wt} \%$ silica to $90 \mathrm{wt} \%$ silica. All samples were highly homogeneous, were produced in high yield, and were dense enough for further use as a catalyst support material. The materials were characterized as per their BET surface area, total acidity, acidity strength distribution and type of acidity. The uniform preparation technique allowed the production of a set of silica-aluminas with smoothly varying acidity as a function of composition.
\end{abstract}

\section{EXPERIMENTAL}

\section{Catalyst Preparation}

Silica-aluminas of varying composition (specially in the high-alumina range) and of wellcharacterized properties are not available in the market, hence the need to prepare them. Three methods were tested in search for a homogeneous material with free-flowing characteristics, i.e. large and uniform grain size.

\section{Method 1}

Starting materials: silica gel $\left(40 \% \mathrm{SiO}_{2}\right.$ in water) and $\mathrm{Al}\left(\mathrm{NO}_{3}\right)_{3} \cdot 9 \mathrm{H}_{2} \mathrm{O}$.

Procedure: the required amounts of silica gel and aluminum nitrate were separately dissolved in deionized water. $\mathrm{NaOH}$ solution was added to the nitrate solution to adjust $\mathrm{pH}$ to 4.5 , and was aged overnight. The silica solution was added dropwise to the stirred nitrate solution. The precipitate was aged overnight at $80^{\circ} \mathrm{C}$, then dried and calcined according to the following temperature program: 80 to $600^{\circ} \mathrm{C}$ in $23 \mathrm{hr}$ and cool down to $120^{\circ} \mathrm{C}$.

\section{Method 2}

Starting materials: $\mathrm{Na}_{2} \mathrm{SiO}_{3} \cdot 9 \mathrm{H}_{2} \mathrm{O}$ and $\mathrm{Al}\left(\mathrm{NO}_{3}\right)_{3} \cdot 9 \mathrm{H}_{2} \mathrm{O}$.

Procedure: the nitrate was dissolved in excess $\mathrm{NaOH}$ to form $\mathrm{NaAlO}_{2}$ and was diluted with deionized water. The silicate was directly dissolved in deionized water and added into $1 / 4$ of the aluminate solution while stirring, to obtain solution I. $3 \mathrm{~N} \mathrm{HNO}_{3}$ was added to the other $3 / 4$ $\mathrm{NaAlO}_{3}$ solution until it was neutralized, to obtain solution II. Solutions I and II were mixed while stirring for $45 \mathrm{~min}$. The gel was aged overnight, then filtrated, washed and dried at $100^{\circ} \mathrm{C}$ overnight, and finally calcined at $550^{\circ} \mathrm{C}$ for $4 \mathrm{hr}$. The solid was ion-exchanged with $\mathrm{NH}_{4} \mathrm{Cl}$ solution and was calcined again for 4 more hours. 


\section{Method 3}

Starting materials: $\mathrm{Na}_{2} \mathrm{SiO}_{3} \cdot 9 \mathrm{H}_{2} \mathrm{O}$ and $\mathrm{Al}_{2}\left(\mathrm{SO}_{4}\right)_{3} \cdot 18 \mathrm{H}_{2} \mathrm{O}$.

Procedure: the required amount of silicate was dissolved in distilled water $(\mathrm{pH}=11.8)$ at $35^{\circ} \mathrm{C}$ and neutralized with $3 \mathrm{~N}_{2} \mathrm{SO}_{4}$ until gellification occurred at $\mathrm{pH} 9.6$. This gel was aged at $35^{\circ} \mathrm{C}$ for 15 $\mathrm{min}$. The appropriate amount of aqueous solution of sulfate was added, and the $\mathrm{pH}$ was brought to 6 with $1: 1 \mathrm{NH}_{4} \mathrm{OH}$. The gel obtained was aged for $1 \mathrm{hr}$ at $35^{\circ} \mathrm{C}$ and $1 \mathrm{hr}$ at $45^{\circ} \mathrm{C}$, then its $\mathrm{pH}$ was raised to 9 , and the gel was aged further for $1 \mathrm{hr}$. The slurry was filtered, washed with cold and boiling water, dried at $110^{\circ} \mathrm{C}$ for $2 \mathrm{hr}$, crushed to a powder, and calcined at $550^{\circ} \mathrm{C}$ for $12 \mathrm{hr}$. The samples were ion-exchanged thrice separately with $3 \mathrm{M} \mathrm{NH}_{4} \mathrm{NO}_{3}$ and $3 \mathrm{~N} \mathrm{NH}_{4} \mathrm{OH}$, each for $2 \mathrm{hr}$ at $90^{\circ} \mathrm{C}$.

\section{Method $4: \gamma$-Alumina}

Procedure: $\mathrm{Al}\left(\mathrm{NO}_{3}\right)_{3} .9 \mathrm{H}_{2} \mathrm{O}$ was dissolved in distilled water and $\mathrm{NaOH}$ was added slowly to avoid precipitation. The $\mathrm{NaAlO}_{2}$ solution was stirred at $80^{\circ} \mathrm{C}$ while $\mathrm{HNO}_{3}$ was added dropwise until pH reached 7 . The suspension was filtered and washed with hot $1 \% \mathrm{NH}_{4} \mathrm{NO}_{3}$ solution and distilled water. The precipitate was dried in air at $120^{\circ} \mathrm{C}$ for $4 \mathrm{hr}$ before calcining at $550^{\circ} \mathrm{C}$ for $12 \mathrm{hr}$.

\section{Method 5 : Silica}

Procedure: $\mathrm{Na}_{2} \mathrm{SiO}_{3} .9 \mathrm{H}_{2} \mathrm{O}$ was dissolved in distilled water and neutralized with $3 \mathrm{~N} \mathrm{H}_{2} \mathrm{SO}_{4}$ until $\mathrm{pH}=3$. The $\mathrm{pH}$ was then brought to 6 with $\mathrm{NH}_{4} \mathrm{OH}$ and the gel formed was aged at $45^{\circ} \mathrm{C}$ for $2 \mathrm{hr}$. Then the $\mathrm{pH}$ was adjusted to 9 and the gel aged for 12 more hours. Further processing was similar to that for $\gamma$-alumina.

\section{Catalyst Characterization}

\section{Surface Area}

BET surface area of the catalysts was measured using a conventional all-glass and quartz vacuum manifold provided with electronic manometer. The samples were first evacuated while heated to $100^{\circ} \mathrm{C}$ for $1 \mathrm{hr}$, then cooled to liquid $\mathrm{N}_{2}$ temperature. A 3-point adsorption isotherm was then fitted to the BET equation, and surface area was obtained.

\section{Ammonia Chemisorption (Static)}

The same all-glass vacuum manifold used for BET surface area measurement was utilized in this case. The samples were evacuated while heated to $500^{\circ} \mathrm{C}$, then cooled to $120^{\circ} \mathrm{C}$. At this temperature an adsorption isotherm was constructed. Saturation was taken as indicative of complete neutralization of acidic sites (total acidity). 


\section{Ammonia Chemisorption (Dynamic) and TPD}

The pulse adsorption and temperature-programmed desorption (TPD) apparatus consisted of a quartz reactor inside a tubular furnace, whose temperature was controlled by a temperature programmer. The reactor outlet was routed to a thermal conductivity detector. The reactor inlet was connected to a six-port chromatographic valve, and the flowrate was mass-flow controlled at 100 $\mathrm{ml} / \mathrm{min}$. The samples were pretreated in $\mathrm{He}$ flow at $500^{\circ} \mathrm{C}$, and then cooled to $120^{\circ} \mathrm{C}$. Measured pulses of $\mathrm{NH}_{3}$ were carried over the samples at $120^{\circ} \mathrm{C}$ every $15 \mathrm{~min}$ and the residual $\mathrm{NH}_{3}$ was quantified at the catharometer. Saturation was taken as a measure of total acidity. The temperature of $120^{\circ} \mathrm{C}$ was chosen to avoid physisorption.

To obtain the TPD spectrum, the sample temperature was cooled to $50^{\circ} \mathrm{C}$ and then increased to $550^{\circ} \mathrm{C}$ at a constant rate of $10^{\circ} \mathrm{C} / \mathrm{min}$, and maintained at $550^{\circ} \mathrm{C}$ for $20 \mathrm{~min}$, while monitoring the desorption with the thermal conductivity detector.

\section{Amine Chemisorption (Dynamic)}

Other amines (butylamine, pentylamine) were chemisorbed and desorbed in the same manner as ammonia.

\section{Infrared Spectra of Adsorbed Pyridine}

Reflectance spectra of powdered samples were obtained with a Perkin-Elmer FTIR (1720) equipped with a diffuse reflectance IR cell (SpectraTech) capable of providing the sample with environmental control, vacuum, temperature up to $600^{\circ} \mathrm{C}$, and gas flow. The samples were pretreated at $450^{\circ} \mathrm{C}$ under $\mathrm{He}$ flow $(5 \mathrm{ml} / \mathrm{min})$ for $1 \mathrm{hr}$ and then cooled to $200^{\circ} \mathrm{C}$ before taking a blank spectrum.

Pyridine was adsorbed on the samples at $200^{\circ} \mathrm{C}$ by injecting $2 \mu \mathrm{l}$ pulses of liquid pyridine in an upstream reservoir at room temperature. All pyridine was evaporated and transported by flowing $\mathrm{He}$ in about $20 \mathrm{~min}$. Spectra of adsorbed pyridine were then recorded at $200^{\circ} \mathrm{C}$ after $1 \mathrm{hr}$, and the absorption bands were manipulated and quantified with Micro-Search, software supplied by Sprouse Scientific Systems.

\section{RESULTS AND DISCUSSION}

The preparation of silica-aluminas of varying composition over the range $0-100 \%$ proved to be a critical step in this part of the project. After numerous trials with the methods outlined above, only method 3 yielded samples with large yield at all compositions, and with uniform properties, one of which was large grain size. Hence all further experimentation was carried out on samples obtained by method 3. Large batches of silica-aluminas were prepared to assure enough supply of wellcharacterized supports for further studies.

The determination of acidity via ammonia chemisorption involved careful repetitions until reproducible results were obtained. It was concluded that the static method did not yield results as reproducible as the dynamic method. The static method also yielded chemisorption amounts that could be troublesome to interpret in terms of only acidity; for example, pure silica chemisorbed 
ammonia to about $1 / 2$ the amount chemisorbed by pure alumina. The dynamic method was highly reproducible and produced amounts of ammonia chemisorption that could be interpreted as measure of total acidity; for example silica chemisorbed about 1/10 the ammonia chemisorbed by alumina. Thus the results reported here are those obtained by the dynamic method.

Table 1 shows the surface area and total acidity of the prepared silica, alumina and silicaaluminas. Also shown is the subdivision of total acidity into three components: weak, medium and strong acidity, resulting in about $25-30 \%$ weak, $48-53 \%$ medium and 22-25\% strong acid sites for all samples, irrespective of composition. Such subdivision was arbitrarily obtained from the spectra of ammonia TPD (Fig. 1), as shown in Fig. 2. Therefore, one conclusion is that the total amount of acidity has a maximum at a composition silica:alumina $=25: 75 \mathrm{wt} \%$, but the strength distribution is the same for all compositions.

In order to avoid any bias imposed by any particular probe molecule, other amines were used to quartify acidity, namely n-butylamine, n-pentylamine and pyridine. Fig. 3 shows a comparison of the acidity quantitation by three of these probes, which shows that all amines give consistent evaluations of total acidity, regardless the character of the amine. This result also constitutes indirect evidence that all acid sites are amply exposed to the adsorbed phase and present little or no steric hindrance to the adsorption of larger amines. The TPD of the larger amines is shown in Figs. 4 (n-pentylamine) and 5 (pyridine). While the pyridine spectrum resembles that of ammonia, the n-pentylamine spectrum has its own features. That is interpreted in terms of the decomposition (reaction) that undergoes the saturated amine as opposed to no decomposition of ammonia or pyridine, during heating. No other special information has been derived from these spectra thus far. There is no major shift of the desorption maxima as a function of composition, as it could have been expected if the strength of adsorption (sirength of acidity) were a function of composition.

It must be noticed that reevaluation of the acidity per unit surface area yields Fig. 6, which demonstrates that alumina has the highest concentration of surface acid sites. The addition of silica dilutes such concentration. It is not obvious from these TPD spectra the nature of those acidic sites. That information is provided by the infrared spectra, as discussed next.

Fig. 7 presents the IR spectra of adsorbed pyridine in the region of 1400 to $1700 \mathrm{~cm}^{-1}$. This regions contains bands that are indicative of pyridine aujsorbed in Lewis and Bronsted acid sites. The band at $1447 \mathrm{~cm}^{-1}$ is characteristic of Lewis sites (LPy) while the band at $1548 \mathrm{~cm}^{-1}$ indicates Bronsted sites (BPy); the band at $1492 \mathrm{~cm}^{-1}$ is a combination one [1]. This figure demonstrates that silica does not contain any Lewis or Bronsted acid sites and alumina contains only Lewis acid sites. The Bronsted acidity increases with silica content in silica-aluminas and has a maximum at a composition silica:alumina $=75: 25 \mathrm{wt} \%$. To facilitate such comparison Table 2 shows the relative areas under the LPy and BPy bands, as well as the relative ratio BPy/(BPy+LPy) which is proportional to the abundance of Bronsted acid sites. It is not possible from these data alone to calculate the absolute amount of Bronsted acid sites, since the infrared extinction coefficients were not measured. Furthermore, only the trend in the growth of the relative Bronsted acidity should be taken as significant, since the ratio of molar extinction coefficients $\varepsilon^{\mathrm{L}}{ }_{1450} \mathcal{E}^{\mathrm{B}}{ }_{1545}$ is not constant. Several authors have found such ratio to vary as a function of solid composition and measurement and pretreatment conditions[2]. These limitations also preclude a comparison between the total acidity evaluated from the infrared spectrum (integration under the LPy and BPy bands) and ammonia or amine chemisorption. The latter should be taken as a more accurate measurement of total acidity. 


\section{CONCLUSIONS}

A method was developed to prepare a set of silica-alumina materials with smoothly varying acidity as a function of composition. This set was well characterized as for their surface area and acidity properties: total acidity, strength distribution, and nature of the acidity. The set can be utilized as an acidity gauge for further studies of catalysis by solid acids, or as supports with controlled acidity.

\section{REFERENCES}

1. K. Tanabe, in Catalysis: Science and Technology (J.R. Anderson and M. Boudart, Editors) Springer-Verlag, Berlin, 1981, Vol.2, p. 231.; M. C. Kung and H. H. Kung, Catal. Rev.-Sci. Eng. 27(1985)425

2. J. W. Ward, J. Catal. 11(1968)271; M. R. Basila, T. R. Katner, and K. H. Rhee, J. Phys. Chem. 68(1964)3197 
Table 1

Physico-chemical properties of alumina, silica and silica-aluminas

\begin{tabular}{|c|c|c|c|c|c|c|c|}
\hline \multirow[b]{3}{*}{$\begin{array}{l}\text { Surface } \\
\text { Area }\left(\mathrm{m}^{2} / \mathrm{g}\right)\end{array}$} & \multirow{3}{*}{$\begin{array}{l}\mathrm{Al} 2 \mathrm{O} 3 \\
\\
\end{array}$} & \multirow{2}{*}{\multicolumn{2}{|c|}{ SA $1090^{\text {SA2 }}$}} & & \multicolumn{2}{|c|}{ SA7525 } & \multirow{2}{*}{$\begin{array}{l}\mathrm{SiO}_{0} \\
0\end{array}$} \\
\hline & & & & SA50 & & SA90 & \\
\hline & & 264 & 297 & 306 & 294 & 382 & 311 \\
\hline Acidity $(\mathrm{mmol} / \mathrm{g})$ & & & & & & & \\
\hline Total & .304 & .503 & .512 & 438 & .265 & .162 & .001 \\
\hline & 25.3 & 23.9 & .26 .9 & 29.2 & 30.1 & 28.4 & \\
\hline Medium, \% & 49.0 & 54.5 & 53.5 & 52.1 & 48.3 & 46.3 & \\
\hline Strong, $\%$ & 25.7 & 21.7 & 19.5 & 18.7 & 21.6 & 25.3 & \\
\hline
\end{tabular}

SA1090 means silica:alumina $=10: 90 \mathrm{wt} \%$, etc.

Table 2

Evaluation of Areas under Infrared Absorption Bands

Relative Area

LPy BPy

Ratio

BPy/(BPy+LPy)

\begin{tabular}{llll}
\hline A1203 & .776 & .000 & .000 \\
SA1090 & .513 & .018 & .034 \\
SA2575 & .698 & .086 & .110 \\
SA5050 & .464 & .153 & .248 \\
SA7525 & .293 & .182 & .383 \\
SA9010 & .294 & .176 & .375 \\
SiO2 & .000 & .000 & .000 \\
\hline
\end{tabular}

Note: LPy corresponds to $1447 \mathrm{~cm}^{-1}$

BPy corresponds to $1548 \mathrm{~cm}^{-1}$ 


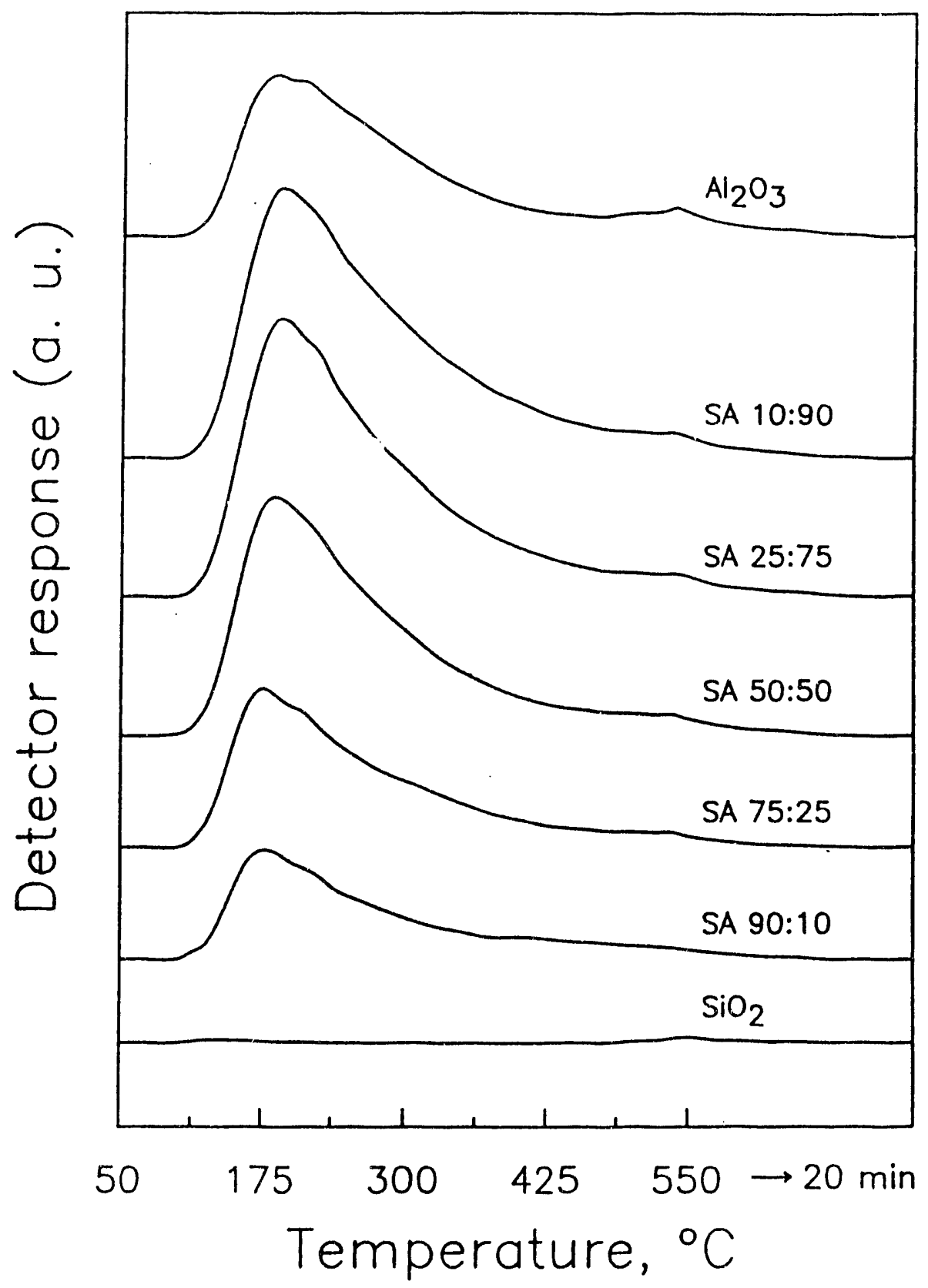

Fig. 1 Temperature programmed desorption of ammonia (see text for conditions) 


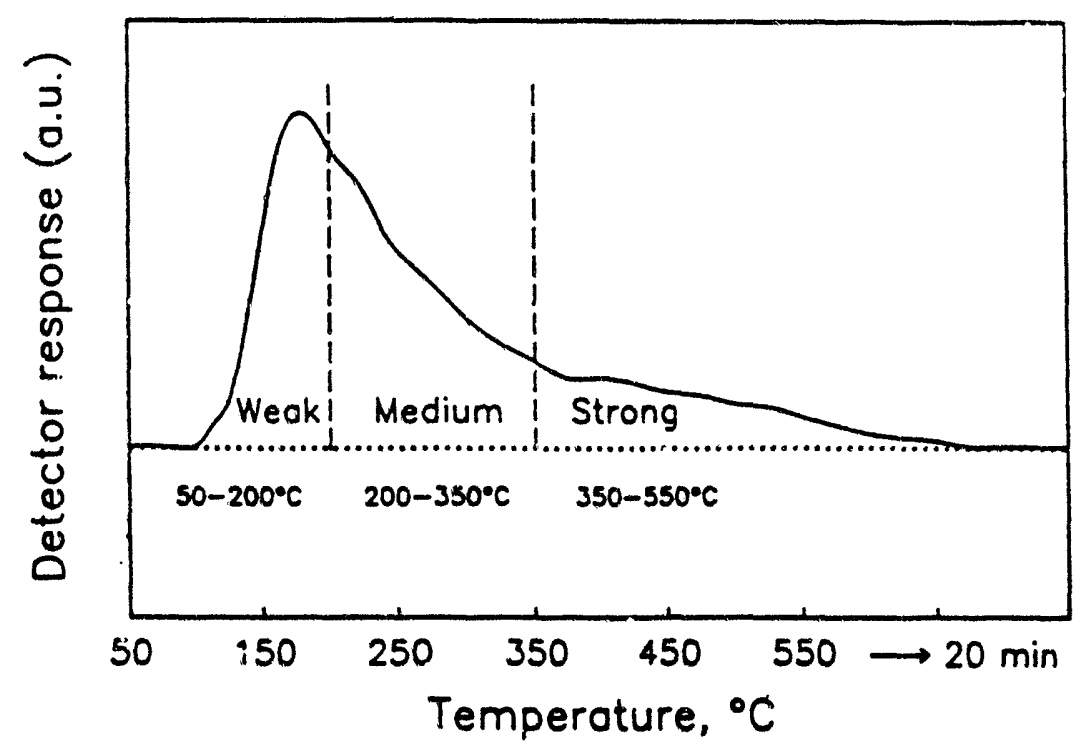

Fig. 2 Subdivision of acidity according to strength

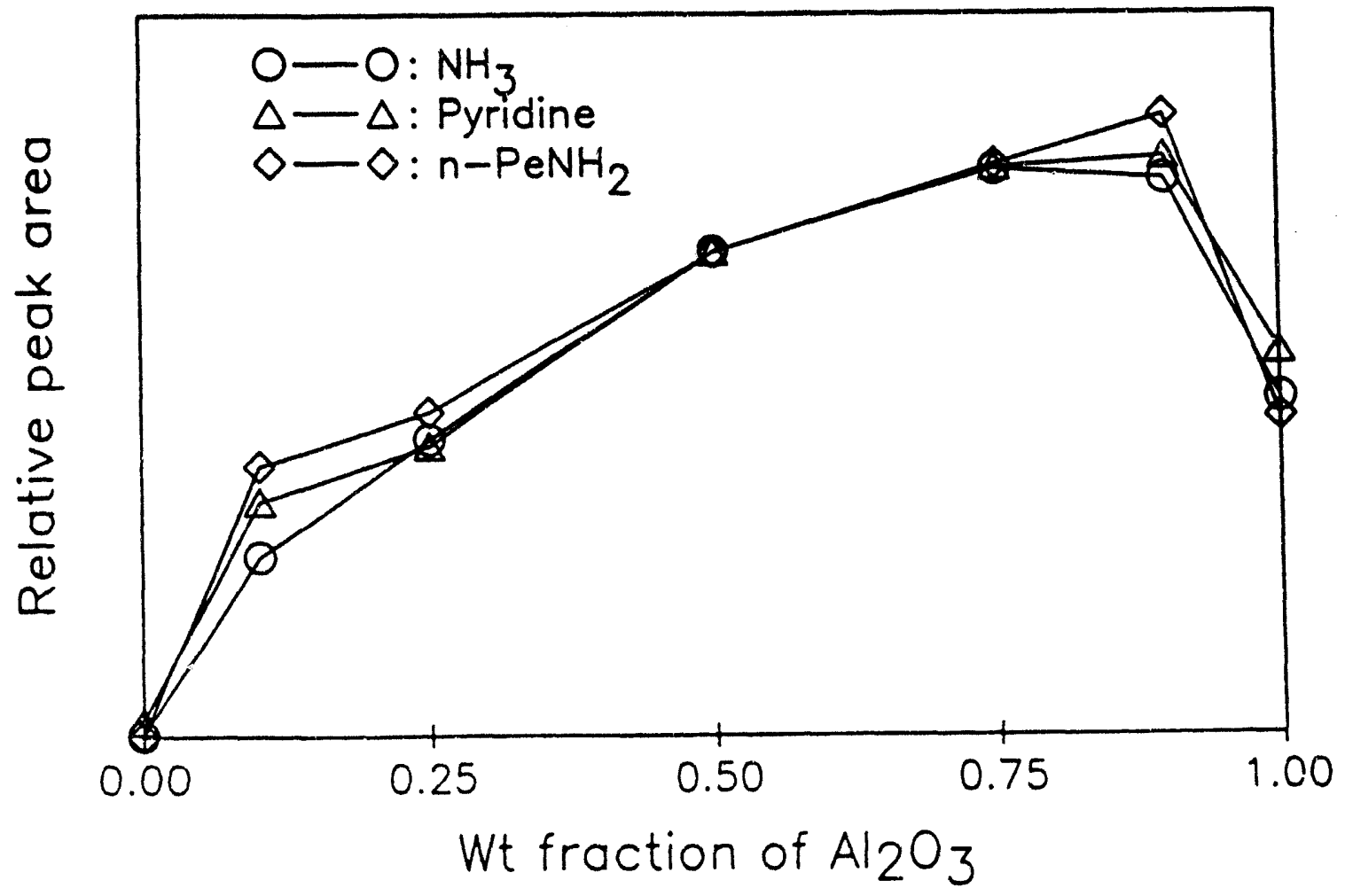

Fig. 3 Total acidity evaluation with three basic probes 


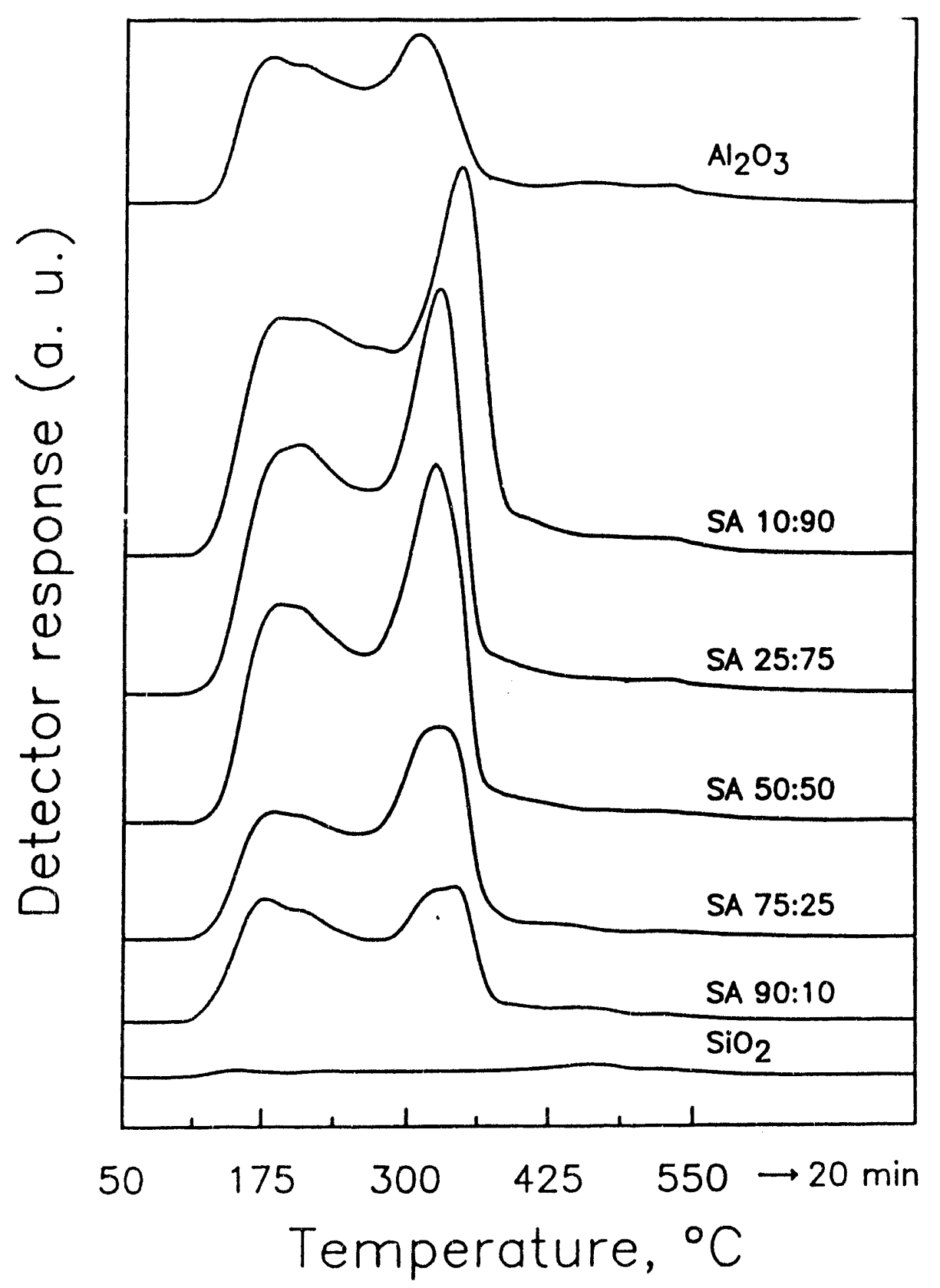

Fig. 4 TPD of n-pentylamine (see text for conditions) 


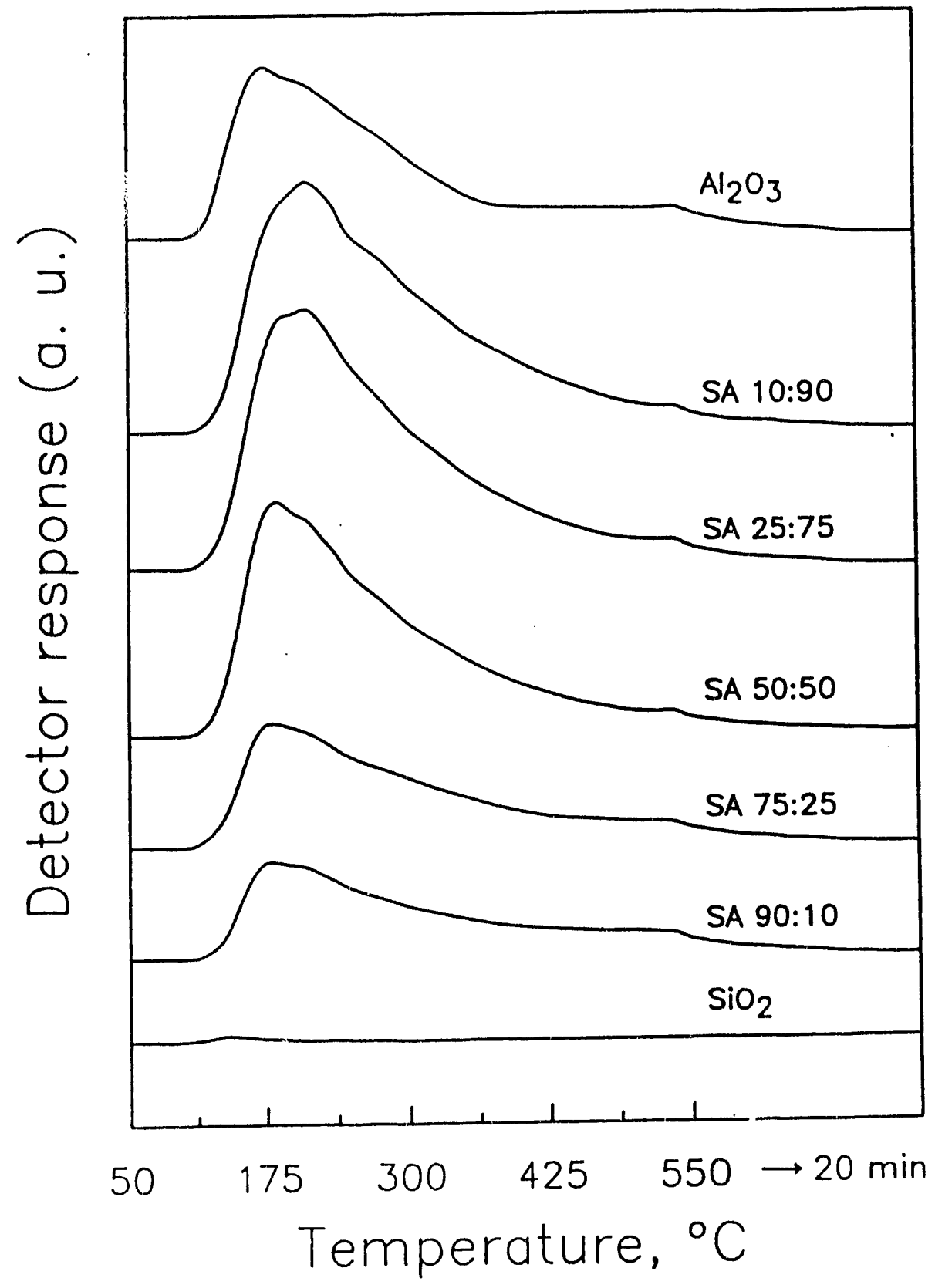

Fig. 5 TPD of pyridine (see text for conditions) 


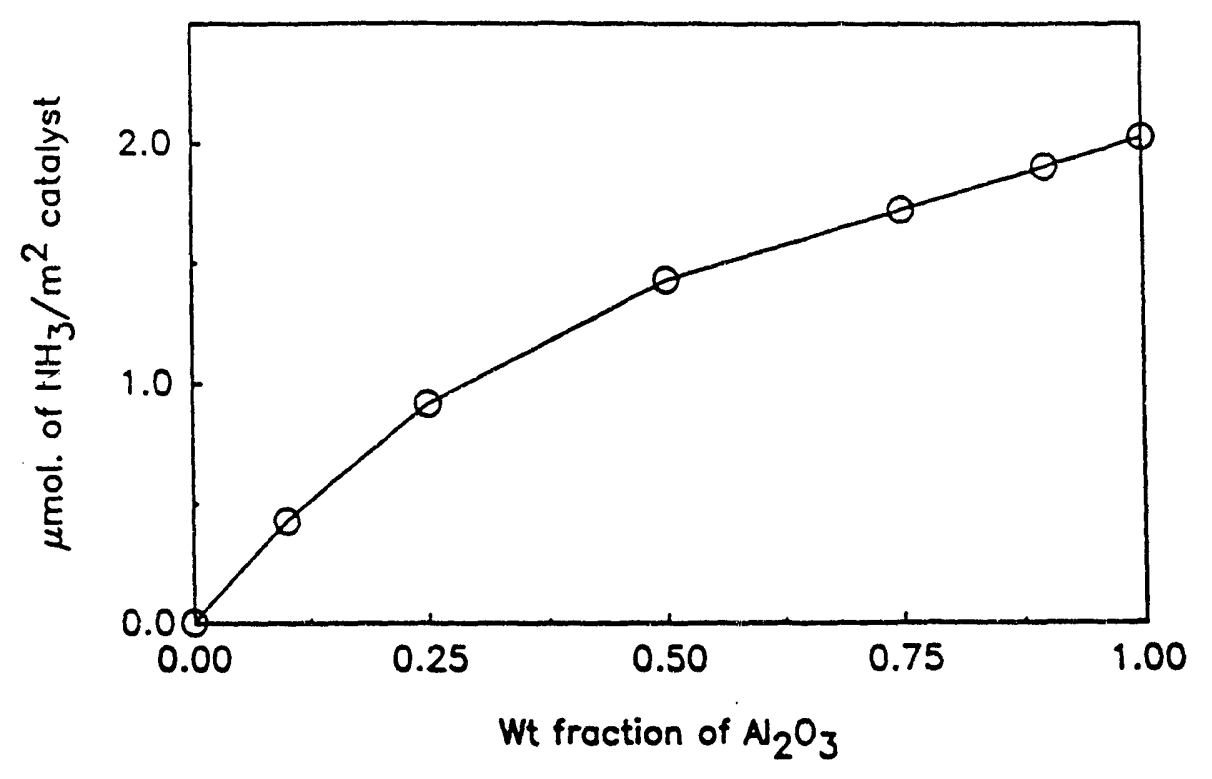

Fig. 6

Total acidity per unit surface area

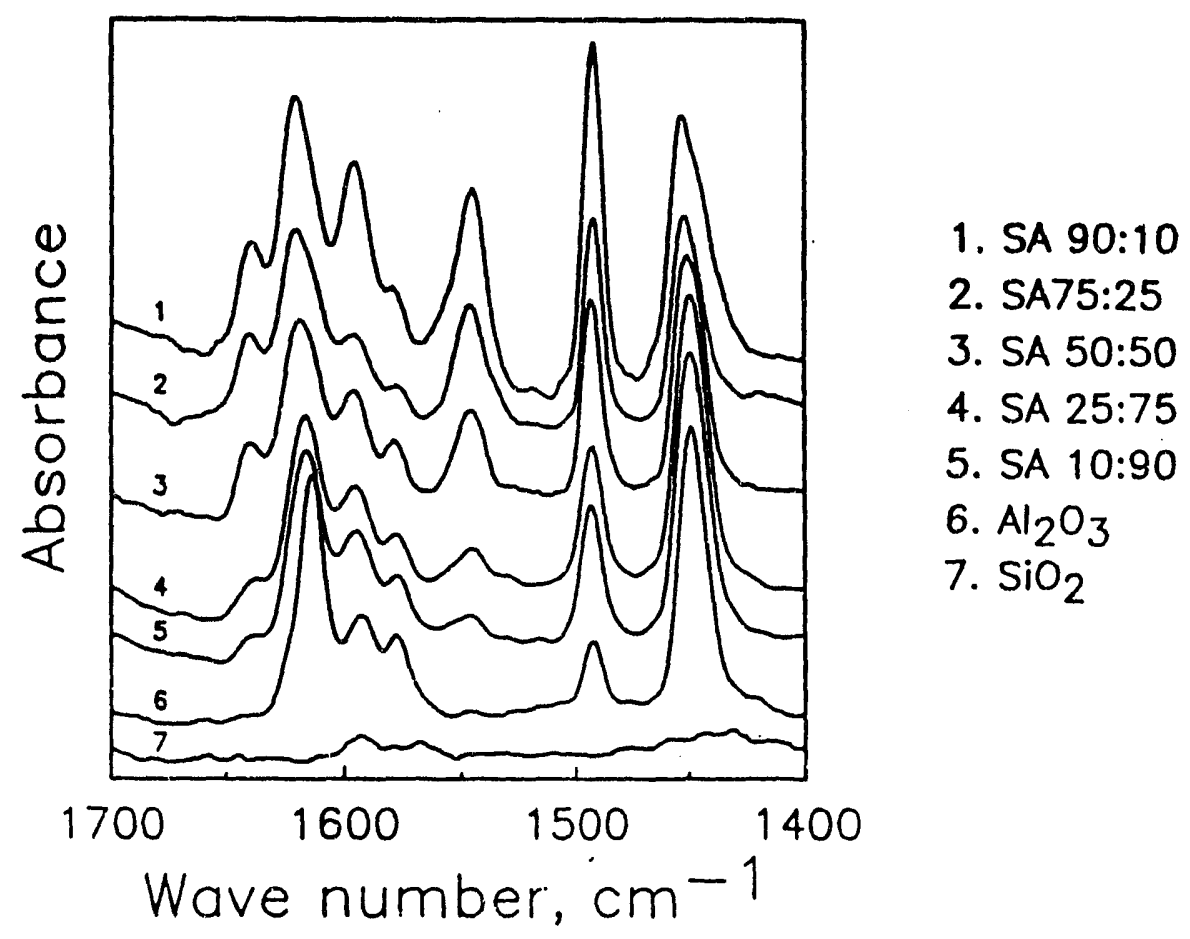

Fig. 7 Diffuse reflectance infrared spectra of adsorbed pyridine (see text for conditions) 
Report DOE/PC/89771-13

\title{
Part 2: PIPERIDINE DENITROGENATION OVER SILICA-ALUMINAS
}

\begin{abstract}
The reactions of piperidine catalyzed by gamma-alumina and amorphous silica-aluminas (weight ratios of 10:90,50:50, and 90:10) were studied to evaluate the effect of acidity on denitrogenation activity. The total piperidine conversion to various products through condensation, dehydrogenation and denitrogenation increases with increasing amounts of total acidity (Brönsted and Lewis). The formation of hydrocarbons as a result of denitrogenation, however, increases only with increasing number of Brönsted-acid sites, in accordance with a Hofmann-like deamination mechanism.
\end{abstract}

\section{INTRODUCTION}

There is some evidence that lenitrogenation activity is improved by using molybdenum catalysts on strongly acidic supports, $k$ i: as zeolites or silica-aluminas[1,2]. The reason for this improvement is not clear, althusy.t it is possible that an acidic Hofmann-like deamination pathway is operative [3], in parallel to the hydrogenolysis of saturated $\mathrm{C}-\mathrm{-N}-\mathrm{-} \mathrm{C}$ bond. According to such mechanism (Scheme 1) saturated $\mathrm{N}$ is protonated by a Bronsted-acid site to form quaternary $\mathrm{N}+$. Subsequently, B-H is removed and then C--N--C scission occurs. If this mechanism is valid, then increasing the Bronsted acidity of the molybdenum catalysts will accelerate the Hofmann-elimination pathway. There is, however, need for more evidence to support this claim.

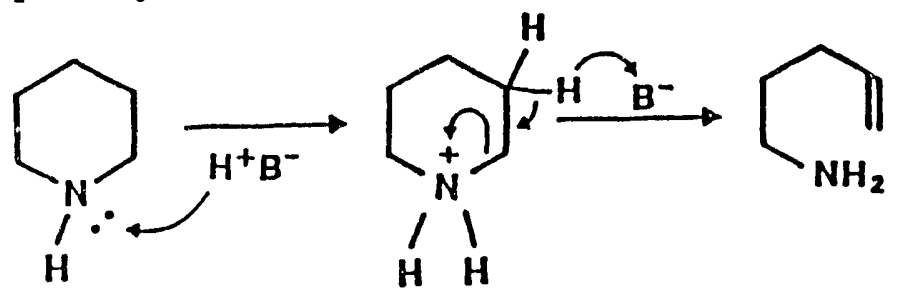

Scheme 1. Brönsted-acid catalyzed ring opening step

Previous related work[4] has been focused on studying the detailed mechanism of cyclic amines over mildly acidic catalysts (namely alumina) without any hydrogenation function. The mechanistic roles of Brönsted and Lewis acidity and basicity have been indicated, but no systematic change of catalyst acidity has been performed to study its effect on the mechanism.

In this project the main objective is to evaluate the effects of both amount and strength of surface acidity on deamination activity. For this purpose gamma-alumina, a series of silica-aluminas, and silica were prepared, characterized, and tested for the deamination reaction of piperidine, which is 
Report DOE/PC/89771-13

an intermediate in the HDN of pyridine. In order to evaluate selectively the role of acidity in general and Brönsted acidity in particular during deamination, catalysts having only acidic function and no hydrogenating function are used.

\section{EXPERIMENTAL}

Alumina was prepared by first mixing $\mathrm{Al}\left(\mathrm{NO}_{3}\right)_{3} .9 \mathrm{H}_{2} \mathrm{O}$ and $\mathrm{NaOH}$ to obtain $\mathrm{NaAlO}_{2}$ solution, which in turn was neutralized with dil. $\mathrm{HNO}_{3}$ at $70^{\circ} \mathrm{C}$. Silica-aluminas $\left(\mathrm{SiO}_{2} / \mathrm{Al}_{2} \mathrm{O}_{3}\right.$ weight ratios $=10: 90,50: 50,90: 10$ ) were prepared according to established techniques[5], and as specified in part 1 of this report. Silica was obtained from $\mathrm{Na}_{2} \mathrm{SiO}_{3} .9 \mathrm{H}_{2} \mathrm{O}$ and dil. $\mathrm{H}_{2} \mathrm{SO}_{4}$ at $\mathrm{pH} 9$.

BET surface areas were determined by nitrogen sorption at $-196^{\circ} \mathrm{C}$ using an all-glass vacuum apparatus. Total acidity by $\mathrm{NH}_{3}$ chemisorption was done in a quartz pulse reactor in flowing helium $(100 \mathrm{ml} / \mathrm{min})$, dosing measured pulses of $\mathrm{NH}_{3}$ at $120^{\circ} \mathrm{C}$ every $15 \mathrm{~min}$ until saturation was observed.The temperature of $120^{\circ} \mathrm{C}$ was chosen so as to completely avoid the physisorption of ammonia. The total mass of $\mathrm{NH}_{3}$ adsorbed was calculated by adding up the fractions adsorbed in every pulse. Before chemisorption, the catalyst was treated at $500^{\circ} \mathrm{C}$ under He flow. After chemisorption, the catalyst was cooled to $50^{\circ} \mathrm{C}$ and TPD was carried out under helium flow by linearly ramping the temperature of the catalyst from 50 to $550^{\circ} \mathrm{C}$ at $10^{\circ} \mathrm{C} / \mathrm{min}$, and staying at $550^{\circ} \mathrm{C}$ for $20 \mathrm{~min}$, while monitoring the desorption of $\mathrm{NH}_{3}$ with a thermal conductivity detector. The TPD spectrum obtained was arbitrarily divided into three segments viz., 50--200, 200--350 and $350--550^{\circ} \mathrm{C}$. The areas under these segments were assigned to $\mathrm{NH}_{3}$ desorbing from weak, medium and strong acidic sites, respectively.

A Perkin-Elmer FTIR (model 1720) and a computer data station were used to collect and process infrared spectra. A diffuse reflectance IR cell (Spectra Tech) equipped with environmental chamber capable of providing the catalyst sample with high vacuum, gas flow, and heating from room temperature to $600^{\circ} \mathrm{C}$, was used. The catalysts were pretreated at $450^{\circ} \mathrm{C}$ under He flow ( 5 $\mathrm{ml} / \mathrm{min}$ ) for 1 hour and cooled to $200^{\circ} \mathrm{C}$ before taking a blank spectrum.

Pyridine was then adsorbed on the catalysts to saturation at $200^{\circ} \mathrm{C}$, by injecting $2 \mu \mathrm{l}$ of dry pyridine in an upstream reservoir at room temperature. The liquid pyridine was evaporated in 20 min under these conditions. The IR spectra of the adsorbed pyridine were then recorded at $200^{\circ} \mathrm{C}$ after $1 \mathrm{hr}$. The areas under the pyridine absorption peaks were calculated using the software program Micro-Search, supplied by Sprouse Scientific Systems, Inc.

The catalyst samples (particle diameter $<150 \mu$ ) were pretreated in flowing $\mathrm{H}_{2}(30 \mathrm{ml} / \mathrm{min})$ at $500^{\circ} \mathrm{C}$. Each catalyst $(200 \mathrm{mg})$ was tested for their activity and selectivity with the piperidine denitrogenation reaction, using a feed of $0.031 \mathrm{~mol} \%$ piperidine vapor in hydrogen $(30 \mathrm{ml} / \mathrm{min})$. The reaction was carried out in a 1/4"--OD glass fixed-bed reactor, at atmospheric pressure and four temperatures: $320,340,360$ and $380^{\circ} \mathrm{C}$. The temperature of the catalyst was monitored by a thermocouple positioned very close to the catalyst bed. An insulated cylindrical metal block provided with cartridge heaters was used as a furnace whose isothermicity was confirmed by employing a moving thermocouple.

The inlet and effluent lines were wrapped with electrical heating tape (temperature: $120-130^{\circ} \mathrm{C}$ ) to avoid condensation of reactants and products. The product was analyzed by on-line gas 
chromatograph (HP 5890A) equipped with two separate columns, viz. a $10 \%$ Carbowax $1500+$ $1 \% \mathrm{KOH} / \mathrm{Chromosorb} \mathrm{W}$ and an $\mathrm{n}$-Octane/Porasil $\mathrm{C}$, and a 10-port sampling valve. The analysis technique, described in detail in Ref. 15, allowed separation of all the hydrocarbons and nitrogen-containing compounds present in each vapor sample.

The reaction was carried out continuously for 12 hours at each temperature, for a total of 48 hours over each catalyst. The conversion values reported here are those measured at steady state, when the deactivation rate was negligible.

\section{RESULTS AND DISCUSSION}

For each of the five catalysts Table 1 reports : (a) the measured BET surface area; (b) the total acidity determined from $\mathrm{NH}_{3}$ chemisorption, and expressed in moles of $\mathrm{NH}_{3}$ per unit weight of catalyst; and (c) the distribution of acidity among weak, medium and strong acid sites, determined from TPD of $\mathrm{NH}_{3}$. The TPD profiles and the infrared spectra of adsorbed pyridine are shown in Figs. 1 and 2, respectively. Since the acidity of silica is negligibly low, its strength distribution was not measured.

The acidity distribution results of Fig. 1 could be precisely reproduced. No residual $\mathrm{NH}_{3}$ was detected by heating to higher temperature after TPD experiments. Also table 1 shows that the mass balance of adsorbed and desorbed $\mathrm{NH}_{3}$ closes exactly. Thus, the total acidity obtained by this method was considered quantitative. It was so concluded that the total acidity per unit weight reached a maximum for silica:alumina=10:90.

The broad TPD curves indicate a broad distribution of binding strength of $\mathrm{NH}_{3}$, according to the classical interpretations of Ehrlich and Redhead for single crystals[6,7] and Cvetanovic and Amenomiya for powders[8]. Such binding strength can be taken as a measure of acid strength. Qualitatively, without attempting to deconvolute all of the component curves from the overall distribution, it was observed that the feature between 130 and $350^{\circ} \mathrm{C}$ could be analyzed into at least two first-order desorption peaks. The feature at $540^{\circ} \mathrm{C}$ involves at least one peak. Thus the distribution can be divided arbitrarily into three regions $\left(50--200,200--350\right.$, and $\left.350--550^{\circ} \mathrm{C}\right)$ to provide a qualitative measure of the amount of weak, medium and strong acid sites, without considering the nature of the acidity. Table 1 indicates that regardless of the composition, in all silica-aluminas and alumina, 24--30\% of all acid sites are weak, $45--55 \%$ are medium and $19--26 \%$ are strong. The nature of this acidity was then examined from the results of infrared spectroscopy of adsorbed pyridine (Fig. 2).

Pyridine is known to chemisorb on oxides in three modes: on Lewis-acid sites by transfer of the lone pair of electrons of $N$, or by coordination of the $\pi$-electrons of the ring, and on Brönsted-acid sites by tran: fer of proton from the site to the $N$. In addition, a physisorption mode has been reported[9] up to about $200^{\circ} \mathrm{C}$. Of relevance in this instance is the classification of acidic sites into Lewis and Brönsted by quantifying the pyridine adsorbed on these sites. It has been well documented[10,11] that the band at $1447 \mathrm{~cm}^{-1}$ is characteristic of pyridine adsorbed on Lewis-acid sites (LPy), the band at $1548 \mathrm{~cm}^{-1}$ corresponds to Brönsted-acid sites (BPy), and the band at 1492 $\mathrm{cm}^{-1}$ is a combination one. Fig. 2 shows that alumina contains only Lewis-acid sites, whereas silica-aluminas contain both Lewis and Brönsted sites. Pyridine does not adsorb on silica at $200^{\circ} \mathrm{C}$, hence shows no absorption bands. However, at relatively low temperature $\left(120^{\circ} \mathrm{C}\right), \mathrm{SiO}_{2}$ 
exhibited two bands at 1447 and $1599 \mathrm{~cm}^{-1}$ (not shown here) which correspond to pyridine H-bonded to non-acidic silanol groups[9].

To calculate the amount of Brönsted and Lewis acid sites from IR spectra, the molar extinction coefficients for BPy and LPy absorption bands are required. The absolute coefficients for these bands, however, are very dependent on silica-alumina composition, pretreatment and conditions of measurement, hence are not reported in the literature. On the other hand, the relative molar extinction coefficients for Brönsted and Lewis bands are frequently reported, although with little agreement among different workers[12,13], with values for $\varepsilon^{\mathrm{L}} 145 \mathrm{E}^{\mathrm{B}} \mathrm{B}_{1545}$ varying from 1.1 to 8.8. Therefore, the results reported in Fig. 2 can not be used to quantify the absolute amounts of Lewis and Brönsted sites, and should not be compared to the results provided by $\mathrm{NH}_{3}$ chemisorption.

Despite the impossibility of calculating absolute acidities from Fig. 2, it is possible to obtain the relative amount of Brönsted acidity. With the reasonable assumption that $\varepsilon^{\mathrm{L}}{ }_{1450} / \varepsilon^{\mathrm{B}}{ }_{1545}$ is constant among different silica-aluminas, the relative Brönsted acidity can be compared. In this work, $\varepsilon^{L}{ }_{145} \varepsilon^{B}{ }^{B} 1545=1$ was adopted, which is close to the value obtained by Ward[12] under conditions similar to ours. The relative areas under the peaks 1548 and $1447 \mathrm{~cm}^{-1}$ indicate that the relative Brönsted acidity increases with increasing $\mathrm{SiO}_{2}$ content, in agreement with other investigators[14].

The acidic characteristics thus determined were then correlated with the activity and selectivity in the piperidine reaction. The observed reaction products were classified into three groups: (a) hydrocarbons (formed by denitrogenation), (b) pyridine, and (c) other nitrogen compounds. The last category included quinoline, isoquinoline, 5,6,7,8-tetrahydroquinoline, 5,6,7,8-tetrahydroisoquinoline, and alkylpyridines. Three different piperidine conversions were considered appropriate: overall piperidine conversion, piperidine conversion to pyridine (dehydrogenation), and piperidine conversion to hydrocarbons (denitrogenation). They are presented in table 2 , with the exception of the conversion for silica, which showed no activity.

The overall conversion is directly related to the total number of acid sites, as shown in Fig. 3 for the runs at 320 and $340^{\circ} \mathrm{C}$. This conversion could also have been related to the total amount of medium or strong acid sites, as inferred from the acidity distribution shown in Table 1, but not to the relative amount of Brönsted sites, which is maximum for silica:alumina=90:10. The conclusion reached is that both Brönsted and Lewis acid sites are active in transforming piperidine. The specific role of each type of acid site can not be totally ascertained from these experiments, but the importance of those sites is outlined in the following observations. The pyridine formation by dehydrogenation of piperidine is maximum for pure alumina, wherein only Lewis-acid sites are present, and decreases for the silica-aluminas with decreasing amount of Lewis-acid sites, i.e., increasing amount of Brönsted-acid sites. In independent experiments it was also found that the reaction of pure pyridine over alumina, silica-aluminas and silica did not proceed to an appreciable extent under $400^{\circ} \mathrm{C}$. An argument in agreement with these observations is that both types of acid sites catalyze the acidic dehydrogenation of piperidine to pyridine, but Brönsted sites also catalyze the condensation of pyridine with partially saturated amines, leading to the observed products quinoline, isoquinoline, 5,6,7,8-tetrahydroquinoline, 5,6,7,8-tetrahydroisoquinoline, and alkylpyridines.

Finally, the piperidine conversion to hydrocarbons does not increase with total acidity, but with Brönsted acidity. The plot of denitrogenation activity (\%conversion) against 
Brönsted/(Brönsted+Lewis) ratio (Fig. 4) shows that the denitrogenation activity is directly related to the amount of Brönnsted sites. This result provides strong evidence of a Hofmann-like ring-opening mechanism (Scheme 1). It is also evident, from the denitrogenation activity of alumina, that pure Lewis acidity does not catalyze the denitrogenation of piperidine. The observed residual activity for denitrogenation is caused by the weak Brönsted acidity present on alumina under reaction conditions.

\section{CONCLUSIONS}

New evidence has been provided that acid sites catalyze the reactions of piperidine under hydrotreatment conditions. Thus, the overall conversion of piperidine is in direct relationship with the total (Brönsted and Lewis) acidity. Piperidine reactions were classified into i) acid-base catalyzed dehydrogenation that yields pyridine, ii) condensation that yields larger amine molecules, and iii) denitrogenation which produces hydrocarbons. It was shown that Lewis acidity catalyzes acidic dehydrogenation and condensation, but not denitrogenation. Thus, alumina shows only small denitrogenation activity, due to weak Brönsted-acid sites formed under reaction conditions. On the other hand, strong Brönsted acidity catalyzes denitrogenation. Thus silica-aluminas, with increasing amount of Brönsted-acid sites (and decreasing amount of Lewis acid sites), show increasing denitrogenation activity.

\section{REFERENCES}

1. M. J. Ledoux, in Catalysis (G. C. Bond and G. Webb, Editors), Specialist Periodical Reports, The Royal Society of Chemistry, London, 1985, Vol. 7, p. 125; and patents cited therein.

2. A. L. Henseley Jr., A. M. Tait, J. T. Miller and T. D. Nevitt, U.S. Patent 4,406,779 (1983); J. T. Miller and M. F. Hineman, J. Catal. 85(1984)117

3. N. Nelson and R. B. Levy, J. Catal. 58(1979)485

4. M. J. Ledoux and M. Sedrati, J. Catal. 83(1983)229

5. J. S. Magee and J. J. Blazek, in Zeolite Chemistry and Catalysis (J. B. Rabo, Editor) ACS Monograph 171, ACS, Washington D.C., 1976, p. 615.

6. G. Ehrlich, J. Appl. Phys. 32(1961)4; Adv. Catal. Relat. Subj. 14(1963)271

7. P. A. Redhead, Vacuum 12(1962)203

8. R. J. Cvetanovic and Y. Amenomiya, Adv. Catal. Relat. Subj. 17(1967)103; Catal. Rev. 6(1972) 21

9. E. P. Parry, J. Catal. 2(1963)371 
10. K. Tanabe, in Catalysis: Science and Technology (J.R. Anderson and M. Boudart, Editors) Springer-Verlag, Berlin, 1981, Vol.2, p. 231.

11. M. C. Kung and H. H. Kung, Catal. Rev.-Sci. Eng. 27(1985)425

12. J. W. Ward, J. Catal. 11(1968)271

13. M. R. Basila, T. R. Katner, and K. H. Rhee, J. Phys. Chem. 68(1964)3197

14. J. A. Schwarz, B. G. Russell and H. F. Harnsberger, J. Catal. 54(1978)303

15. S. Rajagopal, T. Grimm, D.J. Collins, R. Miranda, Anal. Chem. Lett., 23(4) 649-57 (1990). 
Report DOE/PC/89771-13

Table 1

Physico-chemical properties of the synthesized catalysts Catalyst Alumina SA1090 SA5050 SA9010 Silica

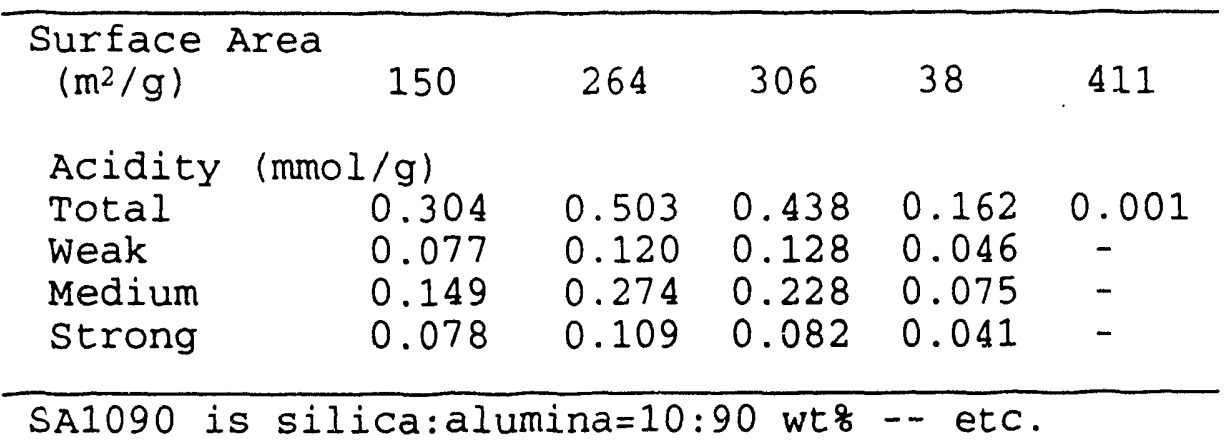

Table 2

Piperidine conversions over alumina and silica-aluminas Reaction temperature, ${ }^{\circ} \mathrm{C}$
$320^{\circ} \quad 340^{\circ} \quad 360^{\circ} \quad 380^{\circ}$

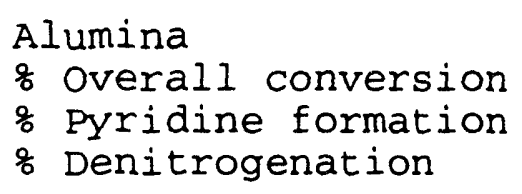

Silica-Alumina $=10: 90$ \% Overall conversion \% pyridine formation $\%$ Denitrogenation

Silica-Alumina $=50: 50$

\% Overall conversion

\% Pyridine formation

\% Denitrogenation

Silica-Alumina $=90: 10$ o Overall conversion \% Pyridine formation

\% Denitrogenation

\begin{tabular}{rrrr}
\hline 9.37 & 17.73 & 43.13 & 62.61 \\
6.01 & 11.06 & 21.32 & 35.42 \\
0.13 & 0.31 & 1.16 & 2.43
\end{tabular}

$\begin{array}{llll}11.31 & 34.71 & 61.42 & 82.6\end{array}$

$\begin{array}{llll}4.8 & 9.38 & 15.54 & 21.41\end{array}$

$\begin{array}{llll}1.63 & 3.41 & 5.43 & 8.15\end{array}$

$\begin{array}{llll}9.15 & 28.74 & 55.05 & 82.53\end{array}$

$\begin{array}{llll}4.4 & 9.2 & 14.51 & 24.12\end{array}$

$\begin{array}{llll}1.87 & 4.3 & 8.29 & 12.74\end{array}$

$\begin{array}{llll}6.92 & 15.65 & 41.59 & 62.26\end{array}$

$\begin{array}{llll}2.88 & 5.6 & 11.9 & 19.77\end{array}$

$\begin{array}{llll}2.36 & 5.36 & 9.57 & 13.1\end{array}$ 
Report DOE/PC/89771

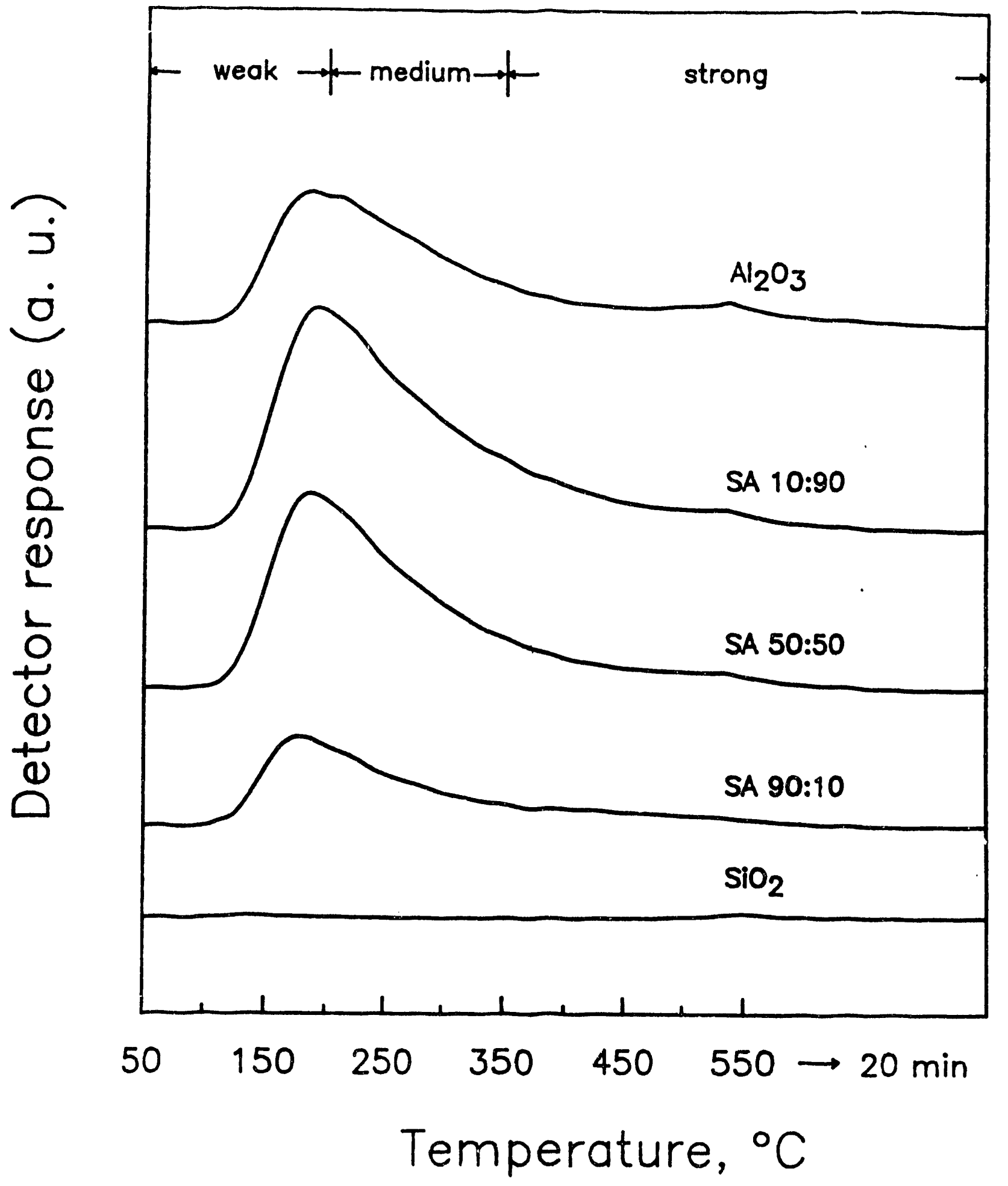

Fig. 1 Temperature programmed desorption profiles of $\mathrm{NH}_{3}$ (See text for conditions) 


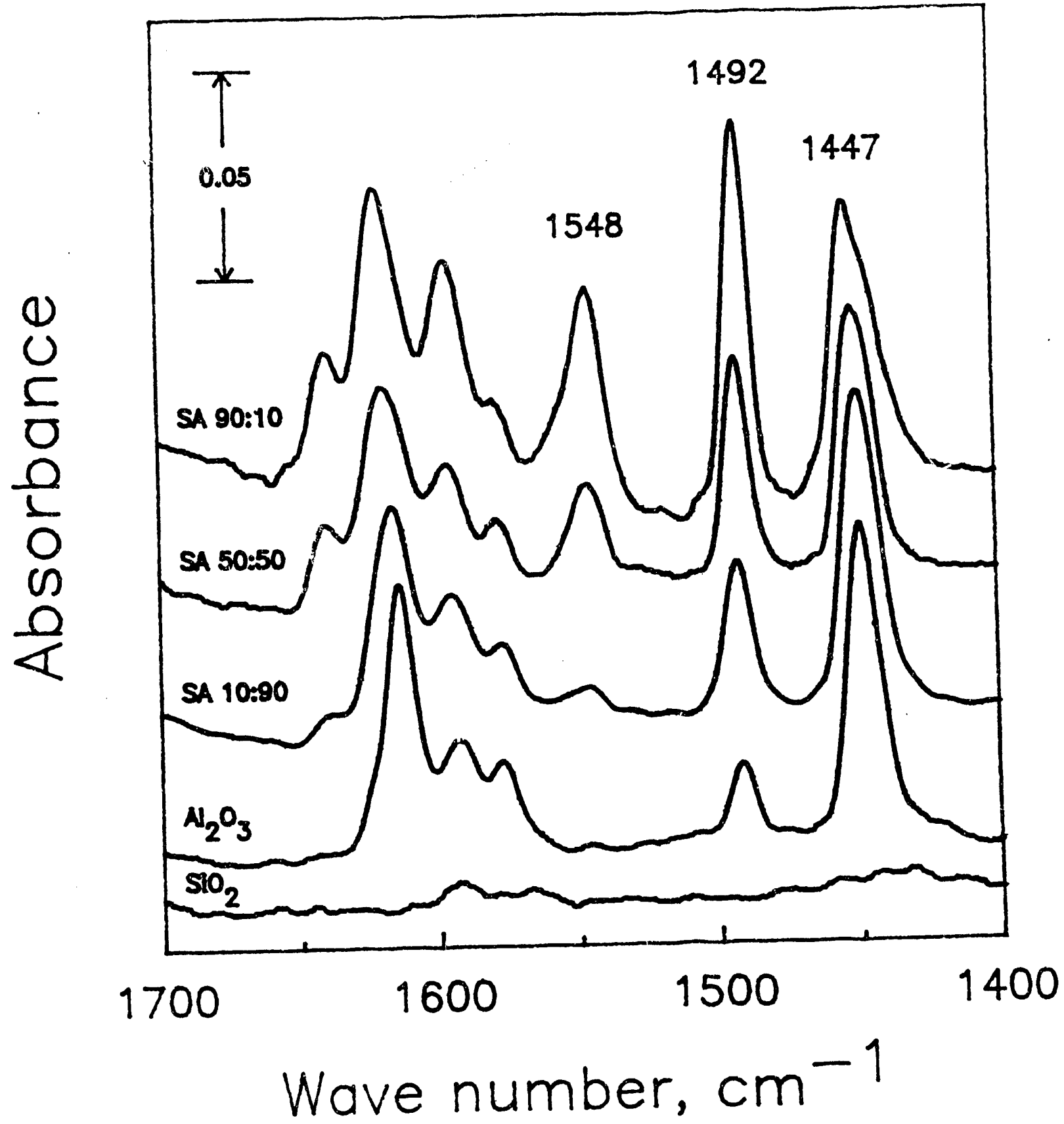

Fig. 2 Diffuse reflectance infrared spectra of adsorbed pyridine at $120^{\circ} \mathrm{C}$ (See text for other experimental conditions). (1) SA 90:10, (2) SA 50:50, (3) SA 10:90, (4) Alumina, and (5) Silica 


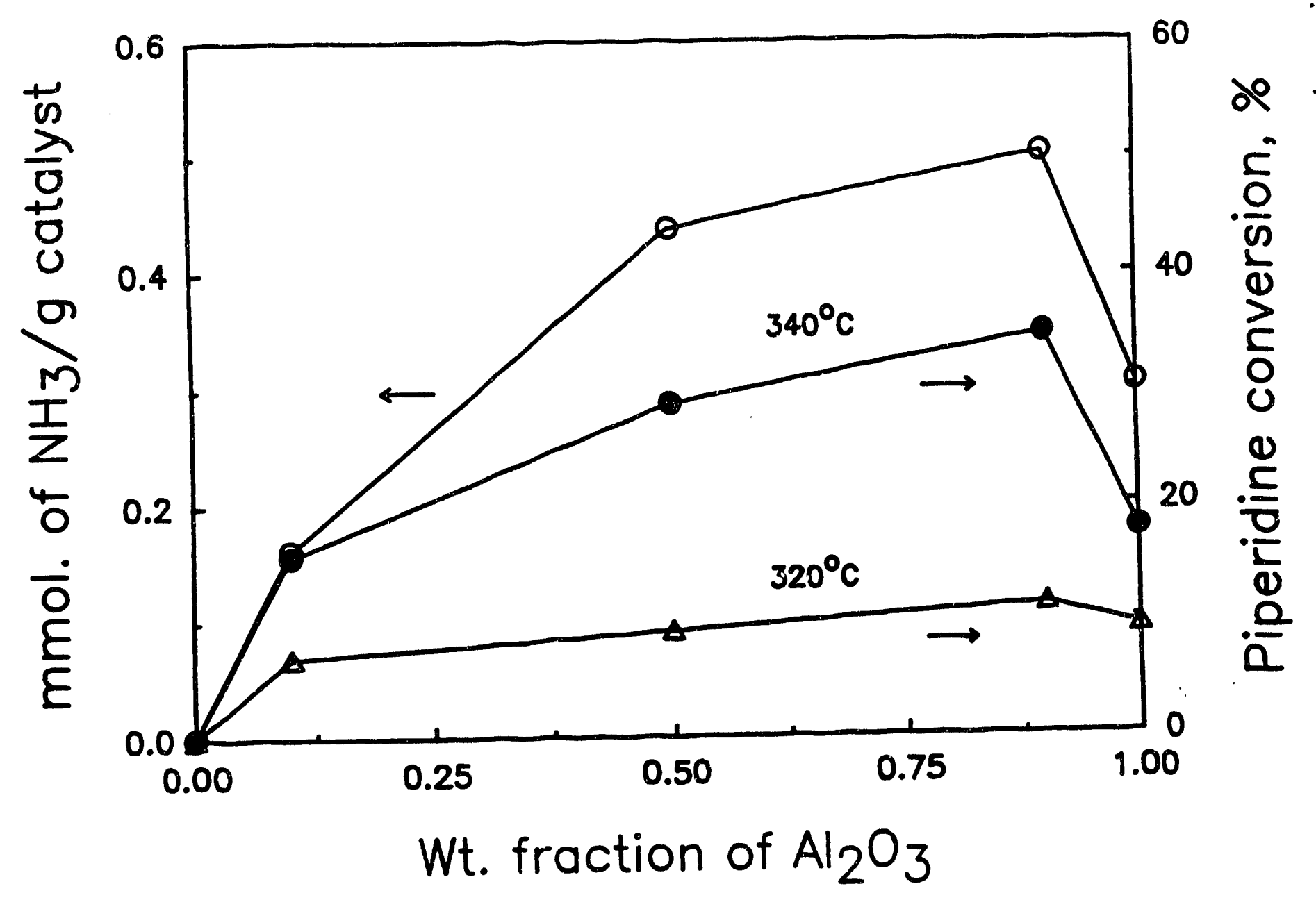

Fig. 3 Total acidity and overall piperidine conversion at $340^{\circ} \mathrm{C}$. (See text for other experimental conditions) 


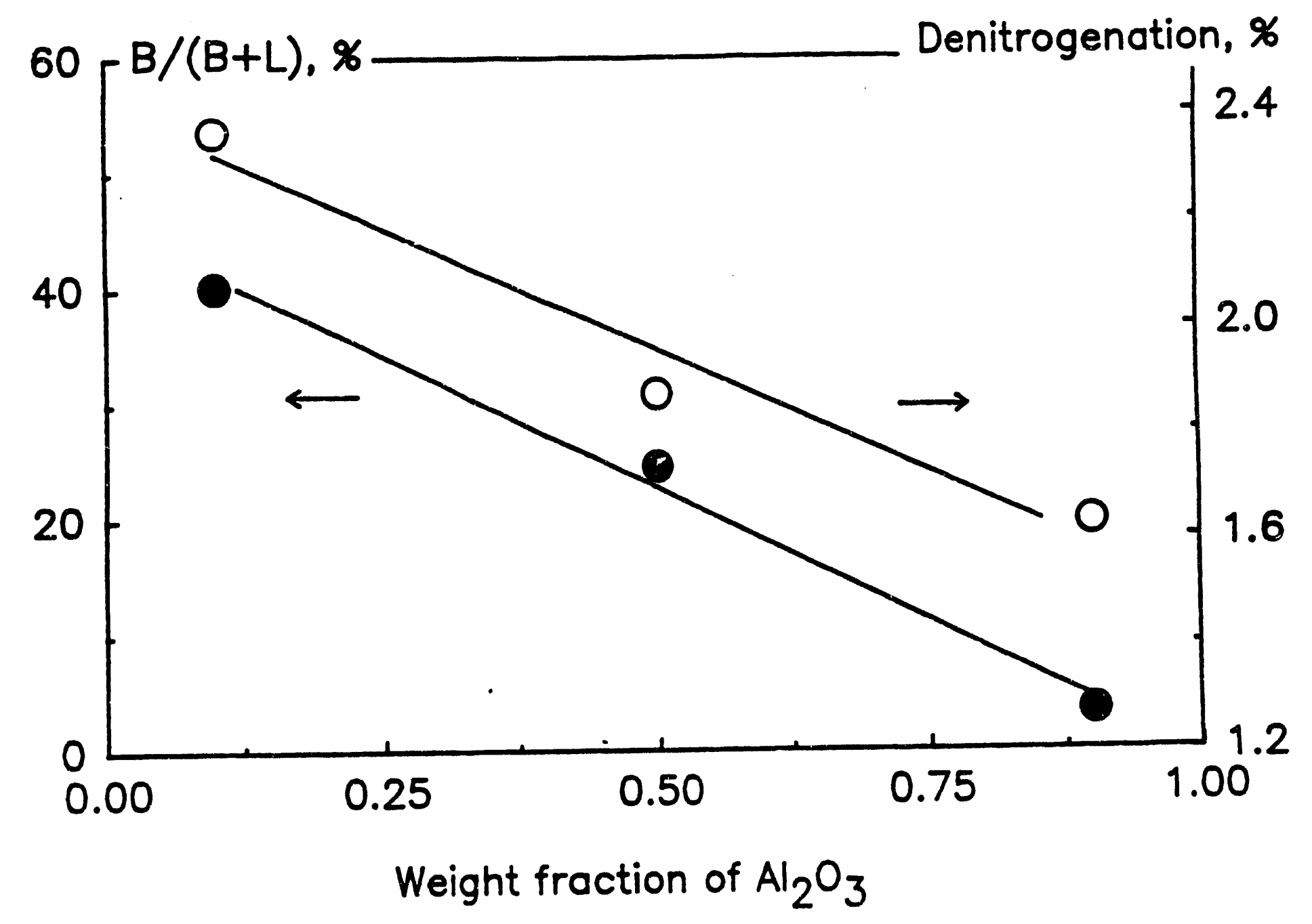

Fig. 4 Fraction of Brönsted acidity and piperidine denitrogenation activity at $340^{\circ} \mathrm{C}$ 
Report DOE/PC/89771-13

\title{
Part 3: PREPARATION AND CHARACTERIZATION OF ACIDIC MOLYBDENA CATALYSTS
}

\begin{abstract}
Mo oxide catalysts supported over a complete series of silica-aluminas have been prepared, and have been characterized with BET, acidity and reducibility measurements. Ammonia chemisorption was used to titrate the total acidity of the supports and catalysts, and TPD of ammonia was used to investigate the changes in distribution of acidity strength that occur when molybdena is loaded.

It was found that the percent increase in acidity when molybdena is loaded is greatest for the silica-rich supports. The strength of the new acid sites appears to be distributed, as in the original supports, except in the case of silica, in which only weak acid sites were generated.

Temperature programmed reduction was utilized to investigate the reducibility and the nature of the Mo oxidic phases, and the distribution of Mo among the different phases. It was expected that the support composition would affect such distribution. The TPR experiments revealed that at least two phases of different reducibility are responsible for the TPR fingerprint spectra. Pure gammaalumina contains mostly dispersed Mo and little clustered Mo oxide. Pure silica contains mostly clustered Mo oxide. Silica-aluminas contain both.
\end{abstract}

\section{INTRODUCTION}

Parts 1 and 2 of this report led to the conclusion that Bronsted acid sites by themselves are catalytically active for the denitrogenation of $\mathrm{N}$-heterocycles, while Lewis sites are not. Thus, a consequence of this work is that the activity of $\mathrm{HDN}$ catalysts towards denitrogenation can be increased by providing additional Brónsted acid sites. The addition of acidity must be limited, however, because coking is also catalyzed by the same acid sites. An increased selectivity to denitrogenation also requires a reduction of Lewis acid sites (on the silica-aluminas), because they catalyze detrimental reactions.

After learning about the general role of each type of acid site present on the silica-aluminas, we proceeded to support Mo oxide on them, with the intention of finding out how the introduction of hydrogenation and hydrogenolysis sites affects the selectivity of the catalyst. Unfortunately, the introduction of Mo oxide not only contributes hydrogenation sites, but also affects the acid sites that were originally present on the silica-alumina support. Moreover, Mo oxide may contribute with additional acid sites of its own.

From the point of view of the surface structure of the catalyst, one must also consider that the support structure may affect the equilibrium structure of Mo oxide. This fact is expected because silica-rich surfaces do not interact as strongly with the molybdate ions (Mo oxide precursors) as alumina-rich surfaces do. 
Therefore, the introduction of Mo oxide on the support generates new variables that have to be carefully characterized before one is able to compare the activity and selectivity obtained with plain silica-aluminas, with the activity and selectivity obtained with Mo oxides supported on those silicaaluminas. Only a careful characterization can ensure that the roles of each type of site are correctly assessed.

The main purpose of the work reported in this section, therefore, was (a) to obtain reproducible supported Mo catalysts, and (b) to partially characterize them. Among the characterized properties are: (a) the new acidity generated by supporting Mo, and c) the reducibility of the resultant Mo phases.

\section{EXPERIMENTAL}

\section{Synthesis of Supports}

The synthesis of a set of silica-alumina supports of reproducible quality entailed the readaptation of sol-gel techniques that were available in the literature. The whole range from 10-90 wt\% silica was prepared using a single optimized technique. Separately, pure silica and gamma-alumina were also synthesized from the same precursors as the silica-aluminas, to maintain a comparative homogeneity and grain uniformity in the whole series. In spite of having the amorphous silica aluminas been known for a long time, the literature had not previously reported on a technique that could be used to synthesize such a wide range of compositions. The then available techniques worked satisfactorily only in a narrow range. The synthesized silica-aluminas were characterized by BET surface area, ammonia chemisorption and TPD, and IR of adsorbed pyridine. Details of the preparation and characterization procedures were given in part 1.

\section{Synthesis of Supported Mo Oxide Catalysts}

Supported molybdena catalysts were prepared by the incipient impregnation method using ammonium heptamolybdate as a precursor. The weight percent of $\mathrm{MoO}_{3}$ on each support was varied with the intention of obtaining variable coverages of the support by the molybdena, from submonolayer up to the equivalent of more than a monolayer. Thus a series of 28 catalysts were prepared, containing 7 different support compositions and 4 different molybdena loadings, as specified in Table 1 .

The impregnated samples were equilibrated at room temperature before drying at $110^{\circ} \mathrm{C}$ for four hours, and calcining at $550^{\circ} \mathrm{C}$ for 12 hours. The 7 catalysts with $8 \mathrm{wt} \% \mathrm{MoO}_{3}$ were prepared repeatedly until reproducible characterization results were obtained. Thus the data reported next will correspond to that particular loading only. We are in the process of repeating the preparation for all 28 catalysts, until reproducibility in the technique is attained. 
Table 1

Supported Molybdena Catalysts

Supports

Silica:Alumina, wt\%
Loadings

$\mathrm{MoO}_{3} \mathrm{wt} \%$

\begin{tabular}{ll}
$0: 100$ & 2 \\
$10: 90$ & \\
$25: 75$ & 4 \\
$50: 50$ & \\
$75: 25$ & 8 \\
$90: 10$ & \\
$100: 0$ & 12 \\
\hline
\end{tabular}

\section{Characterization}

\section{BET Surface Area}

BET surface areas were determined by nitrogen sorption at $-196^{\circ} \mathrm{C}$ using an all-glass vacuum apparatus equipped with a Datametrics pressure sensor.

\section{Ammonia Chemisorption and Temperature Programméd Desorption}

These experiments were done in a quartz $1 / 2^{\prime \prime}$ OD pulse reactor in flowing He $(100 \mathrm{ml} / \mathrm{min})$. The measured $\mathrm{NH}_{3}$ pulses were detected with a thermal conductivity detector, after dosing at $120^{\circ} \mathrm{C}$ every $15 \mathrm{~min}$ until saturation was observed. The temperature of $120^{\circ} \mathrm{C}$ was chosen to completely avoid the physisorption of $\mathrm{NH}_{3}$ on the catalyst. Before chemisorption, the catalyst was pretreated at $500^{\circ} \mathrm{C}$ under He flow. After chemisorption, the catalyst was cooled to $50^{\circ} \mathrm{C}$ and TPD was carried out under He flow by linearly ramping the temperature of the catalyst from $50^{\circ} \mathrm{C}$ to $550^{\circ} \mathrm{C}$ at $10^{\circ} \mathrm{C} / \mathrm{min}$, and then keeping it at $550^{\circ} \mathrm{C}$ for $20 \mathrm{~min}$, while monitoring the desorbing $\mathrm{NH}_{3}$.

\section{Temperature Programmed Reduction}

The reduction of the molybdena loaded catalysts was performed in the same reactor and with a setup similar to the TPD experiments. Before reduction, the calcined sample was exposed to flowing $\mathrm{Ar}$ at $400^{\circ} \mathrm{C}$ for $1 \mathrm{~h}$ to remove moisture. Then the $\mathrm{Ar}$ gas was substituted for a $10 \% \mathrm{H}_{2} / \mathrm{Ar}$ gas mixture as the temperature was ramped from $50^{\circ} \mathrm{C}$ to $550^{\circ} \mathrm{C}$ following the same schedule as in TPD. The thermal conductivity detector responded to the depletion of hydrogen from the $\mathrm{H}_{2} / \mathrm{Ar}$ mixture. In order to avoid the water vapor product from reaching the detector, a condenser at dry ice temperature was placed after the reactor outlet. 


\section{RESULTS AND DISCUSSION}

As stated above, only the reproducible results for $8 \mathrm{wt} \% \mathrm{MoO}_{3}$ will be reported here. The results for the rest of the catalysts will be presented in subsequent sections.

\section{BET Surface Area}

Table 2 reports the surface area of the $8 \mathrm{wt} \% \mathrm{MoO}_{3}$ on silica-alumina catalysts. Notice that 8 wt\% $\mathrm{MoO}_{3}$ is the equivalent of 0.8 monolayer over a $150 \mathrm{~m}^{2} / \mathrm{g}$ support, thus major decrease in surface area would not be expected if the $\mathrm{MoO}_{3}$ were completely dispersed. As observed, however, the surface area decreases upon loading, substantially so in the silica-aluminas and less so in silica and alumina. A possible reason for the large decrease observed for silica-aluminas and silica is that molybdena forms thick deposits (islands) rather than extended monolayers, and plugs the smallest micropores of the supports. This result also indicates a better dispersion of the molybdena on alumina than on any of the other supports. Clearly, the silica-rich surface contains less concentration of reactive $\mathrm{OH}$ groups to react with the molybdate anions and disperse them, than gamma-alumina does.

Table 2

Surface Area of Silica-Aluminas and Molybdena Catalysts $\mathrm{S}_{\mathrm{g}}\left[\mathrm{m}^{2} / \mathrm{g}\right]$ of $8 \mathrm{wt} \% \mathrm{MoO}_{3}$ Catalysts

\begin{tabular}{rrrr} 
wt\% silica & $\mathrm{S}_{\mathrm{g}}$, support & $\mathrm{S}_{\mathrm{g}}$, catalyst & \%decrease \\
\hline $0\left(\mathrm{Al}_{2} \mathrm{O}_{3}\right)$ & 150 & 141 & 6 \\
10 & 264 & 173 & 34 \\
25 & 297 & 213 & 28 \\
50 & 306 & 209 & 32 \\
75 & 294 & 191 & 35 \\
90 & 382 & 277 & 28 \\
$100\left(\mathrm{SiO}_{2}\right)$ & 311 & 255 & 18 \\
\hline
\end{tabular}

\section{Ammonia Chemisorption and TPD}

The amount of $\mathrm{NH}_{3}$ chemisorbed is a measure of total acidity of the catalysts, without discriminating with respect to type or strength of acidity. The TPD profile is an indication of the distribution of acid strength. In that profile the $\mathrm{NH}_{3}$ that is bound more strongly desorbs at higher temperatures. Since there is a continuous distribution of strength, it is convenient to arbitrarily divide the TPD profiles into three regions corresponding to weakly, medium and strongly bound ammonia $\left(50-200^{\circ} \mathrm{C}, 200-350^{\circ} \mathrm{C}\right.$ and $\left.350-550^{\circ} \mathrm{C}\right)$. 
The TPD spectra were carefully reproduced several times, and the differences reported in areas or temperature-displacements are real and highly reproducible if the pretreatment is consistently done. The total amount of $\mathrm{NH}_{3}$ adsorbed is completely desorbed under the TPD conditions employed. This was assessed by heating to higher temperatures after the TPD experiment, and by verifying the mass balance of adsorbed and desorbed $\mathrm{NH}_{3}$. The TPD spectra shown in Fig. 1 correspond to the silica-alumina supports, and those in Fig. 2 to the supported $8 \mathrm{wt} \% \mathrm{MoO}_{3}$ catalysts. The total acidity, measured as $\mathrm{mmol} \mathrm{NH}_{3}$ per $\mathrm{g}$ catalyst, is given in Table 3 .

A qualitative comparison of both sets of spectra and of Table 3 indicates that the total amount of acidity increases substantially when molybdena is deposited on the silica-aluminas. This is most obvious for the $75 \%$ and $90 \%$ silica-aluminas and for $\mathrm{SiO}_{2}$. In the case of $\mathrm{SiO}_{2}$ there is no measurable acidity before molybdena is added, thus all of the acidity of the supported catalyst can be associated with the molybdena. As observed, the acidity added is essentially weak, and in the oxidized catalysts it is probably related to coordinatively unsaturated Mo, which behave like Lewis acid sites.

In the case of the silica-aluminas the acidity added by supporting molybdena is of broad strength distribution, since the three regions of --weak, medium, strong-- acidity increase after supporting molybdena. The increase in the acidity in this case could be assigned to the formation of MoVI-O-SilV and MoVI-O-AlII groups at the interface of transition metal oxide and support; due to polarization these groups would generate new Bronsted acid sites, or would strengthen acid sites that are already present on the support.

Table 3

Total Acidity of Supports and Catalysts [ $\mathrm{mmol} \mathrm{NH}_{3} / \mathrm{g}$ ]

\begin{tabular}{rccc} 
wt\% Silica & Support & $8 \mathrm{wt} \% . \mathrm{MoO}_{3}$ & \%increase \\
\hline $0\left(\mathrm{Al}_{2} \mathrm{O}_{3}\right)$ & .304 & .313 & 3 \\
10 & .503 & .517 & 3 \\
25 & .512 & .583 & 14 \\
50 & .438 & .507 & 16 \\
75 & .269 & .456 & 70 \\
90 & .162 & .404 & 150 \\
$100\left(\mathrm{SiO}_{2}\right)$ & .001 & .197 & $\infty$ \\
\hline
\end{tabular}


Report DOE/PC/89771-13

\section{Temperature Programmed Reduction}

A TPR spectrum is a qualitative but very sensitive probe of the oxidation state of Mo and its distribution among the various surface phases. In a sense it can be taken as a "fingerprint" of the supported Mo catalyst. This fingerprint could be utilized in practical ways. For example, when comparing the performance of such catalysts, it is safe to assume that catalysts that show exactly the same TPR fingerprint contain equivalent amounts of Mo distributed in equivalent oxidic phases. On the other hand, it is risky to assume that the TPR fingerprint can always discriminate among different surface species of Mo.

The TPR spectrum is also a practical indication of the reducibility of Mo on a particular support. The area under the curve is proportional to the extent of reduction, and the appearance of various peaks can sometimes be related to the changes in the state of oxidation of Mo. The position of the peaks in the temperature scale is an indication of the reducibility of the individual Mo-O groups (or oxide phases). Higher temperature of reduction indicates more stable Mo-O groups (or oxide phases). Thus it is possible to perceive the appearance of the new phases that are formed by reaction with the support, by means of the appearance of new peaks or by the displacement of peaks in the temperature scale.

The results from the TPR of $8 \mathrm{wt} \% \mathrm{MoO}_{3}$ are shown in Fig. 3. (The experiments were repeated until the spectra were completely reproducible.) It is apparent that the distribution of Mo among various oxidic phases is different for every catalyst. It is also apparent that there are two fundamental reduction peaks at around $400^{\circ} \mathrm{C}(\alpha)$ and around $550^{\circ} \mathrm{C}(B)$. These temperatures of reduction suggest that both $\alpha$ and $B$ correspond to the reduction step

$$
\text { MoVI -.-------->> MoIV }
$$

It is unlikely that the second peak (B) corresponds to the reduction of Mo IV--->II, which the literature has reported to occur at $\mathrm{T}>650^{\circ} \mathrm{C}$.

Thus, the conclusion from these spectra is that the two observed peaks correspond to different oxidic phases of MoVI, which have different reduction potential. The $\alpha$ phase is more reducible than the $B$ phase, probably because of the lower coordination of Mo to the surrounding ions.

The molybdena sypported on silica appears to contain either $B$ phase only or unresolved $\alpha$ and $B$ phases. The reducible amount (i.e. the amount of Mo present in the $\alpha$ and $B$ phases) is much larger on silica than on the other supports even though the Mo wt\% loading is the same. Thus it is possible that a fraction of Mo species could be associated with other phases than $\alpha$ and $\beta$, only that they are not detected by this TPR fingerprint. However, from literature reports it is known that silica will not react strongly with molybdena, thus the formation of other phases is unlikely. Therefore, we conclude that the observed peak(s) represent most of the available Mo on silica.

The molybdena supported on gamma-alumina contains well resolved $\alpha$ and $B$ phases, and the $\alpha$ phase is more abundant. The appearance of the resolved $\alpha$ phase as the alumina content increases indicates that alumina must be involved in the formation of such a phase. The peak shifts towards 
lower reduction temperature, meaning that the reducibility of such phase increases in conjunction with the increasing alumina content. Notice, on the other hand, that the reducibility of the $B$ phase is essentially independent of the support composition, thus such phase is formed without support involvement.

It is also obvious that the extent of reduction of Mo on silica-aluminas decreases as alumina content increases, therefore in these cases the observed $\alpha$ and $B$ phases may not represent all of the available Mo, which may be involved in other chemical bonding environments that are not as reducible.

We can interpret the observed evolution of fingerprints from alumina-rich to silica-rich catalysts by proposing that Mo forms a phase with alumina, the $\alpha$-phase, which probably involves the formation of MoVI-O-AlIII groups of high reducibility. These groups are well dispersed since alumina was seen to contain large density of $\mathrm{OH}$ groups available for reaction with molybdate anions. On the other extreme, the $B$-phase represents MoVI-O-MoVI groups with low reducibility, such as in a stiujle Mo oxide crystallite. Thus the $B$ phase probably represents poorly dispersed Mo which is part of Mo oxide crystallites. It must be emphasized that the Mo present in the $\alpha$ phase on alumina-rich supports is only a small fraction of the available Mo, thus there must exist other phases that are much less reducible, and do not appear in the spectrum. Those phases, not being Mo oxide crystallites ( $B$ phase), must also involve the alumina support.

The reducibility of the $\alpha$ phase decreases (the peak shifts to higher temperatures of reduction) when the chemical environment around the MoVI-O-AlII is affected by the surface composition (decrease density of surface $\mathrm{Al}$ III), and more MoVI-O-MoVI bonds are formed. This can be interpreted as a phase transition between dispersed Mo ( $\alpha$-phase) and agglomerated Mo (B-phase),

$$
\alpha-\cdots>B
$$

when the silica content of the support increases.

\section{CONCLUSIONS}

This part of the report was focused on the characterization of the changes occurring when molybdena is loaded on acidic supports. Ammonia chemisorption was used to titrate total acidity of the supports and catalysts, and TPD of ammonia was used to search for changes in distribution of acidic strength.

It was observed that the total amount of acidity present before loading was increased by the deposited molybdena, and that the \%increase was greatest for the silica-rich supports. The strength of the new acid sites appeared to be distributed in the same proportions of weak, medium and strong acid sites as in the original supports, except in the case of silica, in which only weak acid sites were generated. We assigned the new acid sites to the formation of groups Mo-O-Si and Mo$\mathrm{O}-\mathrm{Al}$, except in the case of silica support, in which the weak acid sites are formed by 
coordinatively unsaturated sites present on the molybdena crystallites, and no acidic Mo-O-Si groups are formed.

The TPR experiments revealed that two phases, which we called $\alpha$ and $B$ phases, are responsible for the TPR spectra. The $\alpha$ phase has a higher reductibility that varies with support composition, and was assigned to a phase containing dispersed Mo-O-Al groups. It was apparent that other phases containing Mo-O-Al groups are present but have lower reducibility (are more stable) and do not appear in the low-temperature TPR spectra. The $B$ phase has a lower reduction potential than the $\alpha$ phase, its reduction potential does not vary with support composition, and was assigned to clustered Mo-O-Mo groups such as those present in Mo oxide crystallites. Pure gamma-alumina support contains mostly dispersed Mo (present in $\alpha$ and other phases) and small amounts of clustered Mo oxide. Pure silica contains mostly clustered Mo oxide. Silica-aluminas contain both. 


\section{FIGURES}

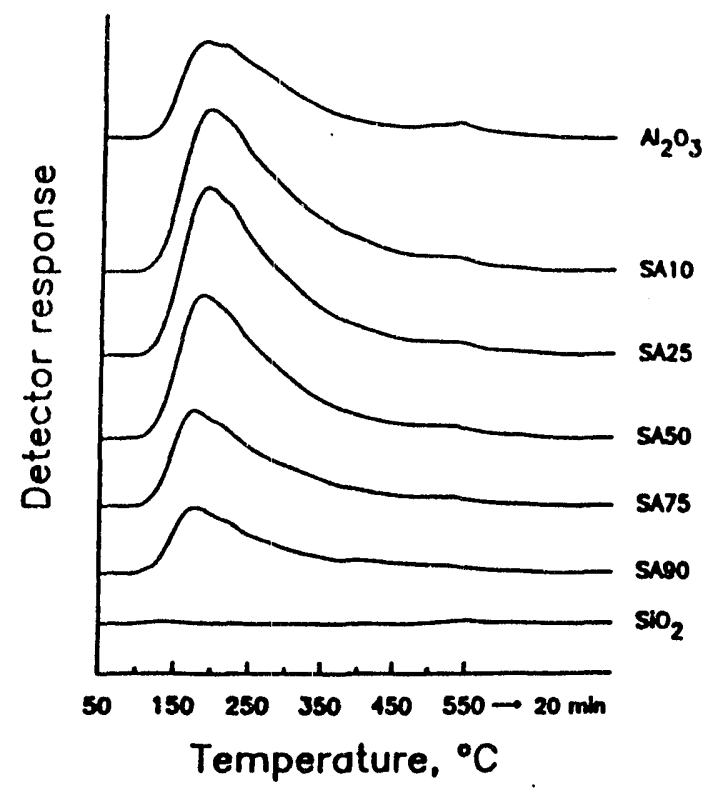

Fig. 1 TPD of $\mathrm{NH}_{3}$ from silica, alumina and silica-aluminas.

Note: SA10 means 10 wt\% silica.

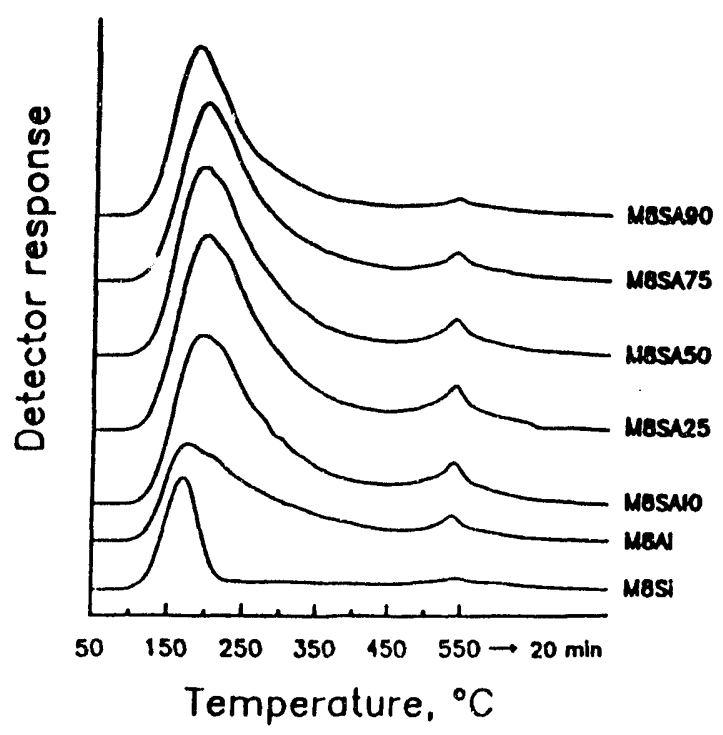

Fig. 2 TPD of $\mathrm{NH}_{3}$ from Mo oxide supported on silica-aluminas.

Note: M8SA10 means $8 \mathrm{wt} \% \mathrm{MoO}_{3}$ on $10 \mathrm{wt}$ i silica-alumina. 


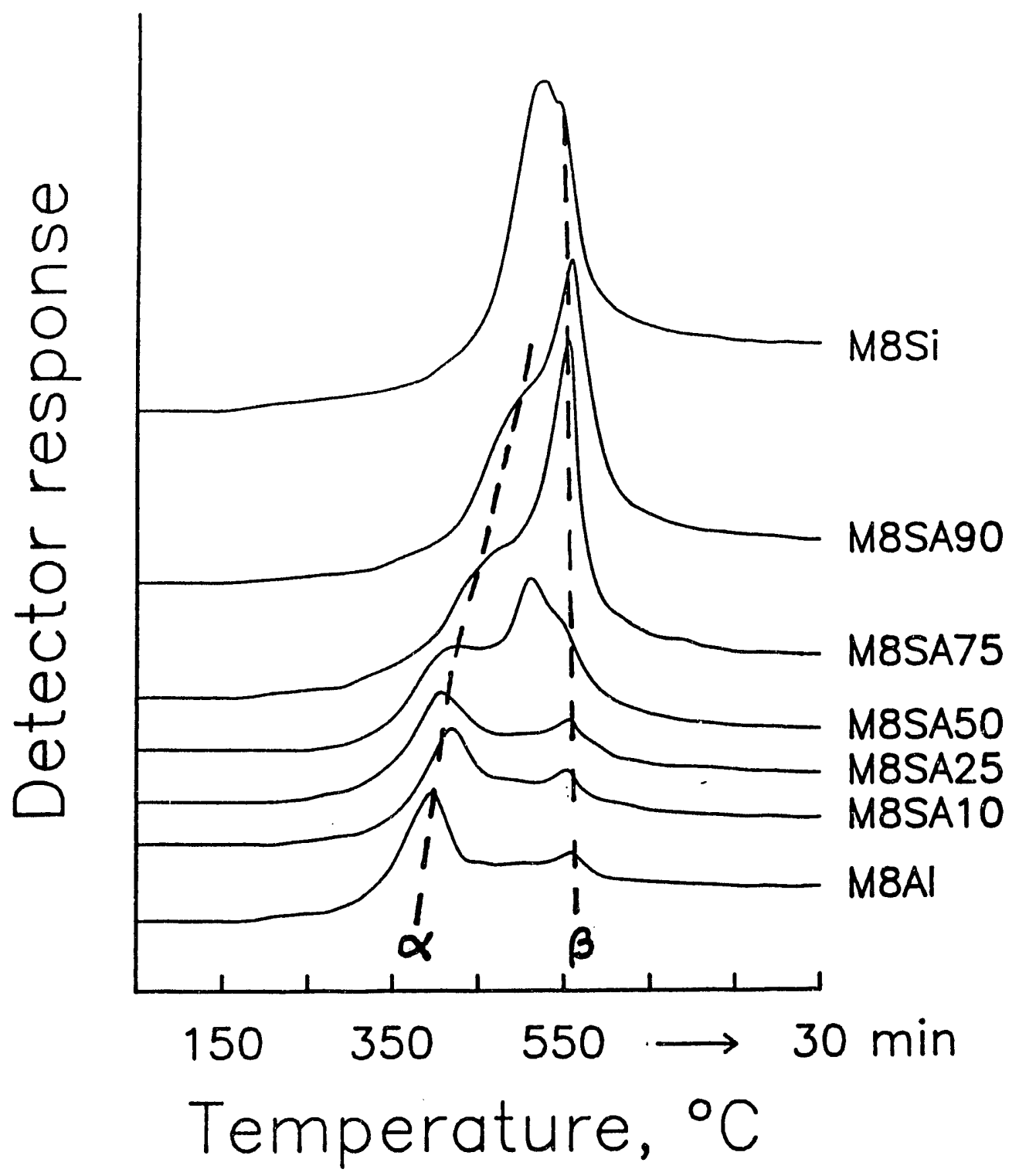

Fig. 3 TPR of 8 wt\% $\mathrm{MoO}_{3}$ supported on silica-aluminas. 
Report DOE/PC/89771-13

\title{
Part 4: INFRARED SPECTROSCOPY OF ACIDIC MOLYBDENA CATALYSTS
}

\begin{abstract}
Mo oxide catalysts supported over a complete series of silica-aluminas have been characterized in the oxidic and reduced states, by means of total acidity measurements and by infrared spectroscopy. Ammonia chemisorption was used to titrate the total acidity of the catalysts, and IR absorption of adsorbed pyridine to distinguish Bronsted from Lewis acid sites. The formation of new acidity upon deposition of molybdena on silica-alumina supports was then explained on the basis of a simple surface model.

The new acidity is of both Lewis and Bronsted type, the preponderance of one over the other depending on support composition, as well as loading and state of oxidation of Mo. High-alumina supports and low Mo loading favor dispersed Mo species, in particular bidentate and monodentate di-oxo Mo species. The latter is responsible for the new Bronsted acidity. Coordinative unsaturation of polymolybdates is responsible for the new Lewis acidity, which is increased upon reduction of 0 . High-silica supports favor monodentate species (high Bronsted acidity) up to 4 $\mathrm{wt} \% \mathrm{MoO}_{3}$. Beyond that, polymolybdate species and Lewis acidity predominate.
\end{abstract}

\section{INTRODUCTION}

To understand better the role of acidic sites in HDN when hydrogenolysis sites are present, molybdena was supported on the series of acidic aluminas. The resulting new acidity and molybdic phases were characterized in part 3 of this report. The oxidized catalysts supported on silicaaluminas showed increases from 3 to $150 \%$ of weak, medium and strong acid sites.

This part of the report is focused on the characterization of the type of acidity (Bronsted or Lewis) generated in the molybdena phases and how that acidity is affected by the loading and state of oxidation of Mo. This latter aspect is relevant in the utilization of the supported catalysts for HDN, where they actually work under reduced conditions.

\section{EXPERIMENTAL}

\section{Synthesis of Supports and Supported Mo Oxide Catalysts}

Silica-aluminas with a range of composition from 10-90 wt\% silica were prepared. Separately, pure silica and gamma-alumina were also synthesized from the same precursors as the silicaaluminas. Supported molybdena catalysts were prepared by the incipient impregnation method using ammonium heptamolybdate as a precursor. Details of the preparation and characterization results were given above. 


\section{Reduction of Mo Oxide Catalysts before IR Spectroscopy}

The catalysts were reduced in a flow reactor consisting of a $1 / 2^{\prime \prime O D ~ q u a r t z ~ t u b e ~ h e a t e d ~ b y ~ a ~ t u b e ~}$ furnace. Before reduction, the calcined samples were exposed to flowing $\mathrm{He}$ at $400^{\circ} \mathrm{C}$ for $1 \mathrm{~h}$ to remove moisture. Then $100 \mathrm{ml} / \mathrm{min}$ of $\mathrm{H}_{2}$ was flown over the catalyst for $4 \mathrm{~h}$ at $500^{\circ} \mathrm{C}$. The samples were cooled, exposed to air for less than $5 \mathrm{~min}$, and transferred to the IR cell, which was equipped with an environmental chamber. There a subsequent reduction with $\mathrm{H}_{2}$ for $1 \mathrm{~h}$ at $500^{\circ} \mathrm{C}$ was produced. This two-part procedure ensured a deep bulk reduction in the first step, and a rereduction of the surface Mo in the second step. It must be noticed that a one-step complete reduction in the IR cell was not possible, because of the high partial pressure of moisture that resulted from the low $\mathrm{H}_{2}$ flowrate attainable through the cell and sample.

\section{Ammonia Chemisorption}

Pulses of $\mathrm{NH}_{3}$ in $100 \mathrm{ml} / \mathrm{min}$ of He carrier were sent over the samples contained in a quartz $1 / 2$ "OD tube. The measured $\mathrm{NH}_{3}$ pulses were detected with a thermal conductivity detector, after dosing at $120^{\circ} \mathrm{C}$ every $15 \mathrm{~min}$ until saturation was observed. The temperature of $120^{\circ} \mathrm{C}$ was chosen to completely avoid the physisorption of $\mathrm{NH}_{3}$ on the catalyst. Before chemisorption, the catalyst was pretreated at $500^{\circ} \mathrm{C}$ under He flow.

\section{Infrared Spectroscopy of Chemisorbed Pyridine}

A Perkin-Elmer 1720 FTIR and computer were used to collect and process infrared spectra of adsorbed pyridine. This spectrometer was equipped with a Spectra Tech diffuse reflectance IR cell that included an environmental chamber. The catalysts in the oxidic state were pretreated in-situ at $450^{\circ} \mathrm{C}$ under He flow for $1 \mathrm{~h}$ and cooled to $200^{\circ} \mathrm{C}$, and the catalysts in the reduced state were cooled to $200^{\circ} \mathrm{C}$ in $\mathrm{H}_{2}$, before taking a blank spectrum. Pyridine was then adsorbed up to saturation at $200^{\circ} \mathrm{C}$, by injecting $2 \mu \mathrm{l}$ pulses of dried pyridine in a reservoir located upstream the cell and maintained at room temperature. Under those conditions, all of the pyridine was carried over the sample within $20 \mathrm{~min}$. In order to prevent strong adsorption of pyridine in the tubings and prolonged bleeding from them, all tubes and valves had to be neutralized with $\mathrm{KOH}$. After purging pyridine vapor with $\mathrm{He}$, the IR spectra of adsorbed pyridine were recorded at $200^{\circ} \mathrm{C}$. The spectral information was manipulated with Micro-Search, software supplied by Sprouse Scientific Systems.

The spectra presented below correspond only to the region of 1400 to $1700 \mathrm{~cm}^{-1}$, which contains bands that pertain to pyridine adsorbed on Lewis and Bronsted acid sites. The band at $1447 \mathrm{~cm}^{-1}$ is characteristic of Lewis sites (LPy) while the band at $1548 \mathrm{~cm}^{-1}$ indicates Bronsted sites (BPy); the band at $1492 \mathrm{~cm}^{-1}$ is a combination one. The areas under the bands are proportional to the abundance of their respective type of site. Since the extinction coefficients were not measured, the absolute amount of acid sites can not be calculated. Furthermore, the ratio of extinction coefficients $\varepsilon^{\mathrm{L}} 1450 / \varepsilon^{\mathrm{B}} 1545$ is a function of solid composition and measurement and pretreatment conditions. Therefore, the relative ratios of areas $\mathrm{BPy} /(\mathrm{BPy}+\mathrm{LPy})$ presented below indicate only a trend in the abundance of Bronsted acid sites. 
Report DOE/PC/89771-13

\section{RESULTS AND DISCUSSION}

Table 1 presents the total acidity of original supports and of oxidized and reduced catalysts. Only the $8 \mathrm{wt} \% \mathrm{MoO}_{3}$ is given, as an illustration of the general behavior of all molybdena catalysts. The last two columns of the table give the increase in the amount of acid sites with respect to the acidity of the support, when molybdena is present in oxidic or reduced forms. The same information can be seen in Fig. 1.

The maximum total acidity occurs in the region of 10-25 wt\% silica, although the maximum gain in acidity produced by molybdena occurs at 75-90 wt\% silica. Substantial acidity is lost during reduction of supported molybdena, but the reduced catalysts are still more acidic than the original supports. A comparison of this information with that derived from TPR suggests that the new acid sites generated by the addition of molybdena are located on the reducible clustered molybdena phases (which we named $B$ phases), and not on the highly dispersed phases ( $\alpha$ phases) or on the support. Thus, alumina-supported molybdena, which is mostly in $\alpha$ phases, produces small gain in net acidity; on the other hand, silica-alumina-supported molybdena, which is largely in $B$ phases, produces large gains in acidity. Silica, which contains only $B$ phases, has the greatest \%increase of acidity, but as shown before, contains exclusively weak acidity. A clearer description of the type and nature of the new acid sites created will be given after examining the IR results.

Table 1

Total Acidity of Supports and Catalysts [mmol $\mathrm{NH}_{3} / \mathrm{g}$ ]

\begin{tabular}{|c|c|c|c|c|c|}
\hline \multirow[t]{2}{*}{ wt\% Silica } & \multirow[t]{2}{*}{ Support } & \multicolumn{2}{|c|}{$8 \mathrm{wt} \% \mathrm{MoO}_{3}$} & \multicolumn{2}{|c|}{ increase, $\mathrm{mmol} \mathrm{NH}_{3} / \mathrm{g}$} \\
\hline & & oxidic & reduced & oxidic & reduced \\
\hline $0\left(\mathrm{Al}_{2} \mathrm{O}_{3}\right)$ & .304 & .313 & .321 & .009 & .017 \\
\hline & .503 & .517 & .531 & .014 & .028 \\
\hline 25 & .512 & .583 & .547 & .071 & .035 \\
\hline 50 & .438 & .530 & .499 & .092 & .061 \\
\hline & .269 & .470 & .358 & .201 & .089 \\
\hline 90 & .162 & .404 & .257 & .242 & .095 \\
\hline $100\left(\mathrm{SiO}_{2}\right)$ & .001 & .197 & .100 & .196 & .099 \\
\hline
\end{tabular}

Fig. 2 shows the $1400-1700 \mathrm{~cm}^{-1}$ IR region for adsorbed pyridine on $8 \mathrm{wt} \% \mathrm{MoO}_{3} /$ silicaaluminas. Other $\mathrm{MoO}_{3}$ loadings produced similar spectra. The distinctive features on oxidic as well as reduced catalysts are: (a) silica-supported molybdena generates only Lewis acid sites, (b) silicaalumina-supported molybdena contains both Lewis and Bronsted acids, and (c) alumina-supported molybdena also contains both types of sites, although alumina support per se does not contain Bronsted acid sites. 
Evaluating the areas under the 1447 and $1548 \mathrm{~cm}^{-1}$ bands, and assuming a ratio of extinction coefficients $\varepsilon^{L_{145}} \mathcal{E}^{\mathrm{B}}{ }_{1545}=1$ for all catalysts, we can plot the relative abundance of Bronsted acid sites as a function of support composition, as in Fig. 3 for oxidic molybdena and Fig. 4 for reduced molybdena catalysts. In general, the oxidic as well as the reduced catalysts contain maximum anount of Bronsted acid sites in the range 75-90 wt $\mathrm{SiO}_{2}$, which does not coincide with the range for maximum amount of total acidity (Fig. 1). Upon reduction of molybdena, the Bronsted acidity drops uniformly for all support compositions, but in much larger proportion than the drop in total acidity (Table 1).

A closer look at Figs. 3 and 4 indicates that the $B / L$ ratios for catalysts with low molybdena loading (Si wt\%) are larger than those for the supports and follow the overall shape of the support curve. On the other hand, as the molybdena loading is increased, the $\mathrm{B} / \mathrm{L}$ curves lose correlation with the support curve, and for a reduced $12 \mathrm{wt} \% \mathrm{MoO}_{3}$ catalyst the $\mathrm{B} / \mathrm{L}$ ratio is almost independent of the support, except for pure silica support.

These results can be interpreted in terms of a simple modil that takes into account the density of reactive $\mathrm{OH}$ groups on the support. The maximum density oicurs on alumina, and lie minimum one on silica. As the alumina is diluted with silica, the OH density falls and the number of surface $\mathrm{Si}-\mathrm{O}-\mathrm{Al}$ groups increases. The Si-O-Al groups ar resnonsible for the support Bronsted aciuity, being maximum at 75-90 wt\% silica. Turing impregnation of ammonium her,tarnolybdate at close to neutral $\mathrm{pH}$, monomeric and polymeric oxo-Nio species react with the support $\mathrm{OH}$ groups to form dispersed Mo phases. When the available $\mathrm{OH}$ groups have been saturated, the remaining oxoMo species precipitate on all of the surface during drying and aggiomerate during caicination to minimize the surface free energy.

For low molybdena loadings (esp. 2 wt\%), mostly dispersed oxo-Mo species (I) are being formed on alumina and possibly some silica-aiuminas ( $\$ 25 \mathrm{wt} \%$ silica). There species do not affect the support Bronsted or Lewis sites, or at most consume as many Lewis sites as they recreate. Such species<smiles>O=[W](=O)(O[AlH])O[AlH]</smiles>

demand a continuous alumina surface. The doubly-anchored di-oxo species might be expected to induce stronger acidity on nearby acid sites on the support, but we can not produce any conclusive evidence of this happening. At $\geq 25 \mathrm{wt} \%$ silica, the OH density is less and the alumina surface is more discontinuous, thus even though dispersed Mo phases are formed for 2 wt\% loading, a predominance of mono-dentate di-oxo species (II) is likely:<smiles>O=[W](=O)(O[Na])O[AlH2]</smiles> 
This species is Bronsted acidic, and is responsible for generating new Bronsted acid sites. The maximum increase in total acidity and ratio of Bronsted sites occurs between 75 and $90 \mathrm{wt} \%$ silica, which is also the region where the maximum number of surface $\mathrm{Si}-\mathrm{O}-\mathrm{Al}$ groups appear, causing the maximum discontinuity of alumina and maximum appearance of mono-dentate Mo species II. The previous discussion is valid for very low contents of Mo (about $2 \mathrm{wt} \%$ ). As the Mo content increases the abundance of II also increases as does the appearance of polymolybdates. The accompanying Bronsted site increment that is observed in Fig. 3 for silica:aluminas $\leq 50 w t \%$, is a consequence of the abundance of species II that is favored by the high density of $\mathrm{OH}$. For silica:aluminas $>50 \mathrm{wt} \%$, the density of $\mathrm{OH}$ is so low that only polymolybdates are formed, either by condensation of species II, or by direct precipitation of polymolybdates from the impregnating solutions Therefore Fig. 3 shows that the optimum loading for maximum occurrence of species II and Bronsted sites is $4 \mathrm{wt} \% \mathrm{MoO}_{3}$. Reduction with $\mathrm{H}_{2}$ decreases the number of Bronsted acid sites, possibly by reducing the di-oxo structure II. It must be noticed that this model of generated acidity can also explain Segawa and Hall's results of surface acidity on molybdena/alumina catalysts [1].

In the model proposed here, the new Lewis acid sites are formed mainly on polymolybdates species, due to coordinative unsaturation of Mo. Such unsaturation, and consequently Lewis sites, should increase in amount as Mo is reduced, a fact which is verified by Fig. 4 . The result is most noticeable for $12 \mathrm{wt} \%$ Mo loading, which contains a major fraction of polymolybdate species, and displays the largest decrease in $\mathrm{B} / \mathrm{L}$ ratio upon reduction. Silica support is unable of generating species II, thus its $\mathrm{B} / \mathrm{L}$ ratio is zero for all $\mathrm{MoO}_{3}$ loading. $\mathrm{MoO}_{3}$ on silica is present exclusively as low-dispersed polymolybdate species, and these species are responsible for the Lewis acidity present.

\section{CONCLUSIONS}

The formation of new acidity upon deposition of molybdena on silica-alumina supports has been explained on the basis of total acidity measurements, TPR, and infrared spectroscopy of adsorbed pyridine. The new acidity is of both Lewis and Bronsted type, the preponderance of one over the other depending on support composition, as well as loading and state of oxidation of Mo. Highalumina supports and low Mo loading favor dispersed Mo species. It was postulated that a monodentate Mo species is responsible for the new Bronsted acidity, while a bidentate di-oxo species does not generate new acidity. Coordinative unsaturation of polymolybdates is responsible for the new Lewis acidity, which is increased upon reduction of Mo. High-silica supports favor monodentate species (high Bronsted acidity) up to $4 \mathrm{wt} \% \mathrm{MoO}_{3}$. Beyond that, polymolybdate species and Lewis acidity predominate. Reduction with $\mathrm{H}_{2}$ causes the appearance of more coordinative unsaturation (more Lewis sites) and the reduction of the monodentate Mo species (less Bronsted sites). 


\section{REFERENCES}

1. K. Tanabe, in Catalysis: Science and Technology (J.R. Anderson and M. Boudart, Edt.) Springer-Verlag, Berlin, 1981, v.2, p.231; M.C. Kung and H.H. Kung, Catal. Rev.-Sci. Eng. 27(1985)425

2. J.W. Ward, J. Catal. 11 (1968)271; M.R. Basila, T.R. Katner and K.H. Rhee, J. Phys. Chem. 68(1964)3197

3. K. Segawa, W.K. Hall, J. Catal. 76(1982)133-143 


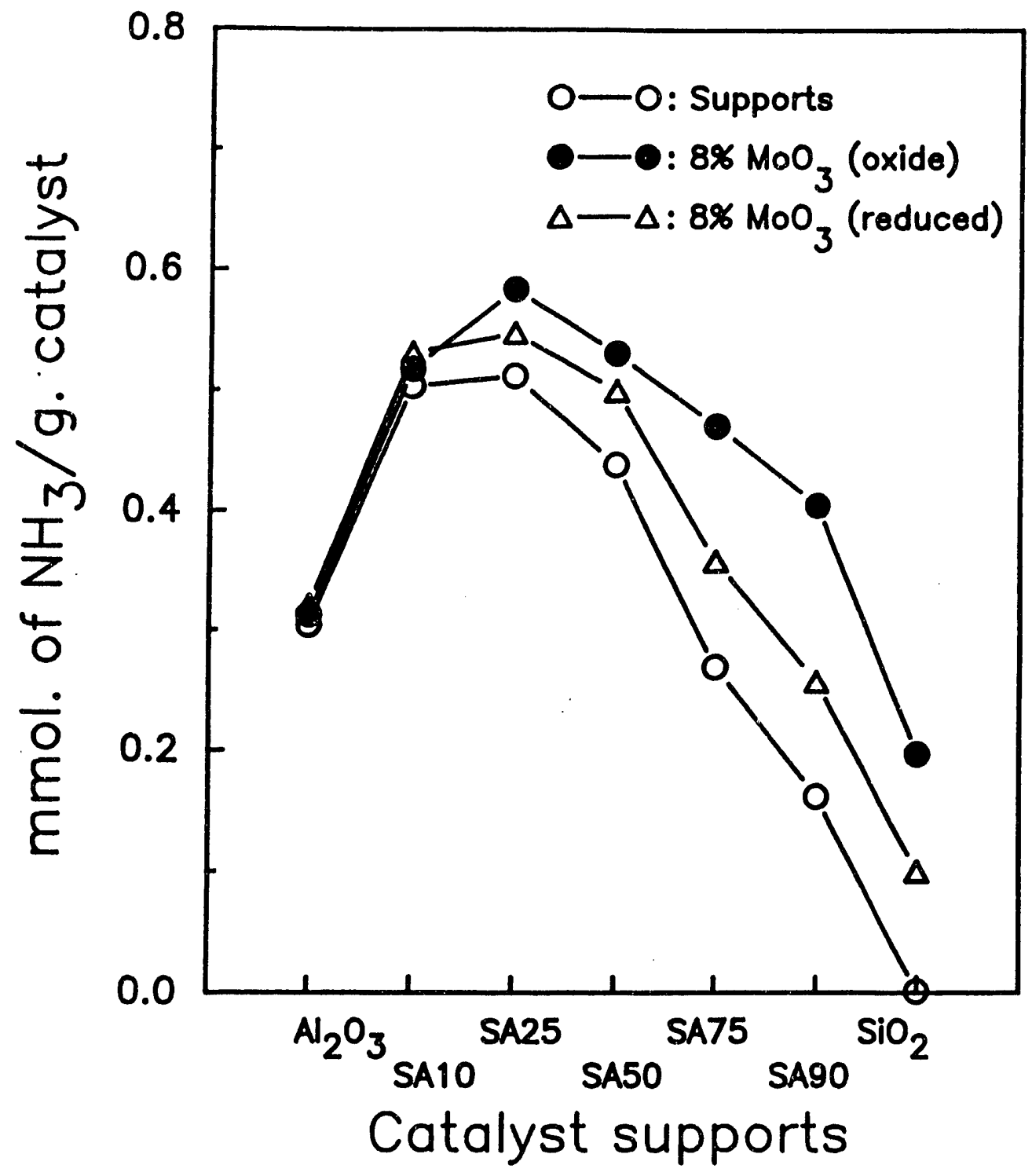

Fig. 1 Total acidity of oxidic and reduced molybdena catalysts over acidic supports. 

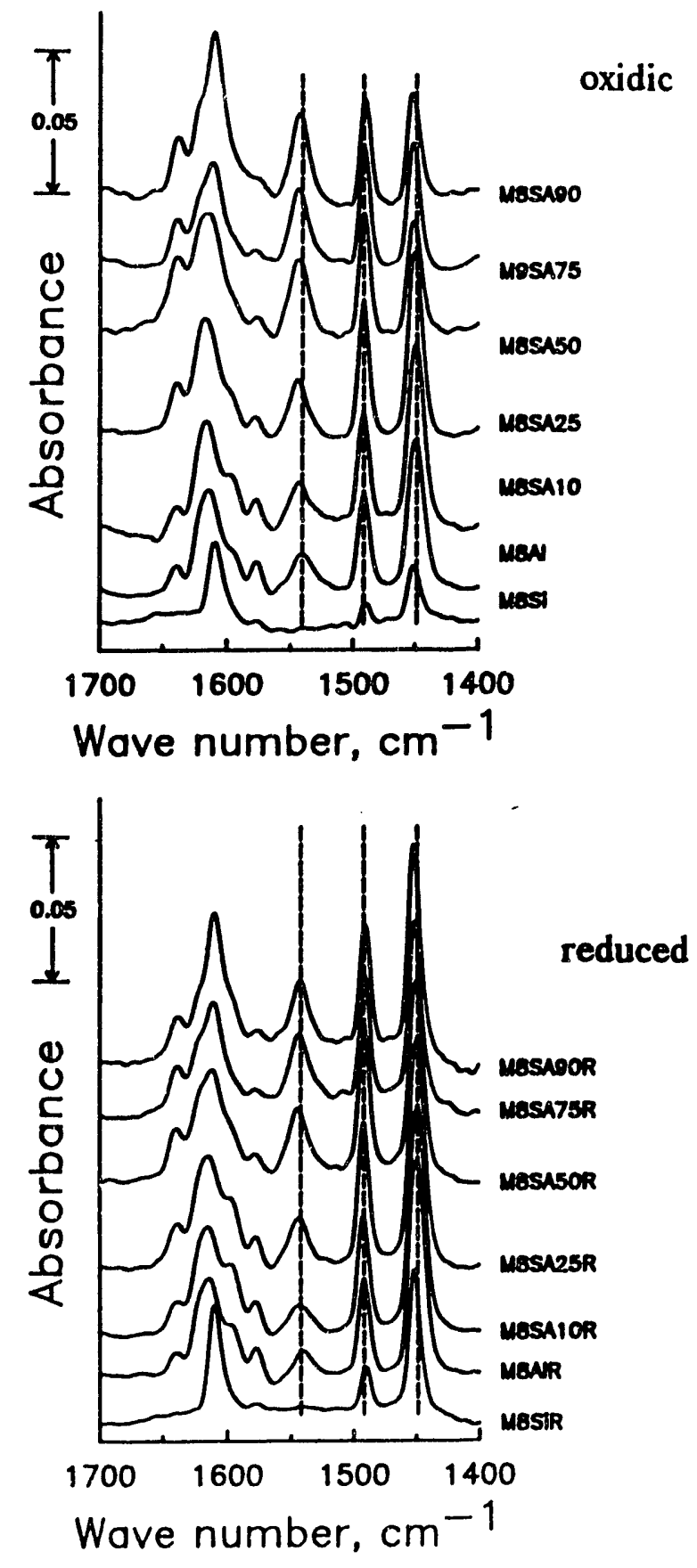

Fig. 2 IR spectra of chemisorbed pyridine on oxidic and reduced molybdena catalysts on supports of varying acidity. 


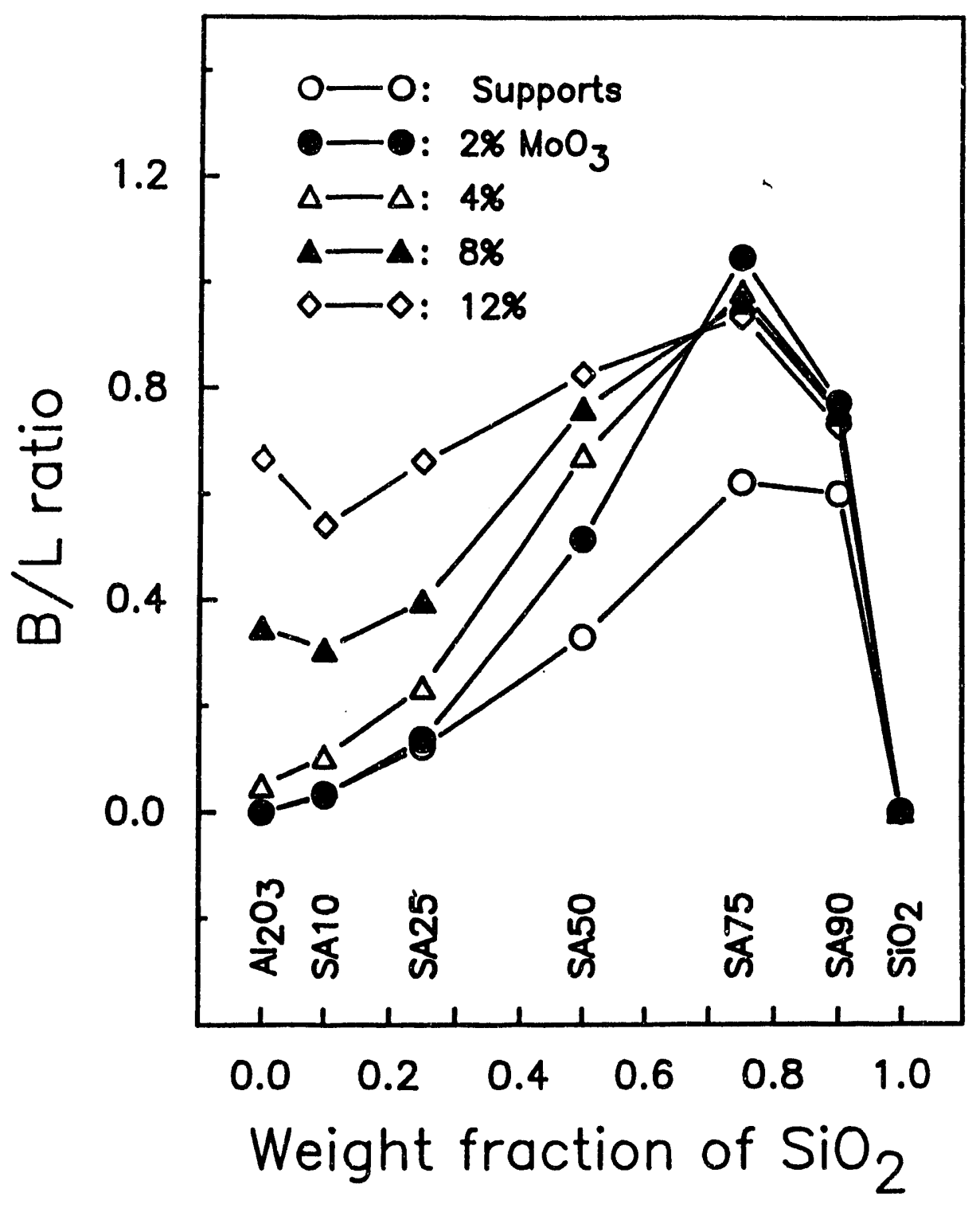

Fig. 3 Ratio of Bronsted to Lewis acidity for oxidic molybdena catalysts. 


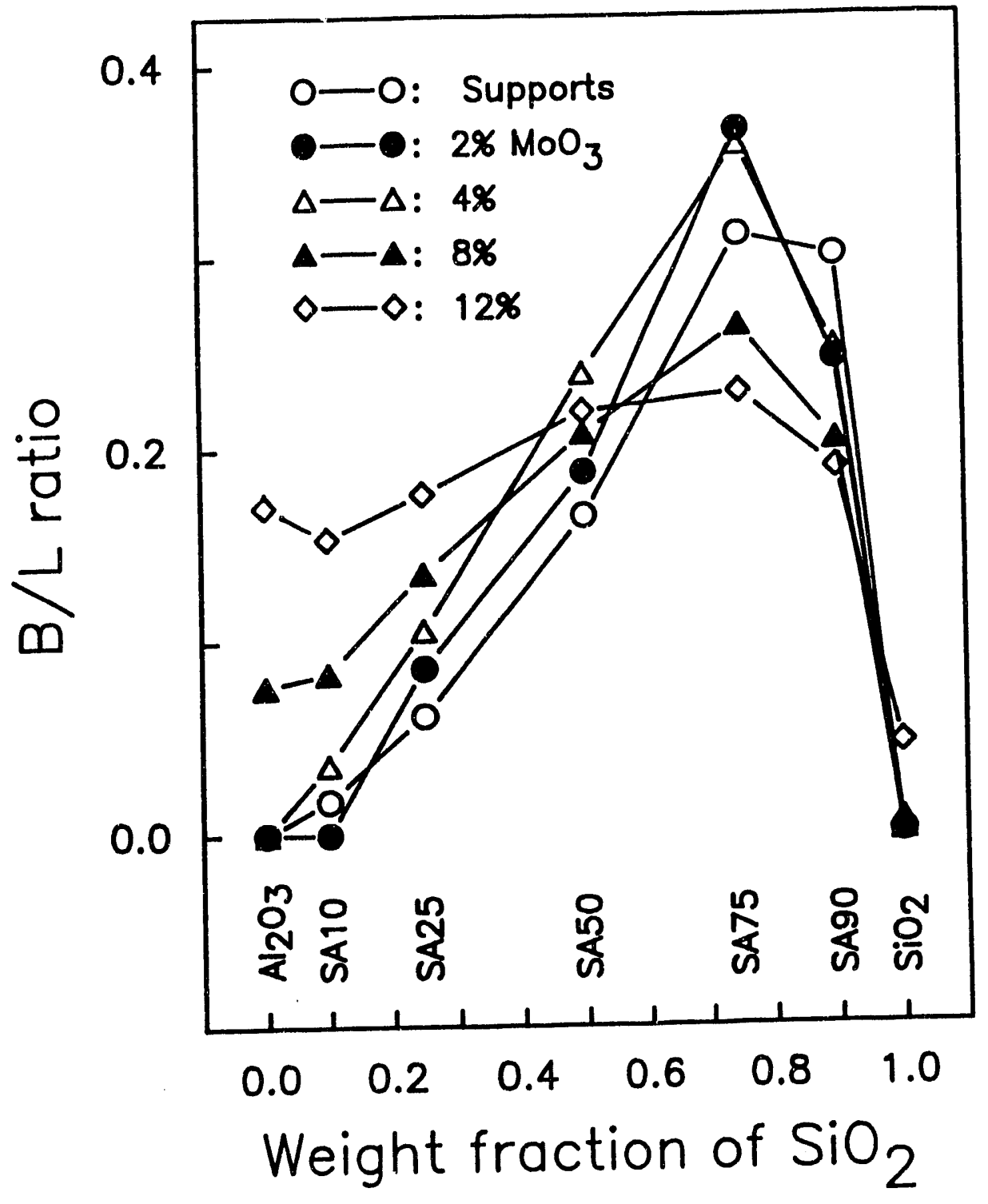

Fig. 4 Ratio of Bronsted to Lewis acidity for reduced molybdena catalysts. 
Report DOE/PC/89771-13

\title{
Part 5: X-RAY DIFFRACTION OF MOLYBDENUM CATALYSTS
}

\begin{abstract}
X-ray diffraction was utilized to determine the nature of the supported phases of Mo over silica, alumina and silica-aluminas. After impregnation and calcination, the oxidic molybdena formed dispersed species (probably of the dioxo type) over gamma-alumina, and dispersed agglomerates of $\mathrm{MoO}_{3}$ over silica. However, on silica-alumina, molybdate was found to interact so strongly with the aluminum cations that it formed $\mathrm{Al}_{2}\left(\mathrm{MoO}_{4}\right)_{3}$, possibly by corrosive chemisorption during impregnation, or by $\mathrm{Al}$ diffusion into molybdena during calcination.
\end{abstract}

After a treatment of reduction with hydrogen at $500^{\circ} \mathrm{C}$, highly dispersed Mo species are formed. These species are $x$-ray amorphous. Having been derived from different precursors, those species have different reducibility and acidity for different support compositions.

\section{INTRODUCTION}

To better understand the role of acidic sites in the presence of hydrogenation and hydrogenolysis sites, molybdena was supported on a series of acidic aluminas, and the resulting new acidity and molybdic phases were characterized as described earlier. The oxidized catalysts supported on silica-aluminas showed increases from 3 to $150 \%$ of weak, medium and strong acid sites.

The new acidity is of both Lewis and Bronsted type, the predominance of one over the other depending on support composition, as well as on loading and state of oxidation of Mo. Highalumina supports and low Mo loading favor dispersed Mo species, in particular bidentate and monodentate di-oxo Mo species. The latter is responsible for the new Bronsted acidity. Coordinative unsaturation of polymolybdates is responsible for the new Lewis acidity, which is increased upon reduction of Mo. High-silica supports favor monodentate species (high Bronsted acidity) up to $4 \mathrm{wt} \% \mathrm{MoO}_{3}$. Beyond that, polymolybdate species and Lewis acidity predominate.

The nature of the reduced molybdena phases is obviously affected by support composition. The silica-rich supports favor reducible phases while the alumina-rich supports favor less reducible phases.

In this part of the work, an x-ray diffraction procedure was developed to follow the history of Mo phases upon catalyst treatment. Previous related work has typically been concerned with molybdena supported only on silica or alumina, or on a few isolated silica-alumina samples [1-2]. One recent publication [3] has also examined molybdena on a series of silica-aluminas, but the molybdena loadings from which the conclusions were derived were e.icessive ( $>15 \mathrm{wt} \%)$. 
Report DOE/PC/89771-13

\section{EXPERIMENTAL}

\section{Synthesis of Supports and Supported Mo Oxide Catalysts}

Silica-aluminas with a range of composition from 10-90 wt\% silica, pure silica and gammaalumina, and supported molybdena catalysts were synthesized and characterized as described before.

\section{Reduction of Mo Oxide Catalysts before X-Ray Diffractometry}

The catalysts were reduced in a flow reactor consisting of a $1 / 2^{\prime \prime O D ~ q u a r t z ~ t u b e ~ h e a t e d ~ b y ~ a ~ t u b e ~ . ~}$ furnace. Before reduction, the calcined samples were exposed to flowing $\mathrm{He}$ at $400^{\circ} \mathrm{C}$ for $1 \mathrm{~h}$ to remove moisture. Then $100 \mathrm{ml} / \mathrm{min}$ of $\mathrm{H}_{2}$ was flown over the catalyst for $4 \mathrm{~h}$ at $500^{\circ} \mathrm{C}$. The samples were cooled, and then exposed to air before being loaded in the $\mathrm{x}$-ray diffractometer.

\section{X-Ray Diffractometry}

The phase and bulk composition, and the dispersion of molybdena, were investigated by means of XRD of the oxidic and reduced catalysts. The oxidic catalysts were those obtained after calcination of the supported Mo oxide. The reduced ones were obtained as described above. It must be mentioned that upon exposure to air, reoxidation occurs on the outermost surface layers of the catalyst. Nevertheless, since XRD is insensitive to surface phase composition, the results obtained should be representative of the overall state of reduced bulk Mo. X-ray powder patterns were recorded at room temperature with a Rigaku D-Max-B horizontal goniometer using the Nifiltered $\mathrm{Cu} \mathrm{K}$-alpha radiation, and were analyzed according to JCPDS database. The sample in the powder form was sprinkled on the sticky side of adhesive tape, which was mounted on the sample support slide. The background given by the adhesive tape was carefully subtracted from all spectra.

\section{RESULTS AND DISCUSSION}

Figs. 1 and 2 show the respective $x$-ray diffractograms of the silica-supported and aluminasupported oxidic catalysts. As seen in Fig. 1, molybdena loadings under $8 \mathrm{wt} \%$ produce $x$-ray amorphous phases, due probably to the high dispersion resulting from the even distribution over the large surface area available. Those agglomerates must be under $5 \mathrm{~nm}$ in diameter, and are probably responsible for the very broad band appearing between 3 and 4.5 angstrom. The bottom spectrum in Fig. 1, corresponding to $12 \mathrm{wt} \%$ molybdena loading, shows that in fact the agglomerates consist of orthorhombic $\mathrm{MoO}_{3}$. The sharp bands belong to grains that are larger than $5 \mathrm{~nm}$ and are superimposed on the broad band belonging to dispersed agglomerates.

Fig. 2 shows that molybdena over alumina is well dispersed, even at $12 \mathrm{wt} \%$ loading. There is no evidence of grains of orthorhombic $\mathrm{MoO}_{3}$ or of finely dispersed agglomerates, as was observed for silica support (Fig. 1). This fact is in agreement with the surface model postulated above, which specified thet Mio over alumina was present mostly as dioxo species, strongly interacting with $\mathrm{Al}-\mathrm{O}$ groups. These surface molybdates do not produce the diffraction pattern of $\mathrm{Al}_{2}\left(\mathrm{MoO}_{4}\right)_{3}$ because they are dispersed as monolayers and do attain a bulk structure. The only sharp bands in the spectra correspond to gamma-alumina. 
Fig. 3 displays the spectra for $12 \mathrm{wt} \%$ oxidic molybdena loaded on the complete series of silica-alumina supports. Now it is clearly seen that as the silica content increases the gammaalumina phase disappears and a new phase becomes visible for 50\% silica-alumina. These new bands correspond to a bulk phase of $\mathrm{Al}_{2}\left(\mathrm{MoO}_{4}\right)_{3}$, and they grow stronger up to $90 \%$ silicaalumina. They disappear and are completely replaced by the orthorhombic $\mathrm{MoO}_{3}$ bands for $100 \%$ silica support.

The new scenario that evolves from this study is that on complex supports such as silicaalumina, Mo-oxo species will preferentially bind to Al-oxo species (and not to Si-oxo species) to the extent of producing a "corrosive chemisorption" during impregnation or maybe $\mathrm{Al}$ diffusion and solid state reaction during calcination. This is one explanation for the appearance of the bulk phase of $\mathrm{Al}_{2}\left(\mathrm{MoO}_{4}\right)_{3}$ and for the absence of $\mathrm{MoO}_{3}$ on $>50 \%$ silica-alumina.

Let us elaborate on those points. Earlier we proposed that during impregnation and calcination of molybdena over silica-alumina, molybdate and polymolybdate species would adsorb and react with Al-O species until saturation occurred. Thereafter, the remaining molybdate (up to $12 \mathrm{wt} \%$ ) would adsorb on the silica-rich surface, and would agglomerate upon calcination. However, if this were the exact case, the x-ray diffractogram for 75 (or 90) wt\% silica-alumina should show the spectrum of $\mathrm{MoO}_{3}$. As observed, only the spectrum of $\mathrm{Al}_{2}\left(\mathrm{MoO}_{4}\right)_{3}$ is shown, which means that Mo is not agglomerated over silica-rich surface.

Let us elaborate further. Let us assume that molybdates from solution adsorb on and saturate all Al-O species present on the silica-alumina surface, and thereafter the remaining molybdate adsorbs on the first layer forming a multilayer molybdate (no molybdate adsorbing on silica-rich surface). Upon calcination the multilayer molybdate would then produce $\mathrm{MoO}_{3}$ and its characteristic spectrum, which is not seen for 75 (or 90 ) wt\% silica-alumina.

As noted before, $\mathrm{Mo}$ dioxo species [surface $\mathrm{Al}_{2}\left(\mathrm{MoO}_{4}\right)_{3}$ ] do not produce a visible spectrum, thus the origin of such spectrum for 75 (or 90) wt\% silica-alumina is related to the formation of multiple ordered layers of $\mathrm{Al}_{2}\left(\mathrm{MoO}_{4}\right)_{3}$. This is possible only if Mo diffuses into alumina or $\mathrm{Al}$ diffuses into molybdena. If Mo diffused into alumina, the formed phase would not be as reducible as observed before, thus the evidence indicates that $\mathrm{Al}$ is diffusing into the molybdate layers. Why this occurs with silica-alumina and not with pure gamma-alumina is explained by the difference in crystal energy between alumina and silica-alumina, or likewise, by the difference in bonding strength of Al in the two different lattices. As x-ray spectra show, silica-alumina is arnorphous while gamma-alumina is crystalline, thus $\mathrm{Al}$ in silica-alumina is more weakly bonded, and therefore is more reactive, than in alumina.

The migration of $\mathrm{Al}$ into the molybdate layers may occur in two occasions: (1) during impregnation, due to the phenomenon of corrosive chemisorption, which has been observed in many cases of Strong Metal Support Interaction; or (2) during calcination, due to the enhanced solid state diffusion produced by high temperatures.

Having explained the crystallographic nature and location of the oxidic molybdenum over the silica-aluminas, let us turn to the actual reacting catalyst, which is in the reduced state. Fig. 4 shows the diffractograms of the reduced catalysts. It is obvious that the bulk phases of $\mathrm{Al}_{2}\left(\mathrm{MoO}_{4}\right)_{3}$ over silica-aluminas, and $\mathrm{MoO}_{3}$ over silica, have been reduced by hydrogen. The resulting phases are amorphous. Another observation from this figure is that the very broad band 
between 3 and 4.4 angstrom has disappeared, indicating that the small agglomerates of $\mathrm{MoO}_{3}$ present in the oxidic atalysts have also been reduced.

As deduced from the presented XRD results, the state of the reduced Mo on the silicaaluminas is likely to be as amorphous Mo oxide with different structure and properties from the Mo oxide present on pure silica or pure alumina surfaces. Previous TPR and $\mathrm{NH}_{3}$ TPD results indeed showed that reducibility and acidic properties of supported molybdena vary as a function of support composition. The origin of such different characteristics is possibly related to the presence of Al in the structure of the amorphous Mo oxide. Further work with techniques such as EXAFS could clarify (or verify) these hypotheses.

\section{CONCLUSIONS}

The nature of the supported phases of Mo over silica, alumina and silica-aluminas has been investigated using $x$-ray diffractometry. After impregnation and calcination, the oxidic molybdena formed dispersed species (probably of the dioxo type) over gamma-alumina, and dispersed agglomerates of $\mathrm{MoO}_{3}$ over silica. However, on silica-alumina, molybdate was found to interact so strongly with the aluminum cations, that it formed $\mathrm{Al}_{2}\left(\mathrm{MoO}_{4}\right)_{3}$. This formation occurred by corrosive chemisorption during impregnation, or by $\mathrm{Al}$ diffusion into molybdena during calcination.

Upon reduction, highly dispersed Mo species are formed (which are amorphous to X-ray diffraction). Having been derived from different precursors, those species will have different reducibility and acidity, depending on the support composition. This, in fact, was evidenced by the temperature programmed reduction and acidity measurement results shown above.

\section{REFERENCES}

1. G. Muralidhar, et al., J. Catal. 89, 274-84 (1984)

2. C.V. Caceres, et al., J. Catal. 122, 113-25 (1990)

3. M. Henker, et al., Appl. Catal. 61, 253-63 (1990) 


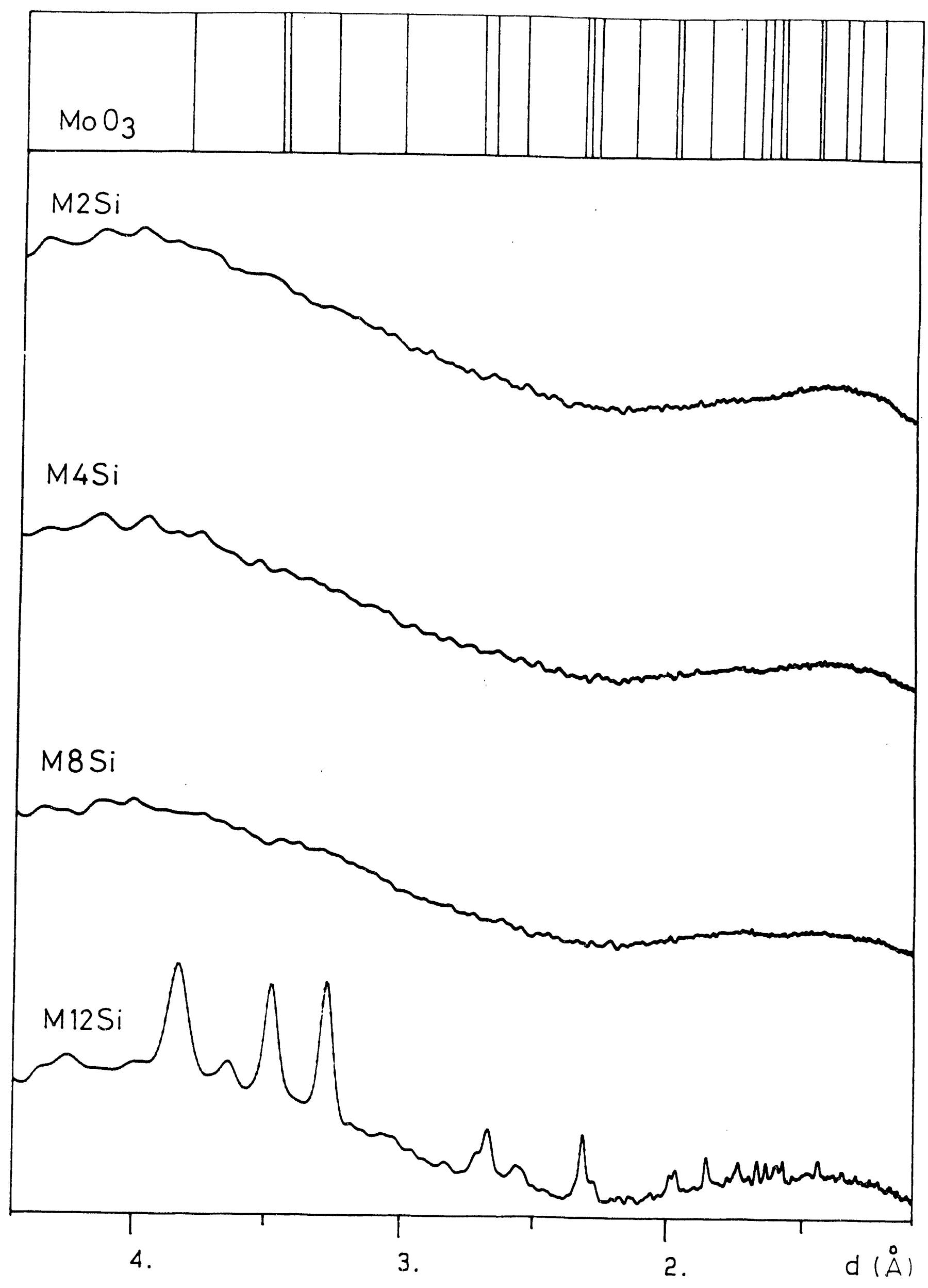

Figure 1 


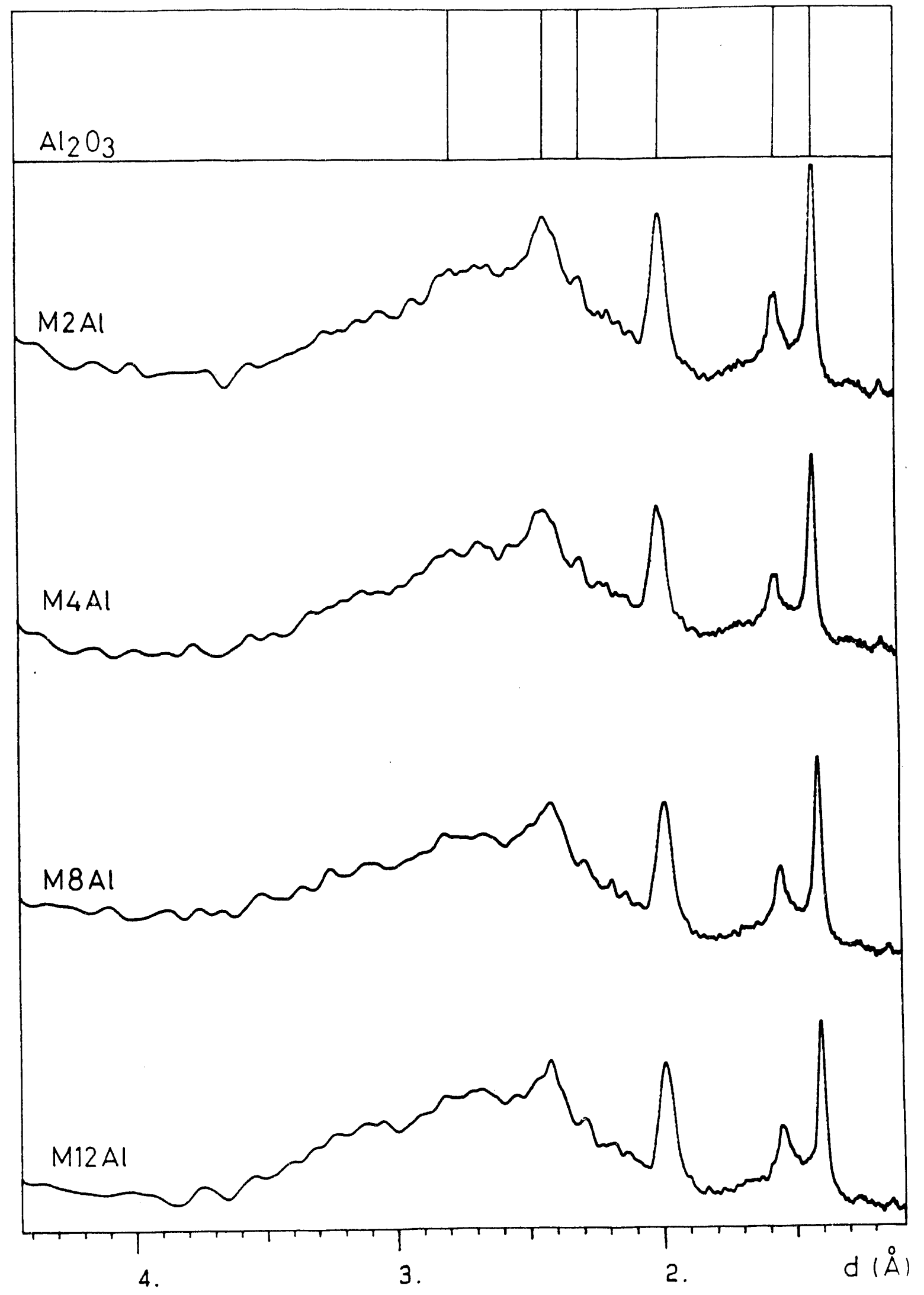

Figure 2 


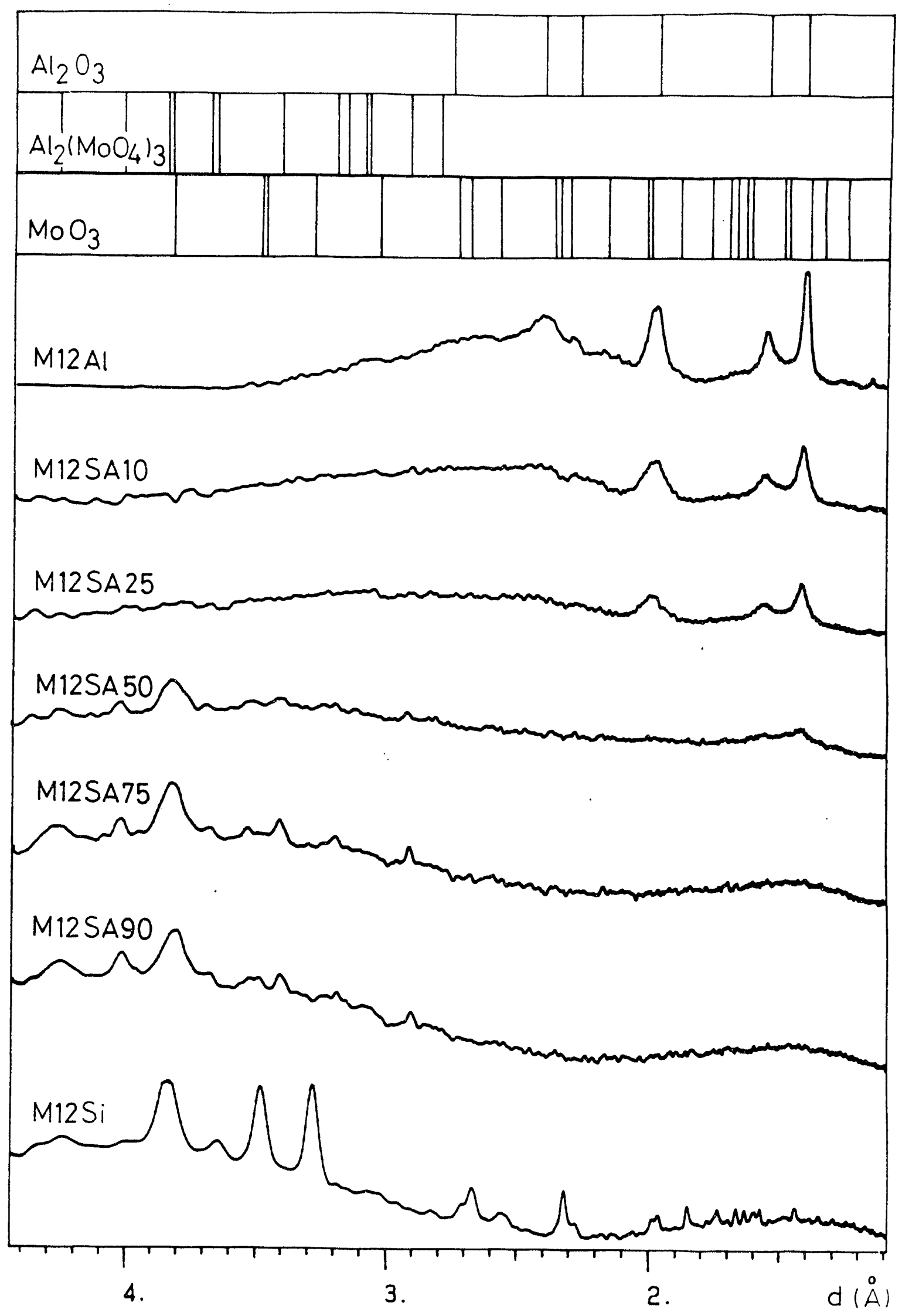

Figure 3 


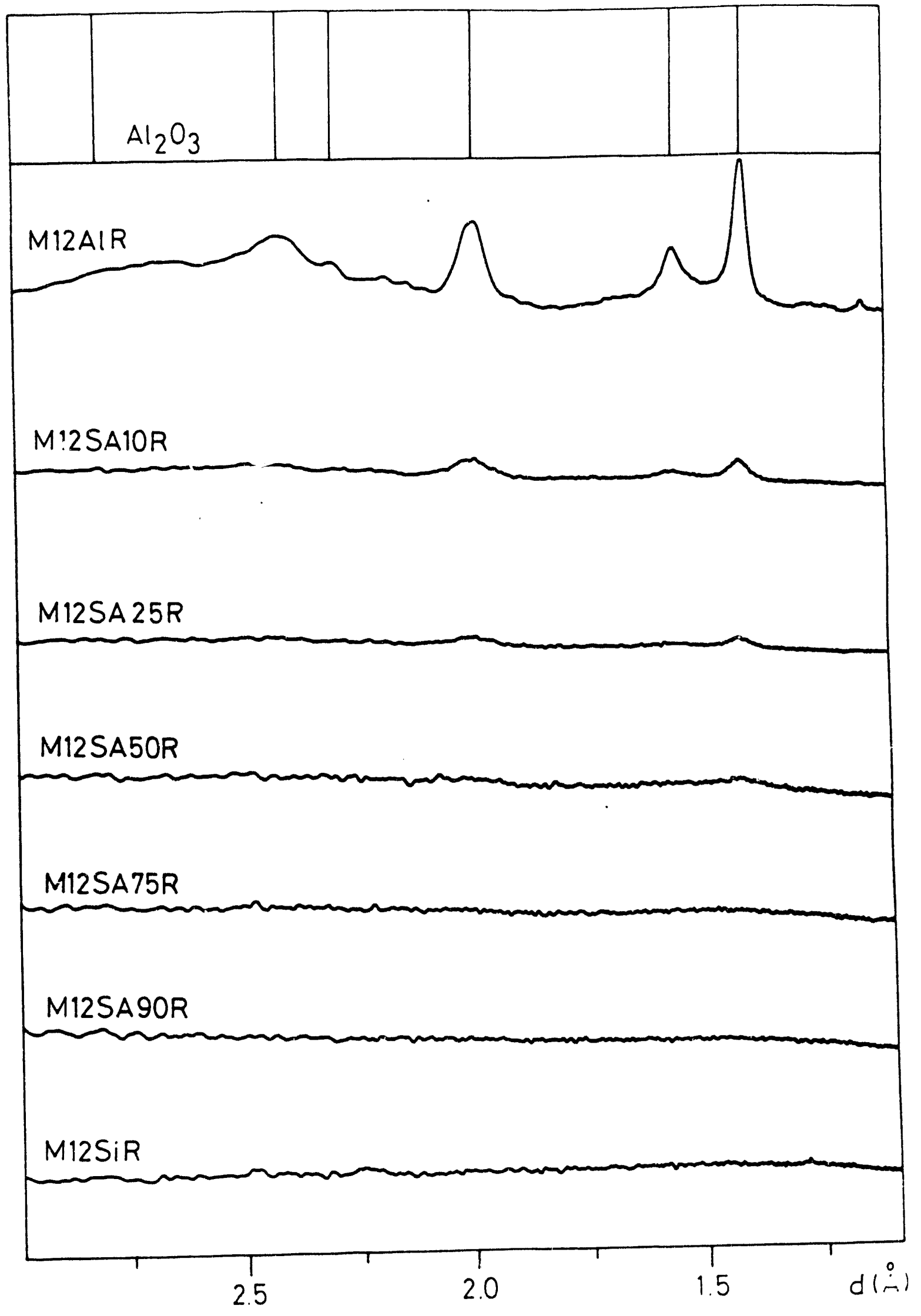

Figure 4 
Report DOE/PC/89771-13

\title{
Part 6: HYDRODENITROGENATION OF PYRIDINE OVER ACIDIC MOLYBDENUM CATALYSTS
}

\begin{abstract}
Activity and selectivity for HDN of a series of acidic molybdena catalysts have been determined using the pyridine HDN reaction. Measurements of total activity, selectivity for HDN, selectivity towards saturated versus unsaturated hydrocarbons, and selectivity for cracking, as a function of support composition and molybdena loading, provide clear evidence of two predominant types of sites: highly reduced Mo sites and highly acidic Bronsted sites. Both sites chemisorb strongly the heterocyclic aromatics and hydrogenated amines. Highly reduced Mo sites are highly active for denitrogenation, as seen clearly for silica-supported catalysts. The acidic sites also contribute to denitrogenation, probably by Hofmann elimination, and are active in cracking and cyclization. The optimum combination of these two types of sites for maximum HDN selectivity occurs at $4 \mathrm{wt} \%$ molybdena loaded on silica-aluminas containing $>50 \mathrm{wt} \%$ silica.
\end{abstract}

\section{INTRODUCTION}

In this project it is proposed that the selectivity of the HDN reaction can be affected by an alteration of the catalyst acidity since it is possible that an acidic Hofmann-like deamination pathway is operative [1] in parallel with the hydrogenolysis of saturated $\mathrm{C}--\mathrm{N}-\mathrm{-C}$ bonds. To understand better the role of acidic sites in the presence of hydrogenation and hydrogenolysis sites, molybdena was supported on a series of acidic aluminas, and the resulting new acidity and molybdic phases were characterized. The new acidity is of both Lewis and Bronsted type, the predominance of one over the other depending on support composition, as well as on loading and state of oxidation of Mo. High-alumina supports and low Mo loading favor dispersed Mo species, in particular bidentate and monodentate di-oxo Mo species. The latter is responsible for the new Bronsted acidity. Coordinative unsaturation of polymolybdates is responsible for the new Lewis acidity, which is increased upon reduction of Mo. High-silica supports favor monodentate species (high Bronsted acidity) up to $4 \mathrm{wt} \% \mathrm{MoO}_{3}$. Beyond that, polymolybdate species and Lewis acidity predominate.

The nature of the reduced molybdena phases is obviously affected by support composition. The silica-rich supports favor more reducible phases, including an apparently segregated $\mathrm{Al}_{2}\left(\mathrm{MoO}_{4}\right)_{3}$ phase, which presumably will have different hydrogenation and hydrogenolysis sites than the less reducible phases, which are favored by alumina-rich supports. It must be noticed that pure gammaalumina does not lead to the formation of $\mathrm{Al}_{2}\left(\mathrm{MoO}_{4}\right)_{3}$. This is only formed upon calcination of Mo oxides over silica-rich silica-aluminas, and is highly reducible. Pure silica supports favor the agglomeration of a phase of $\mathrm{MoO}_{3}$, which is also highly reducible. In these complex catalysts, a varying number of hydrogenolysis sites will be accompanied by a varying number of acidic sites, and their combined roles will affect the activity and selectivity for HDN. 
In this part of the report, the HDN reaction of pyridine was utilized to assess the variation in activity and selectivity produced by the nature of the support. The acidic sites were titrated and characterized as shown above. The hydrogenolysis sites were characterized by the method of low temperature oxygen chemisorption (LTOC), which was utilized to titrate the coordinatively unsaturated sites (cus) of Mo. The results of LTOC are shown in detail in part 7.

\section{EXPERIMENTAL}

\section{Synthesis of Supports and Supported Mo Oxide Catalysts}

Silica-aluminas, pure silica, gamma-alumina and supported molybdena catalysts were synthesized and characterized as previously described.

\section{HDN Reaction}

The reaction was carried out in an atmospheric pressure glass microreactor (Fig. 1). Catalyst reduction was done in situ with a stream of hydrogen $(30 \mathrm{ml} / \mathrm{min}$ STP) at $500 \mathrm{C}$ for 4 hours. After cooling down to the reaction temperature, a 4-way valve allowed the immediate substitution of the pure hydrogen by a stream of $30 \mathrm{ml} / \mathrm{min}$ (STP) of 0.2 mole\% pyridine vapor in hydrogen. The reactor temperature (measured at the catalyst bed) was varied between 360 and $420 \mathrm{C}$. All stainless steel lines were kept at about $90 \mathrm{C}$ to avoid condensation of reactants or products.

The products of reaction were analyzed on-line with a Hewlett-Packard 5890A chromatograph equipped with FID and three columns. They were packed with 10\% Carbowax 1500-1\% KOH/Chromosorb WAW and n-octane/Porasil C, and were time-programmed by means of a 10port Valco valve driven by a HP 19405A sampler controller. Details of the analytical procedure were given earlier [2]. Every sample taken was separated into light hydrocarbons (including all isomers), pyridine, piperidine, and higher amines, by means of this analytical scheme.

\section{Catalysts and Conditions Used for the HDN Reaction}

The samples tested consisted of three different contents of supported molybdena $(4,8$ and 12 $w t \%$ ) on seven different supports (silica, silica-alumina: 10-90, 25:75, 50:50, 75:25, 90:10 $w t: w t \%$, and gamma-alumina). The reactor loading was varied in order to keep the mass of molybdena constant among different catalysts. Thus, the reactor was loaded with $100 \mathrm{mg}$ of the 12 $w t \%$ molybdena catalyst, or $150 \mathrm{mg}$ of the $8 \mathrm{wt} \%$, or $300 \mathrm{mg}$ of the $4 \mathrm{wt} \%$. Specific tests to detect mass transfer limitations were not done. However, the measured energies of activation clearly rule out those limitations for all of the catalyst loadings (see later). The pyridine concentration or mass flowrate was not varied between runs. The conversion was kept differential for most of the runs, and only the steady state results (after more than 4 hours of reaction) are reported.

\section{RESULTS AND DISCUSSION}

Table 1 shows the hydrocarbon compounds and some amines present in the chromatographic analysis of the products of reaction. Other higher aminated products may be present in small amounts at the mild conditions used in this study. Table 2 gives the overall mole\% conversion of 
pyridine for the catalysts and temperatures mentioned, and Table 3 gives the absolute mole\% conversion into denitrogenation products, that is, into hydrocarbons. Figure 2 shows the overall conversion of pyridine and Figure 3 the selectivity for denitrogenation as a function of support composition and catalyst loading. All of the results are given per unit mass of molybdena.

The product distribution of $\mathrm{C1}-\mathrm{C} 5$ hydrocarbons is displayed in Fig. 4, while the isomeric distribution of the C5 hydrocarbons in displayed in Fig. 5 and the paraffin-olefin ratio is shown in Fig. 6. The complete product distribution for $420 \mathrm{C}$ is also given in Table 4. At other temperatures similar trends were observed [2]. The energy of activation for all catalysts is shown in Fig. 7. With values between 20 and $40 \mathrm{Kcal} / \mathrm{mole}$, the observed activation energies allow mass transfer limitations to be ruled out. The "compensation effect" observed between the pre-exponential factor $A$ and the activation energy $E$ is indicative of the energetic heterogeneity of the active sites. The small spread confirms the internal consistency of the data.

The overall conversion (Fig. 2) increases in proportion to the silica content of the support, being maximum for pure silica. It is also seen that the conversion per unit mass of molybdena is inversely related to the loading, being maximum for $4 \mathrm{wt} \%$ molybdena. These results contradict in general the known behavior of alumina-supported catalysts. In those, the maximum activity corresponds to about $12 \mathrm{wt} \%$ molybdena, for which the equivalent of about 1 monolayer of oxide is formed.

In view of earlier characterization results, the present results would indicate that reducibility of the supported molybdena is the most important factor influencing activity, followed by the effect of dispersion of molybdena. Since both reducibility and dispersion grow in oposition to each other when the loading is varied, an optimum loading must occur. Such optimum is about 4 wt\% for supports containing more than $50 \mathrm{wt} \%$ silica. On such supports it was before proposed that molybdena may be effectively dispersed by the scarce surface alumina, forming reducible monodentate species.

The selectivity towards denitrogenation products is also maximized for the most reducible and dispersed catalysts, i.e., $4 \mathrm{wt} \%$-loaded catalysts (Fig. 3). The nature of the sites responsible for this activity is revealed by the other selectivity curves (Figs. 4-6). The hydrocarbon production is composed mainly of $\mathrm{C} 5$ and $\mathrm{C1}, \mathrm{C5}$ being mostly t-2-pentene. As the support composition becomes $>50 \mathrm{wt} \%$ silica, the acidic and hydrogenolysis sites induce the predominance of $\mathrm{C} 1$ and the formation of cyclic C5. The selectivity towards saturated hydrocarbons grows from 1 to about 6 in the same region of support composition.

These results suggest that the appearance of highly reducible sites as well as acidic sites, for $>50 \mathrm{wt} \%$ silica, favors the adsorption strength for unsaturated hydrocarbons and amines. Thus the activity for hydrogenation and hydrogenolysis, as well as the activity for cyclization and cracking, increases. It is possible to assume that the heterocyclic rings strongly adsorbed on reduced Mo sites, are saturated by hydrogenation and lose $\mathrm{NH}_{3}$ by hydrogenolysis, while saturated or partially saturated amines that chemisorb on Bronsted acidic sites lose $\mathrm{NH}_{3}$ by Hofmann elimination, and are cracked to lower hydrocarbons. A verification of the participation of Bronsted acid sites in the HDN mechanism is provided in part 11. 


\section{CONCLUSIONS}

The activity and selectivity of a series of acidic molybdena catalysts during the reaction of HDN of pyridine have revealed that for silica-alumina supports ( $>50 \mathrm{wt} \%$ silica) the optimum loading of molybdena is $4 \mathrm{wt} \%$. At this loading the reducibility and dispersion cooperate to produce an HDN-selective surface composed of two types of sites: highly reduced Mo sites and highly acidic Bronsted sites. Both sites chemisorb strongly the heterocyclic aromatics and hydrogenated amines. The hydrogenolysis sites are surely associated with Mo unsaturation, and are highly active for denitrogenation, as seen clearly for silica-supported catalysts. The acidic sites also contribute to denitrogenation, probably by Hofmann elimination, and are active in cracking and cyclization.

\section{REFERENCES}

1. N. Nelson and R. B. Levy, J. Catal. 58(1979)485

2. S. Rajagopal, T. Grimm, D.J. Collins, R. Miranda, Analyt. Lett., 23(4) 649-57 (1990). 
TABLE 1

Chromatographic Analysis of the Reaction Products

\begin{tabular}{|c|c|}
\hline Compound & $\begin{array}{c}\text { Retention Time } \\
\text { (min) }\end{array}$ \\
\hline Methane & 3.79 \\
\hline Ethane/Ethylene & 4.08 \\
\hline Propane & 6.64 \\
\hline Propylene & 7.55 \\
\hline N-butane & 8.99 \\
\hline 1-Butene & 11.61 \\
\hline Isobutene & 13.16 \\
\hline T-2-Butene & 13.79 \\
\hline N-Pentane & 15.02 \\
\hline Cyclopentane & 16.84 \\
\hline 1 -Pentene & 19.92 \\
\hline Trans-2-Pentene & 23.70 \\
\hline Cyclopentene & 26.47 \\
\hline Pyridine & 29.79 \\
\hline 2-Methyl-Pyridine & 32.92 \\
\hline 4-Methyl-Pyridine & 38.11 \\
\hline
\end{tabular}


TABLE 2

Overall Conversion in Pyridine HDN

The values are expressed in 8 of pyridine moles reacted

\begin{tabular}{|c|c|c|c|c|}
\hline CATALYST & $360^{\circ} \mathrm{C}$ & $380^{\circ} \mathrm{C}$ & $400^{\circ} \mathrm{C}$ & $420^{\circ} \mathrm{C}$ \\
\hline M4AL & 0.5 & 1.0 & 2.6 & 8.0 \\
\hline M4SAIO & 0.6 & 0.8 & 2.0 & 4.6 \\
\hline M4SA25 & 0.7 & 1.2 & 3.0 & 8.7 \\
\hline M4SA50 & 1.7 & 2.5 & 6.3 & 12.0 \\
\hline M4SA75 & 4.3 & 7.2 & 11.0 & 15.0 \\
\hline M4SA90 & 7.0 & 9.9 & 14.2 & 20.1 \\
\hline M4SI & 8.3 & 12.2 & 22.6 & 34.1 \\
\hline MBAL & 1.4 & 3.3 & 9.5 & 14.3 \\
\hline M8SAIO & 1.3 & 2.5 & 3.5 & 12.8 \\
\hline M8SA25 & 1.2 & 2.5 & 9.6 & 13.8 \\
\hline M8SA50 & 3.8 & 5.0 & 9.6 & 14.7 \\
\hline M8SA75 & 1.7 & 3.2 & 7.4 & 10.8 \\
\hline M8SA90 & 3.8 & 6.2 & 9.8 & 15.7 \\
\hline M8SI & 6.6 & 9.0 & 15.5 & 25.0 \\
\hline M12AL & 1.7 & 3.2 & 7.9 & 12.5 \\
\hline M12SA10 & 0.7 & 1.3 & 2.5 & 8.2 \\
\hline M12SA 25 & 0.7 & 1.5 & 7.3 & 11.4 \\
\hline M12SA 50 & 0.9 & 1.5 & 2.6 & 5.9 \\
\hline M12SA75 & 0.5 & 1.7 & 5.8 & 6.4 \\
\hline M12SA90 & 2.3 & 5.4 & 9.0 & 13.1 \\
\hline M12SI & 7.5 & 9.7 & 15.2 & 22.5 \\
\hline
\end{tabular}


TABLE 3

Hydrocarbon Conversion in Pyridine HDN

The values are expressed in of pyridine moles reacted

\begin{tabular}{|c|c|c|c|c|}
\hline CATALYST & $360^{\circ} \mathrm{C}$ & $380^{\circ} \mathrm{C}$ & $400^{\circ} \mathrm{C}$ & $420^{\circ} \mathrm{C}$ \\
\hline M4AL & 0.5 & 0.9 & 2.6 & 5.1 \\
\hline M4SAIO & 0.6 & 0.8 & 2.0 & 4.6 \\
\hline M4SA 25 & 0.7 & 1.2 & 3.0 & 5.7 \\
\hline M4SA50 & 1.7 & 2.5 & 4.3 & 8.2 \\
\hline M4SA75 & 2.9 & 3.9 & 6.5 & 9.9 \\
\hline M4SA90 & 4.0 & 6.0 & 9.3 & 14.4 \\
\hline M4SI & 4.7 & 8.2 & 16.0 & 27.5 \\
\hline M8AL & 1.4 & 3.3 & 5.4 & 9.1 \\
\hline M8SAIO & 1.3 & 2.5 & 3.5 & 7.8 \\
\hline M8SA 25 & 1.2 & 2.5 & 5.2 & 8.8 \\
\hline M8SA50 & 2.3 & 3.0 & 5.5 & 9.7 \\
\hline M8SA75 & 1.7 & 2.2 & 3.9 & 6.1 \\
\hline M8SA 90 & 2.4 & 2.6 & 5.3 & 10.0 \\
\hline M8SI & 3.4 & 5.2 & 10.0 & 18.1 \\
\hline M12AL & 1.7 & 3.2 & 4.5 & 6.8 \\
\hline M12SA10 & 0.7 & 1.3 & 2.5 & 3.8 \\
\hline M12SA25 & 0.7 & 1.5 & 2.8 & 5.1 \\
\hline M12SA50 & 0.9 & 1.5 & 2.1 & 2.8 \\
\hline M12SA75 & 0.5 & 1.7 & 2.5 & 2.8 \\
\hline M12SA 90 & 2.3 & 2.7 & 5.0 & 7.7 \\
\hline MI2SI & 3.2 & 4.7 & 9.1 & 16.3 \\
\hline
\end{tabular}


TABLE 4

Cl-C5 Formation in Pyridine HDN at $420^{\circ} \mathrm{C}$ The values are expressed in $\&$ moles $/ \mathrm{moles}$

\begin{tabular}{|c|c|c|c|c|c|}
\hline CATALYST & $\mathrm{Cl}$ & $\mathrm{C} 2$ & C3 & $\mathrm{C} 4$ & $\mathrm{C} 5$ \\
\hline M4AL & 27.36 & 12.21 & 10.93 & 10.31 & 39.19 \\
\hline MASAIO & 23.09 & 12.41 & 10.50 & 9.13 & 44.86 \\
\hline M4SA25 & 25.89 & 13.72 & 11.35 & 9.50 & 39.53 \\
\hline M4SA50 & 24.00 & 13.24 & 11.24 & 9.41 & 42.11 \\
\hline M4SA75 & 35.71 & 15.64 & 12.11 & 10.47 & 26.07 \\
\hline M4SA 90 & 39.18 & 17.06 & 12.20 & 10.45 & 21.11 \\
\hline M4SI & 41.19 & 17.57 & 12.73 & 11.66 & 16.85 \\
\hline MBAL & 25.62 & 12.66 & 10.94 & 12.70 & 38.09 \\
\hline M8SA10 & 25.10 & 12.92 & 10.78 & 10.71 & 40.49 \\
\hline M8SA25 & 26.28 & 12.72 & 10.93 & 11.11 & 38.96 \\
\hline M8SA50 & 30.68 & 14.89 & 11.82 & 9.71 & 32.90 \\
\hline M8SA75 & 34.47 & 15.00 & 11.98 & 10.02 & 28.53 \\
\hline M8SA 90 & 34.23 & 16.01 & 12.21 & 10.81 & 26.74 \\
\hline M8SI & 38.01 & 17.61 & 12.47 & 11.18 & 20.74 \\
\hline M12AL & 24.98 & 10.54 & 10.49 & 14.37 & 39.62 \\
\hline M12SA10 & 22.29 & 11.17 & 10.34 & 12.87 & 43.32 \\
\hline M12SA 25 & 25.02 & 12.86 & 11.18 & 12.14 & 38.81 \\
\hline M12SA 50 & 27.51 & 13.81 & 11.68 & 11.69 & 35.31 \\
\hline M12SA75 & 30.89 & 14.82 & 11.65 & 11.01 & 31.63 \\
\hline M12SA 90 & 34.41 & 14.87 & 11.53 & 11.14 & 28.04 \\
\hline MI2SI & 38.34 & 19.09 & 11.90 & 11.54 & 19.13 \\
\hline
\end{tabular}




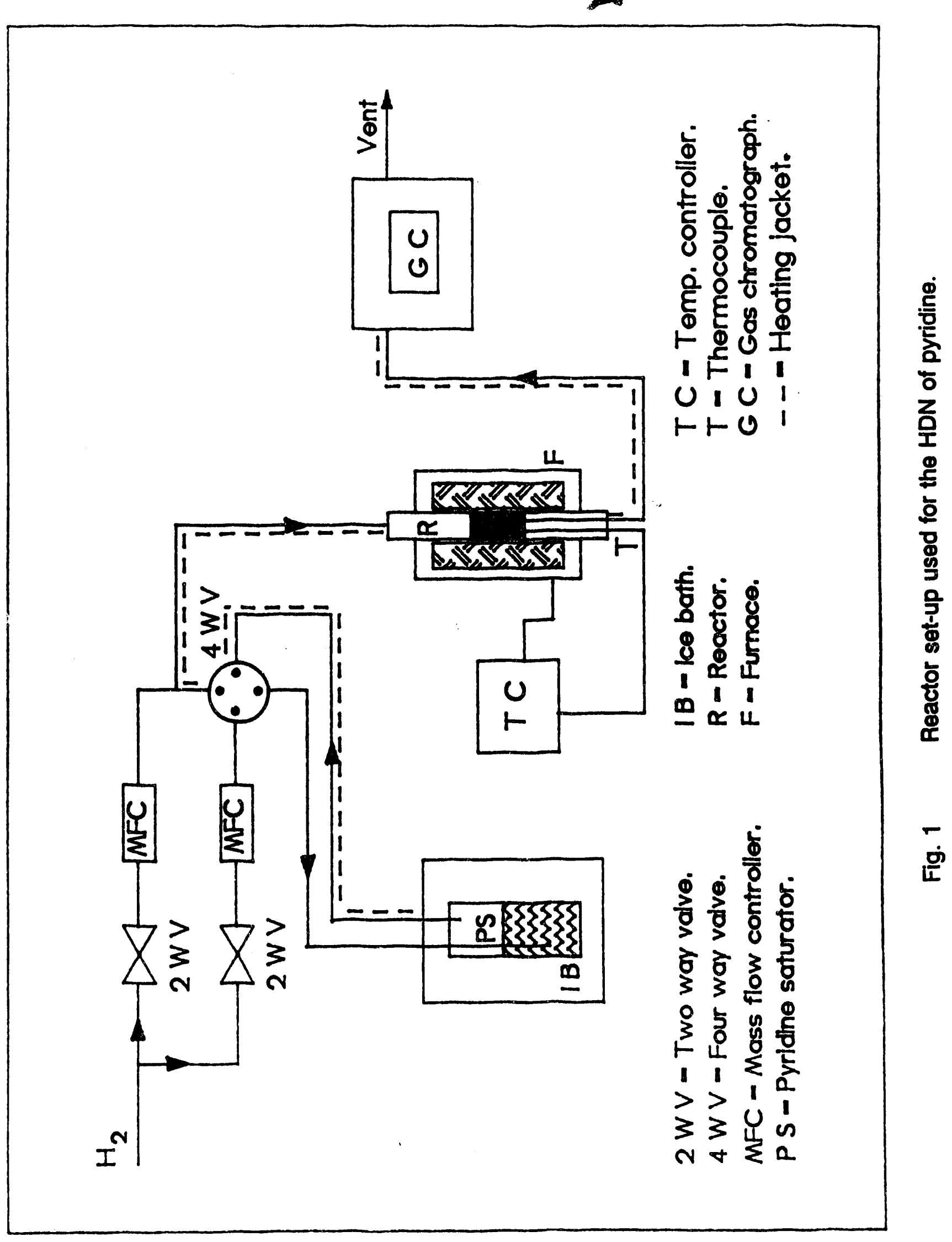



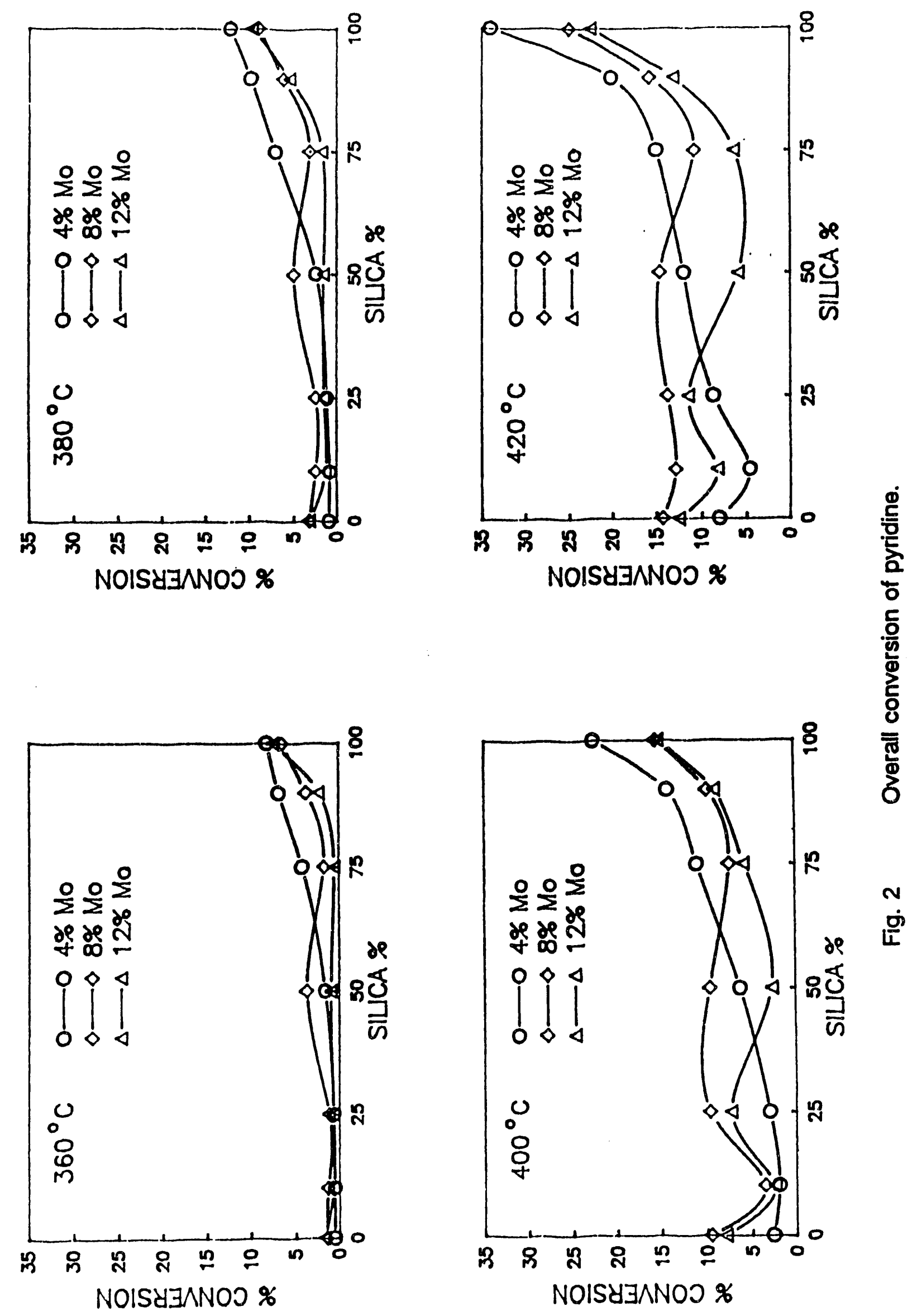


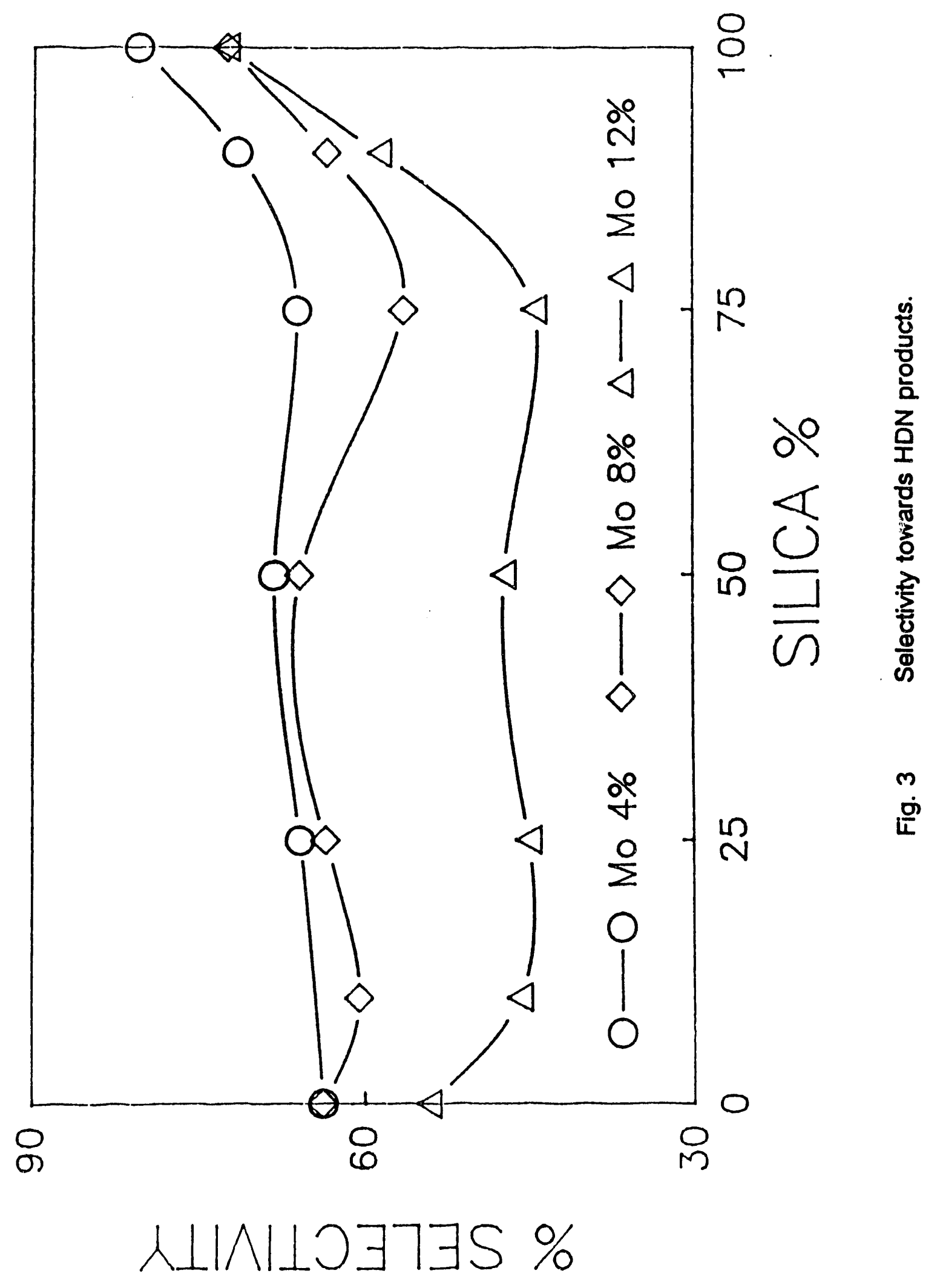



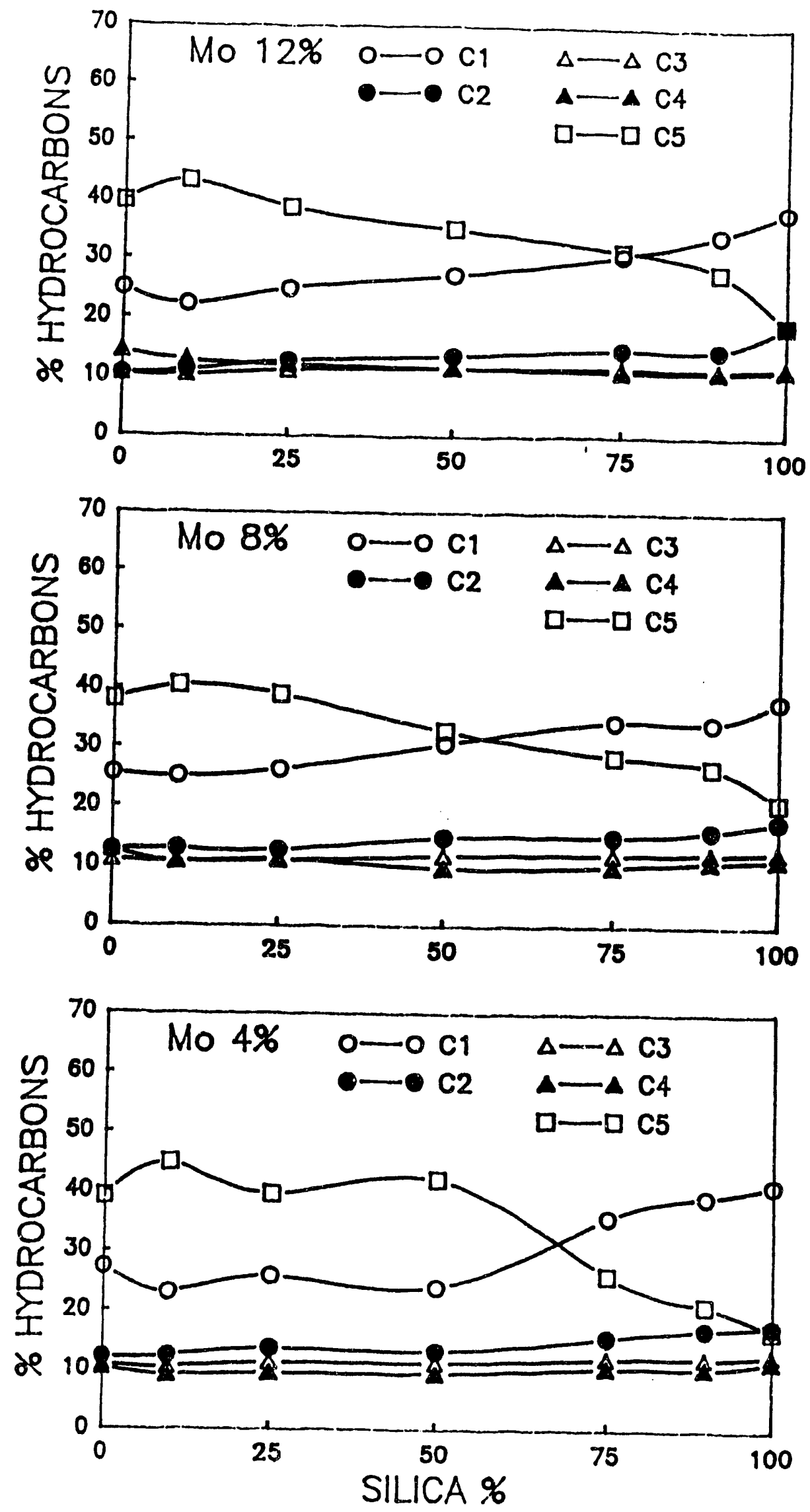

Fig. 4 Distribution of $\mathrm{C} 1-\mathrm{C} 5$ in the product, at $420^{\circ} \mathrm{C}$. 

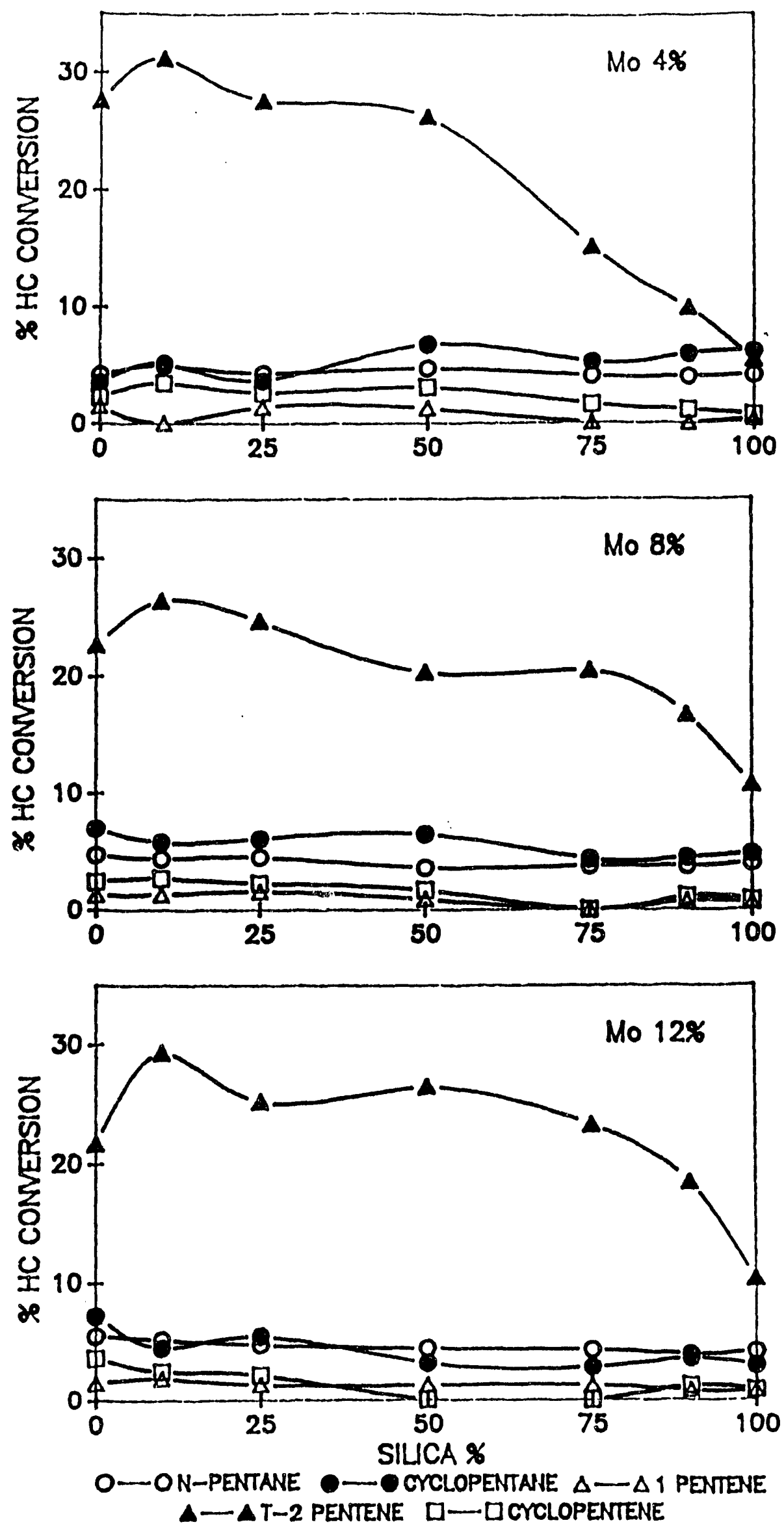

Fig. 5

Isomeric distribution of $\mathrm{C} 5$ in the product 


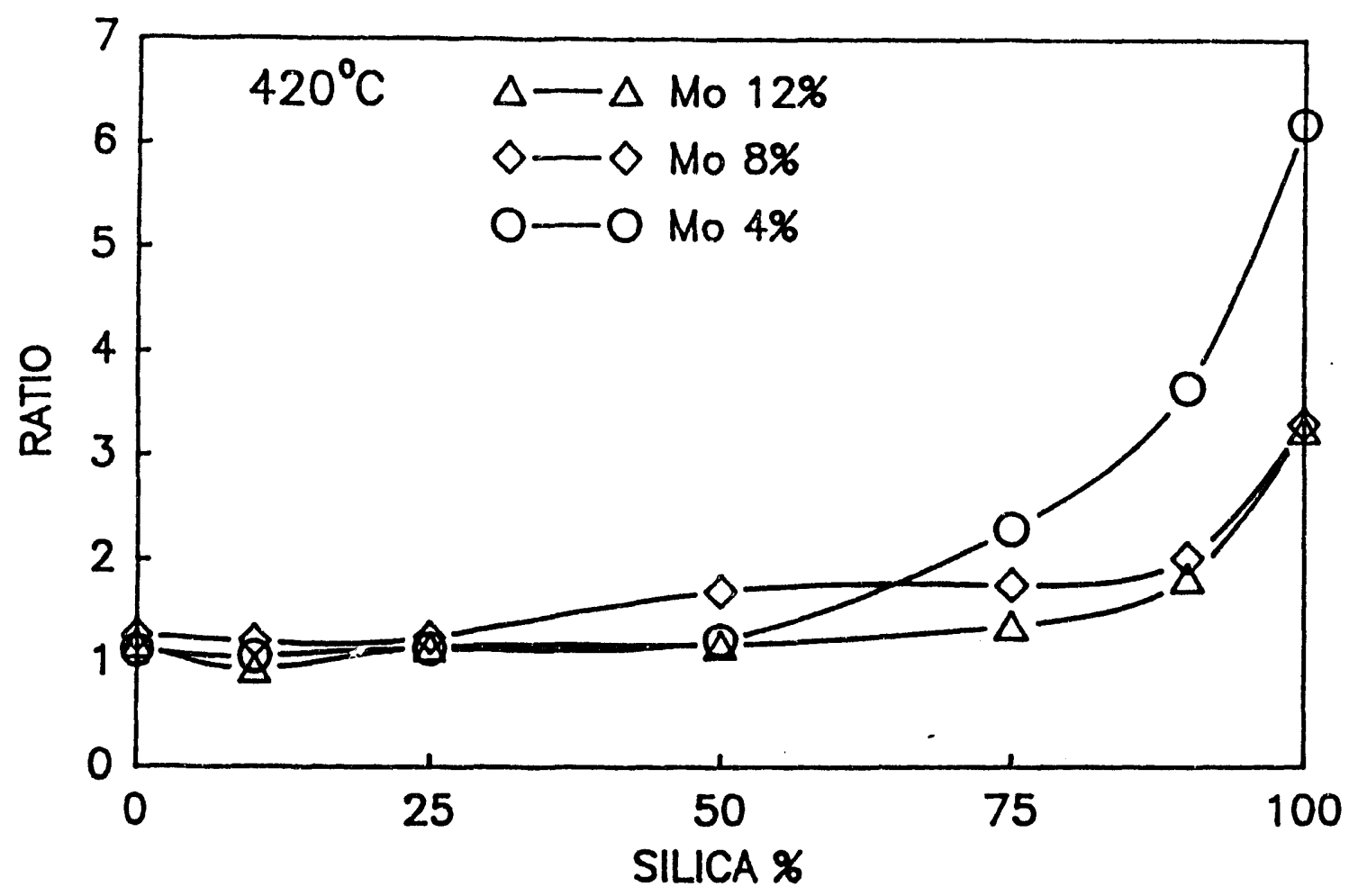

Fig. 6 Paraffin/olefin ratio in the product, at $420 \cdot \mathrm{C}$. 

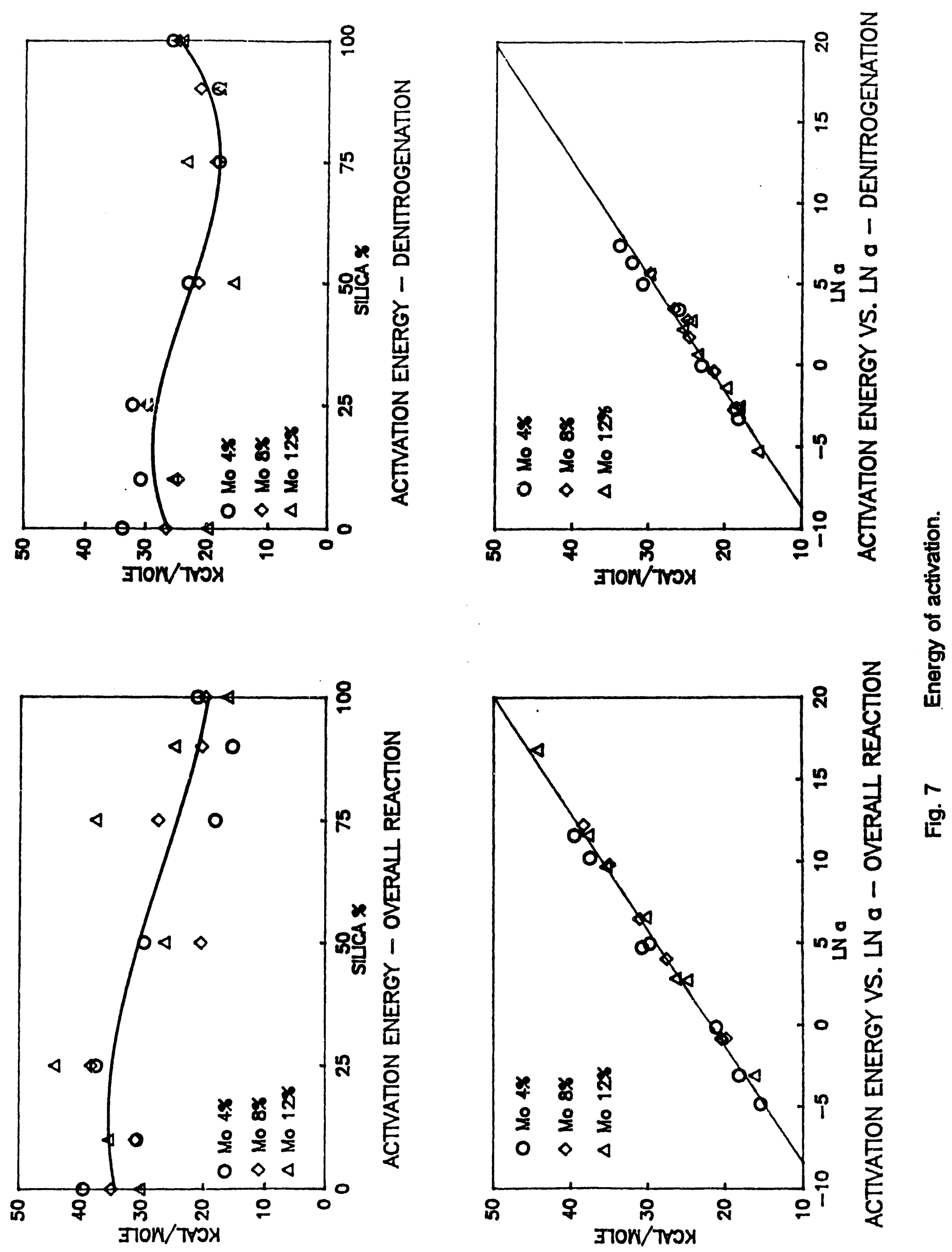
Report DOE/PC/89771-13

\title{
Part 7: LOW TEMPERATURE OXYGEN CHEMISORPTION OVER ACIDIC MOLYBDENUM CATALYSTS
}

\begin{abstract}
The low temperature oxygen chemisorption over acidic molybdena catalysts has evidenced strong reducibility of near-surface Mo, and the effect of catalyst loading and support composition on such reducibility. It was determined that for supports with compositions under $50 \%$ silica, the optimum loading producing maximum surface reducibility is $8 \mathrm{wt} \% \mathrm{MoO}_{3}$, while for supports with more than $50 \%$ silica, the optimum loading is $4 \mathrm{wt} \% \mathrm{MoO}_{3}$. At this loading, a substantial portion of the support (containing acidic sites) is also exposed. The role of Lewis sites produced on the molybdena surface by coordinative unsaturation is the strong adsorption of aromatic or unsaturated amines, and the destabilization of $\mathrm{C}-\mathrm{C}$ and $\mathrm{C}-\mathrm{N}$ bonds. Hydrogenation and hydrogenolysis can then occur by $\mathrm{H}$ addition. The highly acidic Bronsted sites, present on the support as well as on the molybdena, strongly chemisorb the hydrogenated amines. The acidic sites contribute to denitrogenation by Hofmann elimination mechanism, as shown by the abundance of unsaturated hydrocarbons produced, and are also active for cracking and cyclization, as shown by the selectivity towards methane and cyclopentene.
\end{abstract}

\section{INTRODUCTION}

The nature of reduced molybdena phases is obviously affected by support composition. The silica-rich supports favor reducible phases, while the alumina-rich supports favor less reducible phases. Pure silica supports favor the agglomeration of a phase of $\mathrm{MOO}_{3}$, which is also highly reducible. In these complex catalysts, a varying number of hydrogenolysis sites will be accompanied by a varying number of acidic sites, and their combined roles will affect the activity and selectivity for HDN.

The HDN reaction of pyridine was utilized to assess the variation in activity and selectivity produced by the nature of the support. The results revealed that for silica-alumina supports ( $>50$ wt\% silica) the optimum loading of molybdena is $4 \mathrm{wt} \%$. At this low loading the activity and selectivity towards HDN were maximum.

In this part of the report the method of low temperature oxygen chemisorption, utilized to titrate the coordinatively unsaturated sites (cus) of Mo that are responsible for the state of reduction of surface (or near-surface) Mo, is described in detail. The catalysts were reduced under the same conditions utilized before for the pyridine HDN reaction. 


\section{EXPERIMENTAL}

\section{Synthesis of Supports and Supported Mo Oxide Catalysts}

Details of the preparation and characterization results were given before above.

\section{Catalysts Used for LTOC}

The samples tested consisted of three different contents of supported molybdena $(4,8$ and 12 wt\%) on seven different supports (silica, silica-alumina: 10-90, 25:75, 50:50, 75:25, 90:10 wt:wt\%, and gamma-alumina).

\section{Reduction of Mo Oxide Catalysts before Low-Temperature Oxygen Chemisorption}

The catalysts were reduced in-situ, in an adsorption cell in the flow mode (see experimental setup depicted in Fig. 1). Before reduction, the calcined samples were exposed to flowing He at $400 \mathrm{C}$ for $1 \mathrm{~h}$ to remove moisture. Then $100 \mathrm{ml} / \mathrm{min}$ of $\mathrm{H}_{2}$ was flown over the catalyst for $4 \mathrm{~h}$ at $500 \mathrm{C}$. The samples were evacuated (10-7 Torr) at $500 \mathrm{C}$ for 2 hours, and then cooled to $-78 \mathrm{C}$ in an acetone-dry-ice mixture bath while under vacuum.

\section{Low-Temperature Oxygen Chemisorption}

Following the procedure developed by Parekh, Weller, Liu, Garcia Fierro and others [1-4], $300 \mathrm{mg}$ of catalyst was loaded in a glass cell (Fig. 1), reduced as detailed above, and cooled to -78 $C$ in a dry-ice bath. After determining the oxygen adsorption isotherm for a few samples, it was finally determined that a single point adsorption at 300 Torr produced representative measures of the amount of Mo cus. The adsorption saturation pressure for all catalysts was between 300 and 400 Torr, in agreement with literature results [5].

The single-point adsorption consisted of admitting more than 300 Torr of oxygen to the static system whose pressure was monitored with a Barocell electronic manometer. Apparent equilibrium was reached after about $30 \mathrm{~min}$, and adsorption was measured at two pressures about 300 Torr. The adsorption at 300 Torr was calculated by interpolation. Then the system was evacuated for 1 hour and the procedure was repeated. The first adsorbed amount was equated to the combined physi- and chemi-sorption, while the second one to physisorption, thus the difference between the two corresponds only to chemisorption.

\section{RESULTS AND DISCUSSION}

Fig. 2 shows the measured LTOC on three series of catalysts differing in the molybdena loading $(4,8$ and $12 \mathrm{wt} \%)$. The data have been expressed in two units: per weight of catalyst and per weight of molybdena. Assuming that every cus of Mo chemisorbs a single $\mathrm{O}$ (dissociated $\mathrm{O}_{2}$ ), the percent of Mo unsaturation can be calculated as 


$$
\text { cus } \%=\frac{2\left(\mathrm{O}_{2} \text { uptake }\right)}{\text { Total Mo }}
$$

where Total Mo is

$$
\begin{aligned}
& 277 \mu \text { mole/g cat. for } 4 \mathrm{wt} \% \mathrm{MoO}_{3} \\
& 555 \mu \text { mole/g cat. for } 8 \mathrm{wt} \% \mathrm{MoO}_{3} \\
& 833 \mu \text { mole/g cat. for } 12 \mathrm{wt} \% \mathrm{MoO}_{3}
\end{aligned}
$$

Table 1 shows the resulting cus\% obtained after averaging a number of duplicated experiments. Per unit mass of Mo, the cus\% is higher for $\mathbf{8 w t} \%$ Mo for most of the range of support

\begin{tabular}{|c|c|c|}
\hline Catalyst* & $\begin{array}{l}\text { Oxygen Uptake } \\
\mu \text { mole/g cat. }\end{array}$ & $\begin{array}{l}\text { Cus } \\
\%\end{array}$ \\
\hline $\begin{array}{l}\text { M4AL } \\
\text { M4SA10 } \\
\text { M4SA25 } \\
\text { M4SA50 } \\
\text { M4SA75 } \\
\text { M4SA90 } \\
\text { M4SI } \\
\text { M8AL } \\
\text { M8SI } \\
\text { M12AL } \\
\text { M12SI }\end{array}$ & $\begin{array}{l}9.9 \\
8.1 \\
17.2 \\
22.5 \\
27.6 \\
33.4 \\
40.2 \\
45.9 \\
78.5 \\
78.1 \\
90.4\end{array}$ & $\begin{array}{l}7.2 \\
5.8 \\
12.4 \\
16.2 \\
19.8 \\
24.0 \\
29.0 \\
16.6 \\
28.2 \\
18.8 \\
21.6\end{array}$ \\
\hline
\end{tabular}
composition. The increase of cus\% is fastest, though, for the $4 \mathrm{wt} \%$ Mo series.

Table 1

\section{Oxygen Uptake and calculated Mo Cus\%}

Results for cus\% have traditionally been interpreted as a measure of dispersion of Mo, but such interpretation is valid only when each surface Mo contains just one cus $\left(\mathrm{Mo}^{+4}\right)$ and the bulk $\mathrm{Mo}$ is either totally oxidized or is non-oxidizable. If such were the case here, our results would indicate increasing dispersion with increasing content of silica in the support, contrary to past experience. We have resolved this conflict by concluding that upon chemisorption, partial oxidation of the molybdena bulk has occurred. This conclusion is based on the reported TPR results which showed that silica-rich supports are little interar ing with molybdena, and are promoters of molybdena reducibility (and oxidability). Thus our LTOC experiments are inappropriate as a method to measure the Mo dispersion. Rather, the results are measures of oxidability of the cus located on the surface and in some depth within the bulk. As an example, for pure alumina support, for which interaction with molybdena is maximum, oxygen uptake still increases with molybdena loading, in the same manner as oxidability increases. 
Fig. 3 shows the reducibility of supported molybdena, expressed as average change in oxidation number upon reduction with hydrogen under the same conditions as those used for LTOC. Two observations from this figure are that: (i) state of oxidation of Mo can be less than +4 for more than $8 \mathrm{wt} \%$ molybdena and more than $50 \%$ silica, and (ii) the maximum reducibility occurs at around $75 \%$ silica, unlike the maximum LTOC, which occurs for pure silica. The first observation leads us to think that one reason for the large LTOC of silica- and molybdena-rich catalysts is the double-counting of reduced Mo:

$$
\mathrm{Mo}^{+2}+\mathrm{O}_{2} \cdots \mathrm{Mo}_{-\mathrm{O}}^{+6}
$$

the other reason being the oxidation of under-surface cus.

The second observation can be understood when considering that LTOC (Fig. 2) measures near-surface cus density while reducibility (Fig. 3) measures bulk cus density. Thus we can infer that the degree of unsaturation at the surface of molybdena clusters $\left(<8 \mathrm{wt} \% \mathrm{MoO}_{3}\right)$ is higher for silica than for silica-aluminas. This is possible since silica favors the formation of distinct (large) molybdena agglomerates which have highly reducible surfaces. Catalysts with $>8 \mathrm{wt} \% \mathrm{MoO}_{3}$ show an LTOC curve which is almost insensitive to support composition, while the reducibility curve is a strong function of it. This again shows a highly reducible surface, independent of support composition.

The information derived from LTOC, together with results derived from acidity characterization can be used to interpret the activity and selectivity for HDN of pyridine of these catalysts. It was observed that the activity increases in proportion to the silica content of the support, being maximum for pure silica. It was also seen that the conversion per unit mass of molybdena is inversely related to loading of molybdena, being maximum for $8 \mathrm{wt} \% \mathrm{MoO}_{3}$ at support compositions of $<50 \%$ silica, and for $4 \mathrm{wt} \% \mathrm{MoO}_{3}$ at support compositions of $>50 \%$ silica.

The correlation between activity results and LTOC results thus indicate that near-surface reducibility of the supported molybdena is the most important factor influencing activity.

The selectivity towards denitrogenation products follows the same behavior as the activity, and is maximized for the most reducible catalysts. The nature of the sites responsible for this activity is revealed by the detailed selectivity curves. The hydrocarbon production is composed mainly of $\mathrm{C5}$ and $\mathrm{C} 1, \mathrm{C} 5$ being mostly t-2-pentene and including also n-pentane, cyclopentane, 1 -pentene and cyclopentene. As the support composition becomes $>50 \mathrm{wt} \%$ silica, the acidic sites (Lewis and Bronsted-type) induce the predominance of $\mathrm{Cl}$ and the formation of unsaturated and cyclic $\mathrm{C} 5$. The selectivity towards saturated hydrocarbons grows from 1 to about 6 in the same region of support composition, due to the increase in hydrogenation activity.

These results suggest that the appearance of highly reducible sites as well as acidic sites favors the adsorption strength for unsaturated hydrocarbons and amines. Thus the activity for hydrogenation and hydrogenolysis, as well as the activity for cyclization and cracking, increases. It is logical to assume that the heterocyclic rings strongly adsorbed on reduced Mo sites (Lewis acid sites), are saturated by hydrogenation and lose $\mathrm{NH}_{3}$ by hydrogenolysis, while saturated or partially saturated amines that chemisorb on Bronsted acidic sites lose $\mathrm{NH}_{3}$ by Hofmann elimination, and are cracked to lower hydrocarbons. 


\section{CONCLUSIONS}

The technique of low temperature oxygen chemisorption over a series of acidic molybdena catalysts has been used to determine the reducibility of near-surface Mo. It was determined that for supports with compositions under $50 \%$ silica, the optimum loading producing maximum surface reducibility is $8 \mathrm{wt} \% \mathrm{MoO}_{3}$, while for supports with more than $50 \%$ silica, the optimum loading is $4 \mathrm{wt} \% \mathrm{MoO}_{3}$. Notice that at the $4 \%$ loading, a substantial portion of the support (containing acidic sites) is also exposed. The role of Lewis sites produced on the molybdena surface by coordinative unsaturation seems to be the strong adsorption of aromatic or unsaturated amines, and destabilization of $\mathrm{C}-\mathrm{C}$ and $\mathrm{C}-\mathrm{N}$ bonds by nucleophilic attack. Hydrogenation and hydrogenolysis then occur by insertion of $\mathrm{H}$. The highly acidic Bronsted sites, present on the support as well as on the molybdena, strongly chemisorb the hydrogenated amines. The acidic sites also contribute to denitrogenation, probably by Hofmann elimination mechanism, as shown by the abundance of unsaturated hydrocarbons produced, and are also active for cracking and cyclization, as shown by the selectivity towards methane and cyclopentene.

\section{REFERENCES}

1. B.S. Parekh and S.W. Weller, J. Catal. 47, 100-108 (1977)

2. H.C. Liu, et al., J. Catal. 61, 282-284 (1980)

3. J.L. Garcia Fierro, et al., J. Catal. 65, 263-270 (1980)

4. H.C. Liu and S. W. Weller, J. Catal. 66, 65-72 (1990)

5. W.S. Millman and W.K. Hall, J. Catal. 59, 311-313 (1979) 


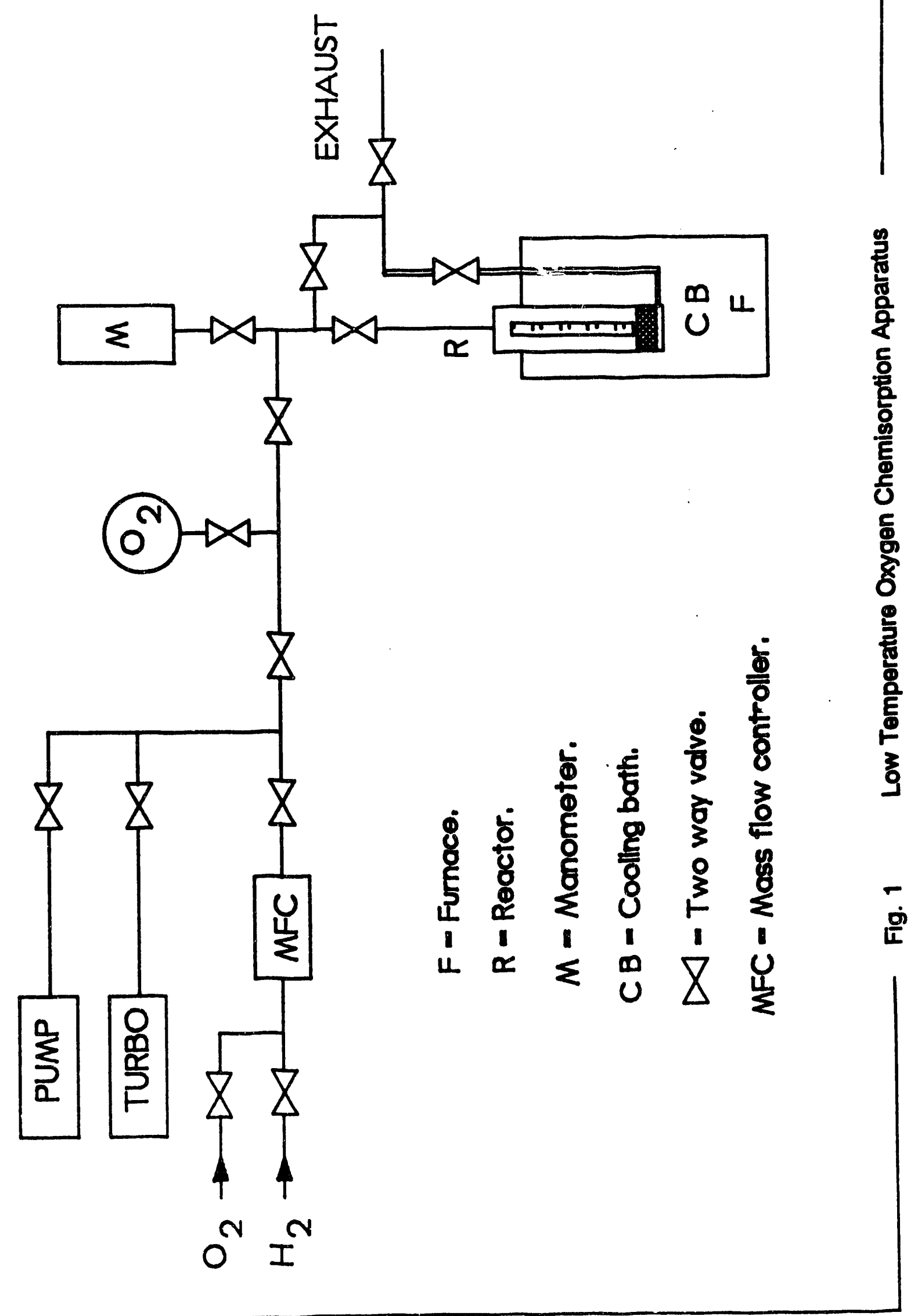



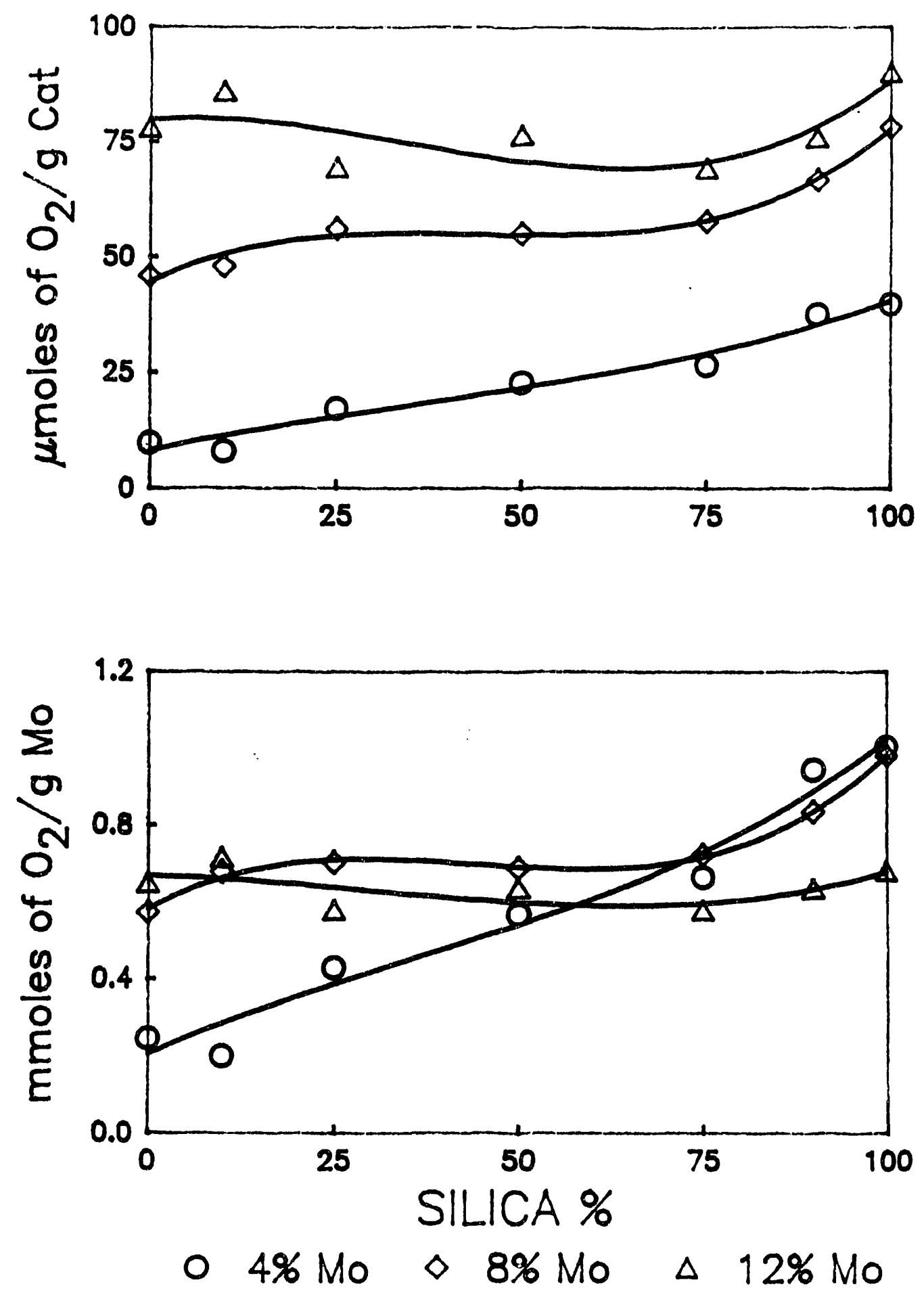

Fig. 2 Amount of Oxygen Chemisorption for all of the Catalysts Investigated (See text for conditions). 


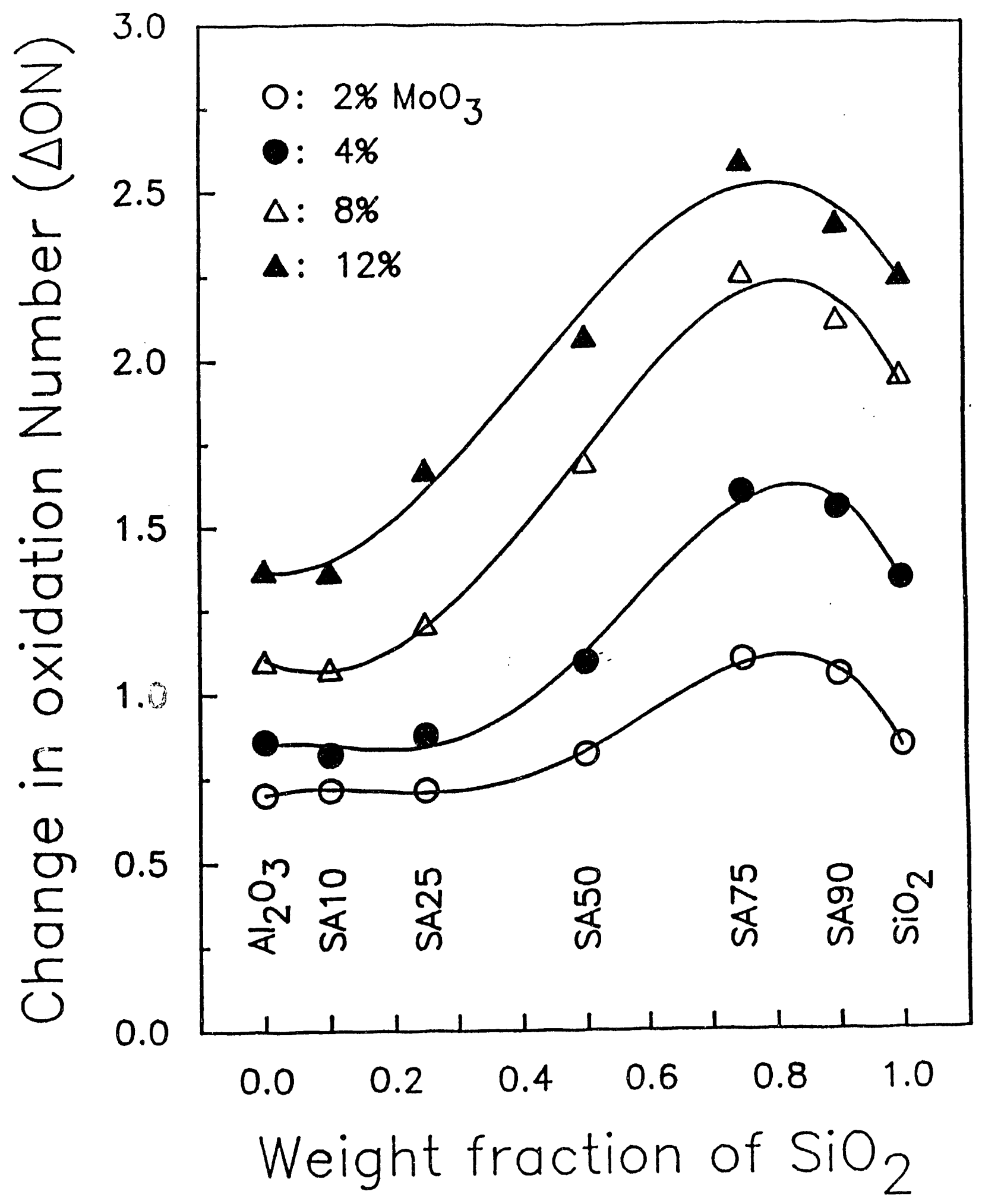

Fig. 3 Average Reducibility of Catalysts as a Function of Molybdena Loading and Support Composition (See Ref. 4 for conditions). 
Report DOE/PC/89771-13

\title{
Part 8: $\mathrm{H}_{2}-\mathrm{D}_{2}$ EXCHANGE IN NON-ACIDIC AND ACIDIC SUPPORTS
}

\begin{abstract}
The exchange of deuterium with surface $\mathrm{OH}$ in silica, alumina and silica-alumina, has been studied under $400^{\circ} \mathrm{C}$, using $\mathrm{D}_{2} \mathrm{O}$ and $\mathrm{D}_{2}$ as deuterium sources. Substantial degree of exchange is achieved in all cases, resulting in the production of surfaces suitable for the study of the interaction of heterocyclic amines with surface $\mathrm{OH}$.
\end{abstract}

\section{INTRODUCTION}

Highly acidic Bronsted sites, present on silica-alumina supports, strongly chemisorb hydrogenated amines. The acidic sites probably contribute to their denitrogenation, as shown by the abundance of unsaturated hydrocarbons produced during HDN of piperidine, and are also active for cracking and cyclization, as shown by the selectivity towards methane and cyclopentene.

The mechanism postulated for this acid-catalyzed denitrogenation must involve the Bronsted acid sites present on the support and molybdena-support interface, since strong Bronsted sites on the molybdena phase itself are unlikely to be formed. In fact, earlier results showed that the amount of Bronsted acidity diminished with increased loading of molybdena. Therefore, the approach taken in this work to show the participation of Bronsted acid sites in the mechanism of HDN of pyridine involves the exchange of surface protons with deuterium cations.

This part of the report describes the exchangeability of various types of surface hydrogen present on silica, alumina and silica-alumina, investigated by diffuse reflectance infrared spectroscopy.

\section{EXPERIMENTAL}

\section{Synthesis of Supports}

Silica-aluminas with a range of composition from 10-90 wt\% silica, pure silica and gammaalumina were synthesized and characterized as already described.

\section{Supports used for Deuterium Exchange}

The samples tested consisted of three different compositions of support: pure silica, pure alumina, and $75 \%$-silica silica-alumina, dried at $120^{\circ} \mathrm{C}$ overnight and calcined at $500^{\circ} \mathrm{C}$ for four hours. 
Report DOE/PC/89771-13

\section{Deuterium Exchange}

The exchange was effected with $\mathrm{D}_{2} \mathrm{O}$ and with $\mathrm{D}_{2}$ in separate experiments, inside a DRIFT cell equipped with environmental chamber. A soft pellet of support without any additive was made with $100 \mathrm{mg}$ of powder compressed at about 200-500 psig for about $5 \mathrm{~min}$. Inside the DRIFT chamber, the support was treated with $10 \mathrm{ml} / \mathrm{min}$ oxygen at $400^{\circ} \mathrm{C}$ during 1 hour in order to eliminate adsorbed $\mathrm{CO}_{2}$, and with $\mathrm{H}_{2}$ under the same conditions in order to allow later comparison with molybdena catalysts equally treated. Finally, the sample was evacuated at $400^{\circ} \mathrm{C}$ during 1 hour (10-5 Torr) to remove gas phase hydrogen.

In case of proton exchange using $\mathrm{D}_{2} \mathrm{O}$, a pulse of about 2 microliters was injected into the closed cell maintained at $300^{\circ} \mathrm{C}$, while the pressure rose because of water evaporation. In case of exchange using $\mathrm{D}_{2}, 2 \mathrm{~atm}$ of gas was kept in the cell maintained at $400^{\circ} \mathrm{C}$ during 1 hour. In both cases the temperature was reduced to $150^{\circ} \mathrm{C}$ under pressure, followed by evacuation at $150^{\circ} \mathrm{C}$ during 1 hour. DRIFT spectra were then recorded during $7 \mathrm{~min}$ under vacuum at $150^{\circ} \mathrm{C}$.

\section{RESULTS AND DISCUSSION}

Figure 1 shows the results of exchange of deuterium from $\mathrm{D}_{2} \mathrm{O}$ with hydrogen from surface silanol groups. Panels a,b and c correspond to the spectra of silica, silica-alumina and alumina before deuterium exchange, and panels $d, e$ and $f$, to the respective spectra after exchange. In agreement with traditional work of Hall et al. [2] and Peri et al. [5], the exchange with deuterium from $\mathrm{D}_{2} \mathrm{O}$ is very fast and occurs instantaneously upon injection, even at $200^{\circ} \mathrm{C}$.

The bands observed in these experiments were assigned following Baumgarten e al. [1]. In silica (panel a) the band at $3744 \mathrm{~cm}^{-1}$ belongs to the terminal silanol groups Si-OH on the surface of grains; these silanols are sufficiently isolated to not interact (via $\mathrm{H}$-bond) with neighboring silanols. The broad band between 3700 and $3300 \mathrm{~cm}^{-1}$ belongs to the $\mathrm{H}$-bonded silanols on the silica surface. After exchange, new bands at $2757 \mathrm{~cm}^{-1}$ and $2720-2400 \mathrm{~cm}^{-1}$ appear, and they correspond to the terminal and deuterium-bonded OD groups, respectively.

Figure 2 (panels a and c) shows identical results for exchange with deuterium from $\mathrm{D}_{2}$, although dissociation and exchange became facile at higher temperature than in the case of $\mathrm{D}_{2} \mathrm{O}$. It must be noted that extending the contact time or increasing the dose of adsorbate did not lead to an increased amount of exchange, which indicated that equilibrium had been reached, although from these experiments alone it was unclear whether the extent of exchange was limited by equilibrium or other factors. It became apparent later that steric factors play an important role in the extent of exchange, since some of the OH detected by IR spectroscopy may be unreachable by the exchanging gas. It is noticeable with both exchanging gases that the isolated $\mathrm{OH}$ exchanges the most, while the $\mathrm{H}$-bonded $\mathrm{OH}$ may be limited for kinetic and thermodynamic reasons.

Figure 1 (panels $c$ and $f$ ) and Figure 2 (panels $b$ and $d$ ) depict the spectra of alumina before and after exchange with $\mathrm{D}_{2} \mathrm{O}$ and $\mathrm{D}_{2}$. The broadness of the bands for this support is due to the existence of several types of surface hydroxyl groups on alumina. Knozinger and Ratnasamy [6], and others [3-4], indicated that five different types of $\mathrm{OH}$ groups can be identified on alumina: (1) isolated $\mathrm{OH}$ on single octahedral $\mathrm{Al},(2)$ isolated $\mathrm{OH}$ on single tetrahedral $\mathrm{Al},(3)$ isolated $\mathrm{OH}$ on 
bridge-bonded octahedral and tetrahedrai $\mathrm{Al},(4)$ isolated $\mathrm{OH}$ on triple-bridge-bonded octahedral $\mathrm{Al}$, and (5) $\mathrm{H}$-bonded $\mathrm{OH}$. The isolated $\mathrm{OH}$ bands lie in the region of about 3700 to $3800 \mathrm{~cm}^{-1}$, while the $\mathrm{H}$-bonded bands lie between 3200 to $3600 \mathrm{~cm}^{-1}$. In the present experiment both isolated and $\mathrm{H}$-bonded bands are apparent for alumina before and after exchange (Figs. 1-2). It seems that the exchange readily occurs with isolated $\mathrm{OH}$ and less readily with $\mathrm{H}$-bonded $\mathrm{OH}$.

Silica-alumina exchange with $\mathrm{D}$ of $\mathrm{D}_{2} \mathrm{O}$ is depicted in Fig. 1 (panels $\mathrm{b}$ and $\mathrm{e}$ ). The unexchanged surface contains isolated silanol groups, as revealed by the sharp $3744 \mathrm{~cm}^{-1}$, as well as aluminumbound hydroxyls. The Bronsted acid $\mathrm{OH}+$ groups are associated with $\mathrm{Si}-\mathrm{O}-\mathrm{Al}$ groups, and also appear in the $3400-3700 \mathrm{~cm}^{-1}$ region, but are not readily distinguishable in the IR spectra. All groups are readily exchanged, as observed in the appearance of the new bands in the 2400-2800 $\mathrm{cm}^{-1}$ region. In all cases (silica, alumina, and silica-alumina) the exchange is limited by equilibrium and (apparently) by steric factors.

\section{CONCLUSIONS}

Diffuse reflectance infrared spectroscopy was used to follow the deuterium exchange of silica, alumina and silica-alumina supports. The exchange was effected at a minimum of $200^{\circ} \mathrm{C}$ with $\mathrm{D}_{2} \mathrm{O}$ and normally at $400^{\circ} \mathrm{C}$ with $\mathrm{D}_{2}$. The in-situ exchanged materials will be utilized to study the interaction of heterocyclic amines with their surface hydroxyl and acidic groups, and to verify the participation of Bronsted acidic hydrogen in the HDN of those heterocyclic amines.

\section{REFERENCES}

1. E. Baumgarten, C. Lentes-Wagner, R. Wagner, J. Molec. Catal. 50, 153-65 (1989)

2. W.K. Hall, H.P. Leftin, F.J. Cheselske, D.E. O'Reilly, J. Catal. 2, 506-17 (1963)

3. J.L. Carter, P.J. Lucchesi, P. Corneil, D.J.C. Yates, J.H. Sinfelt, J. Phys. Chem. 69, 3070-4 (1965)

4. Y. Amenomiya, J. Catal. 22, 109-22 (1971)

5. J.B. Peri, J. Phys. Chem. 70, 2937-45 (1966)

6. H. Knozinger, P. Ratnasamy, Catal. Rev. Sci. Eng. 17, 31 (1978) 


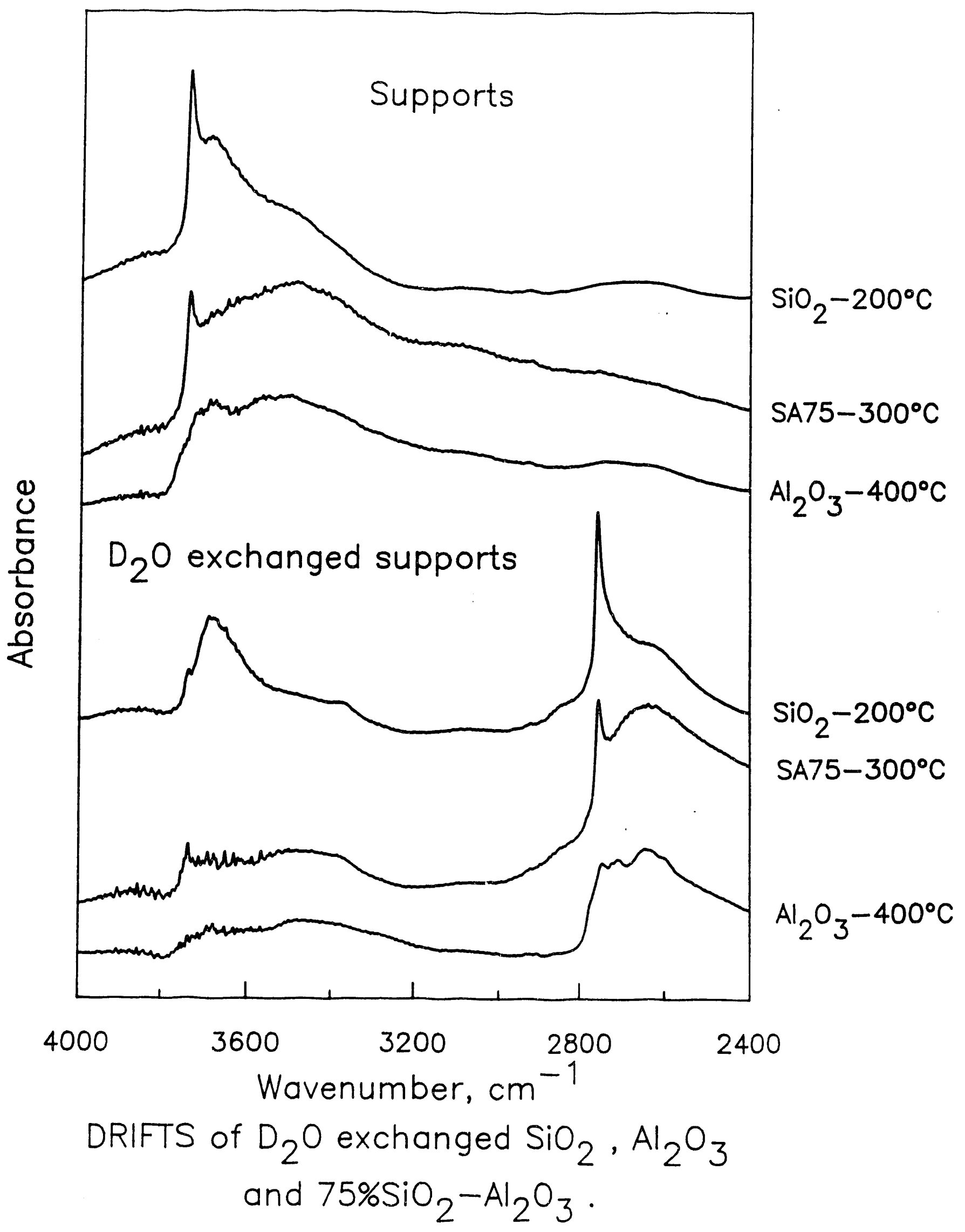




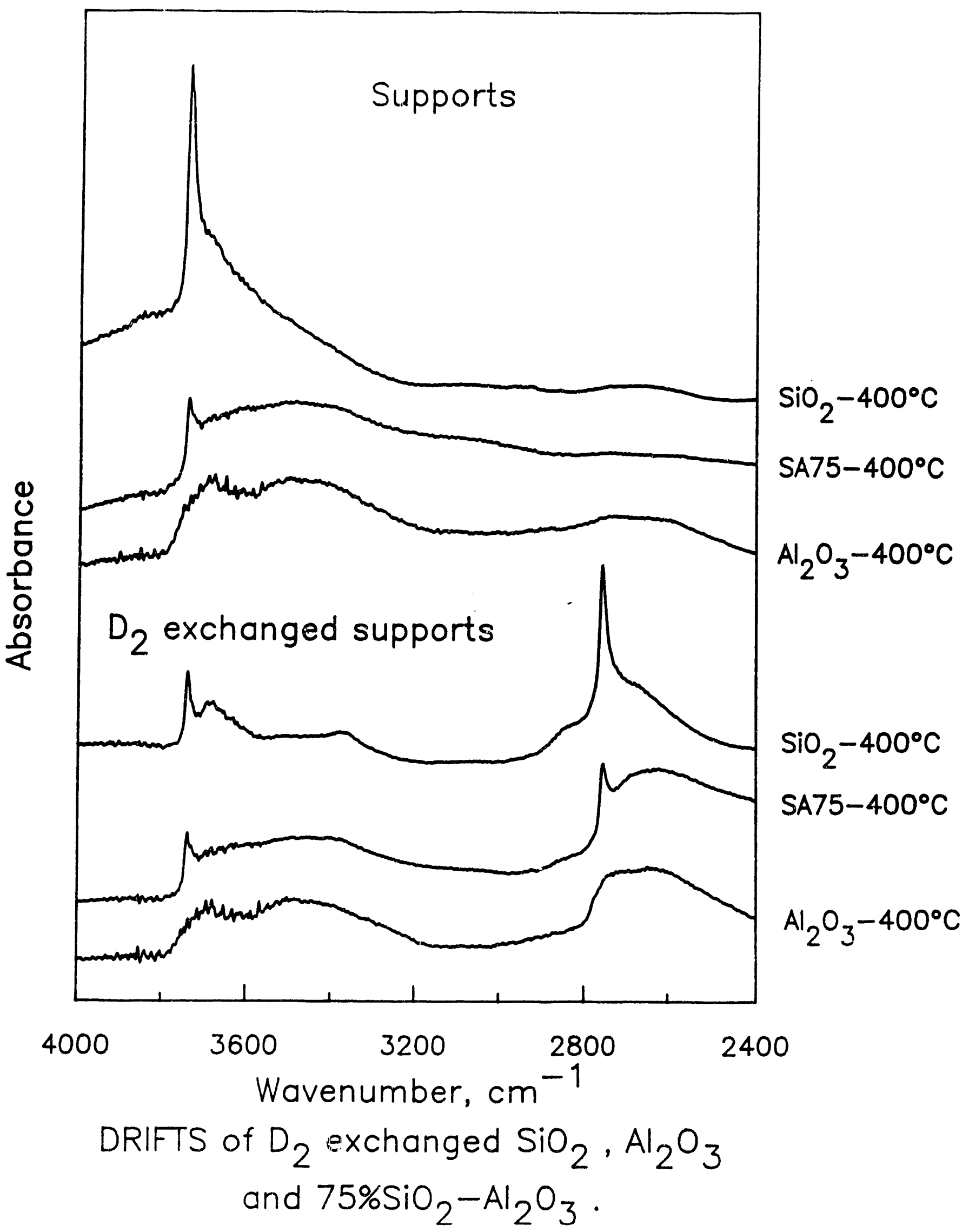


Report DOE/PC/89771-13

\title{
Part 9: $\mathrm{H}_{2}-\mathrm{D}_{2}$ EXCHANGE IN REDUCED MOLYBDENUM CATALYSTS
}

\begin{abstract}
Diffuse reflectance infrared spectroscopy was used to study the deuterium exchangeability of reduced molybdena catalysts supported on silica, alumina and $75 \%$ silica-alumina. It was found that silica hydroxyls react partially with deposited molybdena. The new species formed does not lead to regeneration of hydroxyls on the catalyst. On the other hand, the interaction of molybdena with alumina or silica-alumina leads to the generation of interfacial $\mathrm{OH}$ groups, that compensate for the hydroxyls lost to reaction.
\end{abstract}

\section{INTRODUCTION}

The mechanism proposed for an acid-catalyzed denitrogenation involves Bronsted acid sites present on the support and moiybdena-support interface, since strong Bronsted sites on the molybdena phase itself are unlikely to be formed. In fact, earlier results showed that Bronsted acidity amount diminished with increased molybdena loading. Therefore, the approach taken in this work to show the participation of Bronsted acid sites in the mechanism of HDN of pyridine involves the exchange of surface hydroxyl hydrogen with deuterium. The previous section of this report was dedicated to show that it is possible to exchange deuterium with surface $\mathrm{OH}$ in silica, alumina and silica-alumina, at temperatures under $400^{\circ} \mathrm{C}$, using $\mathrm{D}_{2} \mathrm{O}$ and $\mathrm{D}_{2}$ as deuterium sources. A question remains of whether the loading of molybdenum followed by its reduction will affect the exchangeability of surface $\mathrm{OH}$.

Therefore, in this section we discuss the effect of molybdena loading on exchangeability of surface $\mathrm{OH}$. In particular we searched for qualitative evidence of the presence of $\mathrm{OH}$ coordinated to $\mathrm{Mo}$, in distinction from $\mathrm{OH}$ coordinated to support.

\section{EXPERIMENTAL}

\section{Synthesis of Supports and Supported Molybdena}

Silica-aluminas, pure silica and gamma-alumina were synthesized and characterized as described above. The oxidic catalysts were prereduced in $50 \mathrm{ml} / \mathrm{min} \mathrm{H}_{2}$ at $400^{\circ} \mathrm{C}$ for 4 hours in a fixed-bed microreactor. Subsequently the powder was lightly compressed into a $13 \mathrm{~mm}$ pellet and further reduced in situ in the DRIFT cell, by flowing $\mathrm{H} 2$ at $400^{\circ} \mathrm{C}$ for 1 hour.

\section{Deuterium Exchange}

The exchange was effected with $\mathrm{D}_{2}$ inside a DRIFTS cell equipped with environmental chamber. A catalyst pellet was made with $100 \mathrm{mg}$ of powder with no additives and compressed to about 200 500 psig for about $5 \mathrm{~min}$. The pellet was rereduced as described above. Finally, the sample was 
evacuated at $400^{\circ} \mathrm{C}$ during 1 hour (10.5 Torr) to remove gas phase hydrogen.

For the exchange using $D_{2}, 2$ atm of gas was kept in the cell maintained at $400^{\circ} \mathrm{C}$ during $i$ hour. The temperature was reduced to $150^{\circ} \mathrm{C}$ under pressure, followed by evacuation at $150^{\circ} \mathrm{C}$ during 1 hour. DRIFT spectra were then recorded under vacuum at $150^{\circ} \mathrm{C}$.

Exchange of deuterium using $\mathrm{D}_{2} \mathrm{O}$ was not an option in these experiments due to the high oxidability of the reduced molybdena.

\section{RESULTS AND DISCUSSION}

Figure 1 shows two series of spectra, the first (top four) corresponding to reduced supported molybdena catalysts, and the second (bottom four) corresponding to deuterium-exchanged catalysts. Each series consists of spectra for pure silica support, and for supported molybdena at different loadings: 4,8 and $12 \mathrm{wt} \%$. The bands observed for the supported molybdena catalysts match exactly those for the pure silica support. Thus the assignment given before still prevails. Following Baumgarten et al. [1] the band at $3744 \mathrm{~cm}^{-1}$ belongs to the terminal silanol groups Si$\mathrm{OH}$ on the surface of grains; these silanols are sufficiently isolated to not interact (via $\mathrm{H}$-bond) with neighboring silanols. The broad band between 3700 and $3300 \mathrm{~cm}^{-1}$ belongs to the H-bonded silanols on the silica surface. After exchange, new bands at $2757 \mathrm{~cm}^{-1}$ and $2720-2400 \mathrm{~cm}^{-1}$ appear, and they correspond to the isolated and deuterium-bonded OD groups, respectively.

It is worth observing that the $3744 \mathrm{~cm}^{-1}$ band has reduced intensity at increased molybdena loading, a fact that could signify the effect of coverage of support surface by deposited molybdena. However, when combined with previous reducibility results, the present $\mathbb{R}$ results indicate certain degree of reaction of deposited molybdena with surface hydroxyl groups. This reactivity and interaction is responsible for the less than maximum bulk reducibility exhibited by the silicasupported catalysts. It is also worth observing that the $\mathrm{H}$-bonded silanol bands $\left(3300-3700 \mathrm{~cm}^{-1}\right)$ are not reduced by Mo ioading in the same ratio as the isolated silanol bands, which indicutes that the molybdena coverage is not uniform. This lack of uniformity is caused by the different reactivity of isolated $\mathrm{OH}$ groups when compared to H-bonded groups. Similar conclusions can be derived from the exchanged catalyst series. Furthermore, it is observed that the band positions do not shift as a function of molybdena loading, and this is a strong indication that no $\mathrm{Mo}-\mathrm{OH}$ or Si-OH-Mo are present or that they do not contribute significant absorbance to the spectrum.

Figure 2 refers to spectra of reduced and D-exchanged molybdena catalysts supported on gamma-alumina. Again the top four spectra belong to reduced catalysts and the bottom four to exchanged catalysts. The broadness of the bands caused by these catalysts is due to the existence of several types of surface hydroxyl groups on alumina. Knozinger and Ratnasamy [4], and others [2-3], indicated that five different types of $\mathrm{OH}$ groups can be identified on alumina: (1) isolated $\mathrm{OH}$ on single octahedral $\mathrm{Al},(2)$ isolated $\mathrm{OH}$ on single tetrahedral $\mathrm{Al},(3)$ isolated $\mathrm{OH}$ on bridgebonded octahedral and tetrahedral $\mathrm{Al},(4)$ isolated $\mathrm{OH}$ on triple-bridge-bonded octahedral $\mathrm{Al}$, and (5) $\mathrm{H}$-bonded $\mathrm{OH}$. The isolated $\mathrm{OH}$ bands lie in the region of about 3700 to $3800 \mathrm{~cm}^{-1}$, while the $\mathrm{H}$-bonded bands lie between 3200 to $3600 \mathrm{~cm}^{-1}$. In the present experiments both isolated and $\mathrm{H}$ bonded bands are apparent before and after exchange (Fig. 2). The deposition of molybdena on alumina seems to affect the amount of isolated and $\mathrm{H}$-bonded $\mathrm{OH}$ groups to a lesser extent than in the case of silica, even when data from bulk reducibility studies showed that interaction of 
molybdena with alumina was very strong. The conclusion is that new $\mathrm{OH}$ groups are generated upon deposition of molybdena. Those $\mathrm{OH}$ groups may be of the form Mo-OH or Mo-OH-Al, whose stretching frequency would be red-shified with respect to $\mathrm{Al}-\mathrm{OH}$. Careful observation shows in fact a red shift of the band corresponding to isolated $\mathrm{OH}$, with no decrease in its intensity. This is most obvious for the exchanged catalysts.

Figure 3 depicts the 75\% silica-alumina-supported molybdena catalysts, before and after exchange with $\mathrm{D}_{2}$. The bare support appears to contain isolated silanol groups, as revealed by the sharp $3744 \mathrm{~cm}^{-1}$, as well as aluminum-bound hydroxyls. The Bronsted acid $\mathrm{OH}^{+}$groups are associated with $\mathrm{Si}-\mathrm{O}-\mathrm{Al}$ groups, and also appear in the $3400-3700 \mathrm{~cm}^{-1}$ region, but are not readily distinguishable in these IR spectra. All groups are readily exchanged, as observed by the appearance of the new bands in the $2400-2800 \mathrm{~cm}^{-1}$ region. In opposition to silica (Fig. 1), and more in agreement with alumina (Fig. 2), there is an apparent increase in the amount of OH groups on silica-alumina-supported molybdena when $4 \mathrm{wt} \%$ molybdena is loaded. Again, this is most evident in the deuterated catalysts. Such increase may be associated with the generation of new $\mathrm{OH}$ groups at the interface with the support. Higher loading of molybdena provokes the decrease in interface sites, thus a net decrease in the amount of $\mathrm{OH}$ groups.

\section{CONCLUSIONS}

Diffuse reflectance infrared spectroscopy was used to assess the deuterium exchangeability of reduced molybdena catalysts supported on silica, alumina and $75 \%$ silica-alumina. It was found that silica hydroxyls react partially with deposited molybdena. Such interaction does not lead to hydroxyl regeneration on the catalyst. On the other hand, the interaction of molybdena with alumina or silica-alumina leads to the generation of interfacial $\mathrm{OH}$ groups. The Si-OH-Mo groups in silica-alumina in principle should generate Bronsted acidic characteristics. This, in fact, has been shown previously for 2 and 4\%-loaded 75\%-silica-aluminas, which are more Bronsted-acidic than the support itself. On the other hand, the Al-OH-Mo groups formed on alumina do not generate new Bronsted acidity.

\section{REFERENCES}

1. E. Baumgarten, C. Lentes-Wagner, R. Wagner, J. Molec. Catal. 50, 153-65 (1989)

2. J.L. Carter, P.J. Lucchesi, P. Corneil, D.J.C. Yates, J.H. Sinfelt, J. Phys. Chem. 69, 3070-4 (1965)

3. Y. Amenomiya, J. Catal. 22, 109-22 (1971)

4. H. Knozinger, P. Ratnasamy, Catal. Rev. Sci. Eng. 17, 31 (1978) 
Report DOE/PC/89771-13

\section{FIGURES}

Fig. 1 Diffuse reflectance IR spectra of reduced and deuterium-exchanged molybdena catalysts supported on silica.

Code: Si: silica, M4Si: $4 \%$ molybdena/silica, M8Si: $8 \%$ molybdena/silica, etc.

Fig. 2 Diffuse reflectance IR spectra of reduced and deuterium-exchanged molybdena catalysts supported on alumina.

Code: Al: alumina, M4Al: $4 \%$ molybdena/alumina, M8Al: $8 \%$ molybdena/alumina, etc.

Fig. 3 Diffuse reflectance IR spectra of reduced and deuterium-exchanged molybdena catalysts supported on $75 \%$-silica silica-alumina. Code: SA75: 75\% silica-alumina, M4SA75: 4\% molybdena/75\%silicaalumina,etc. 


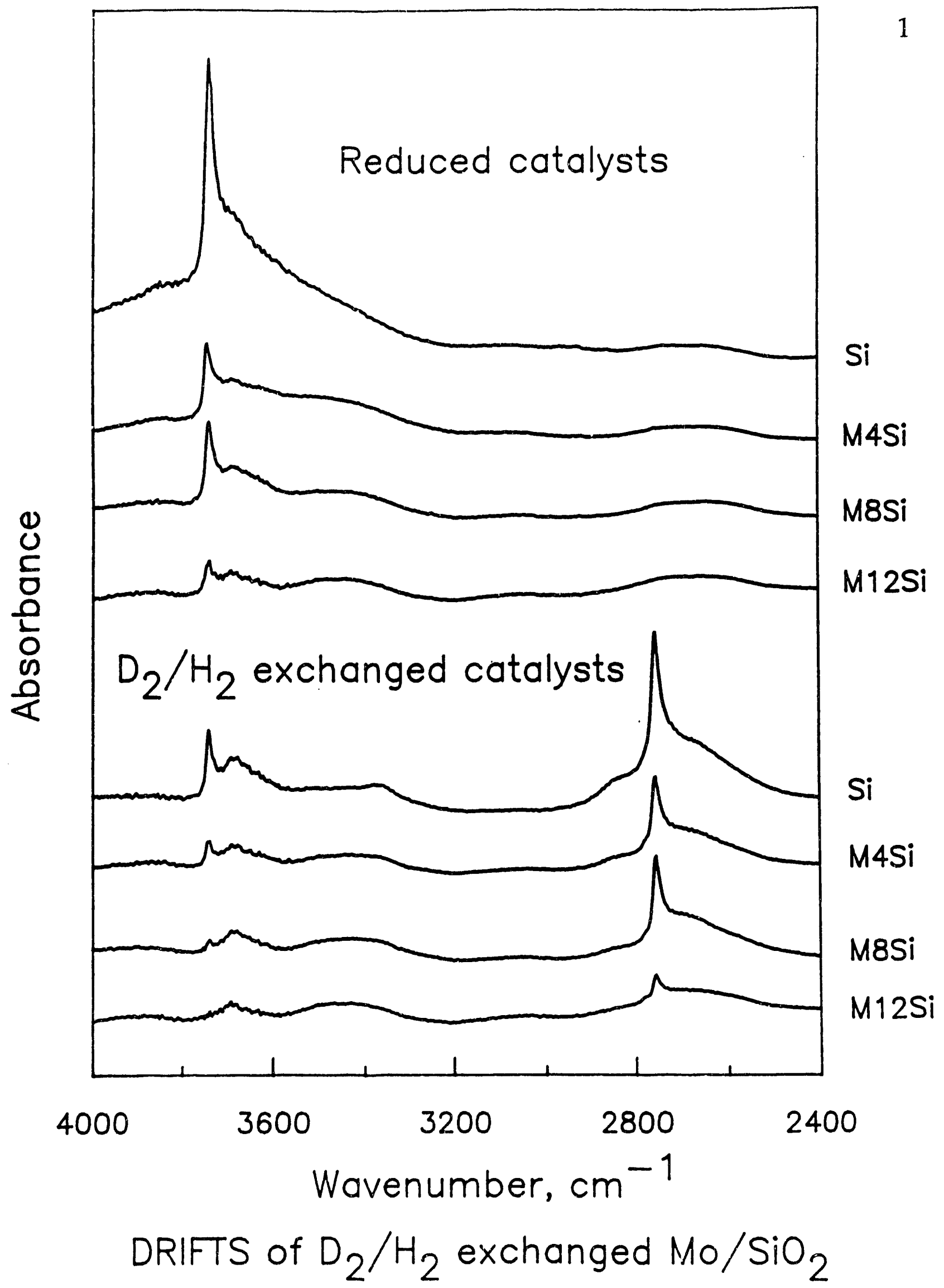




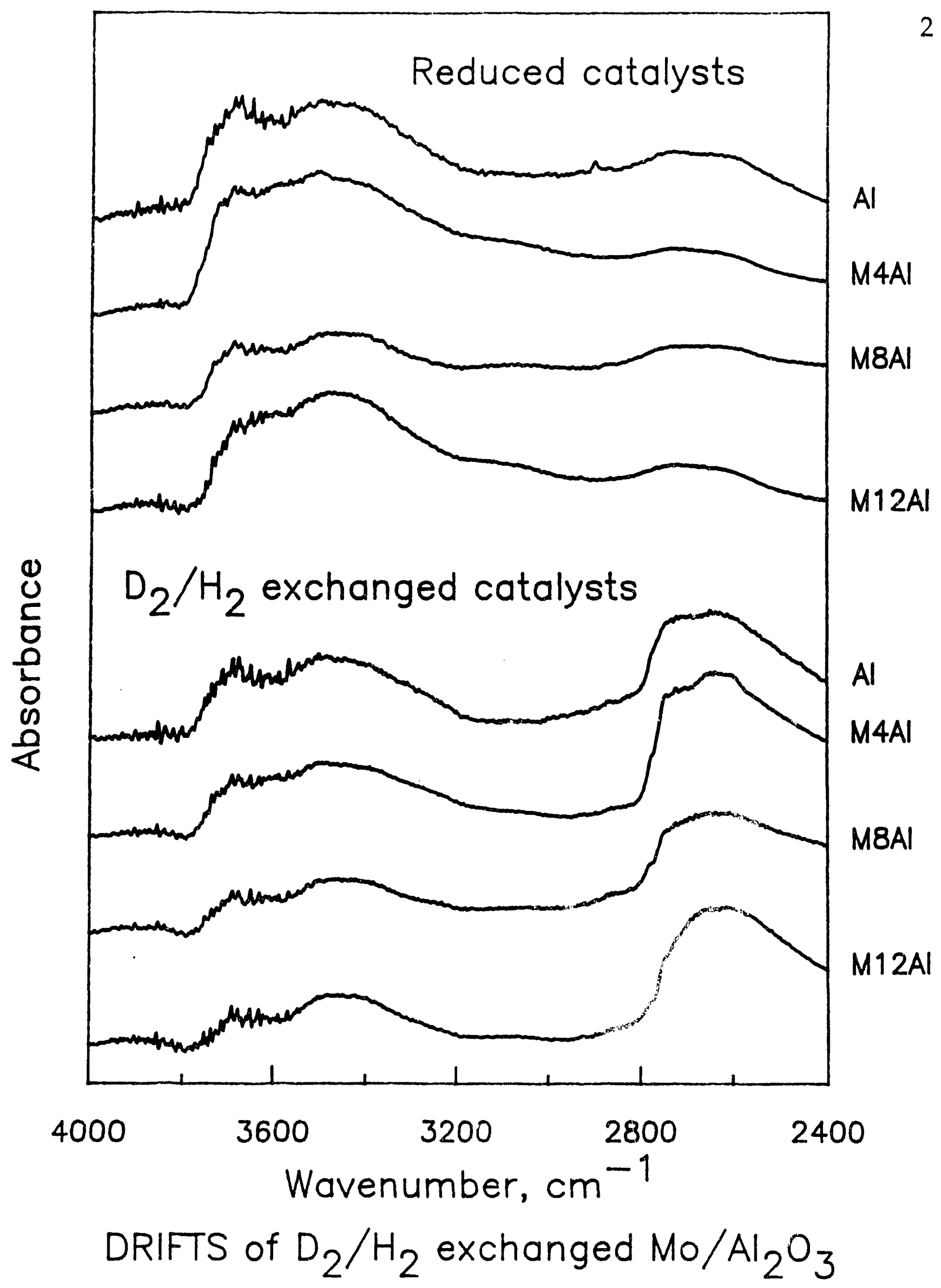




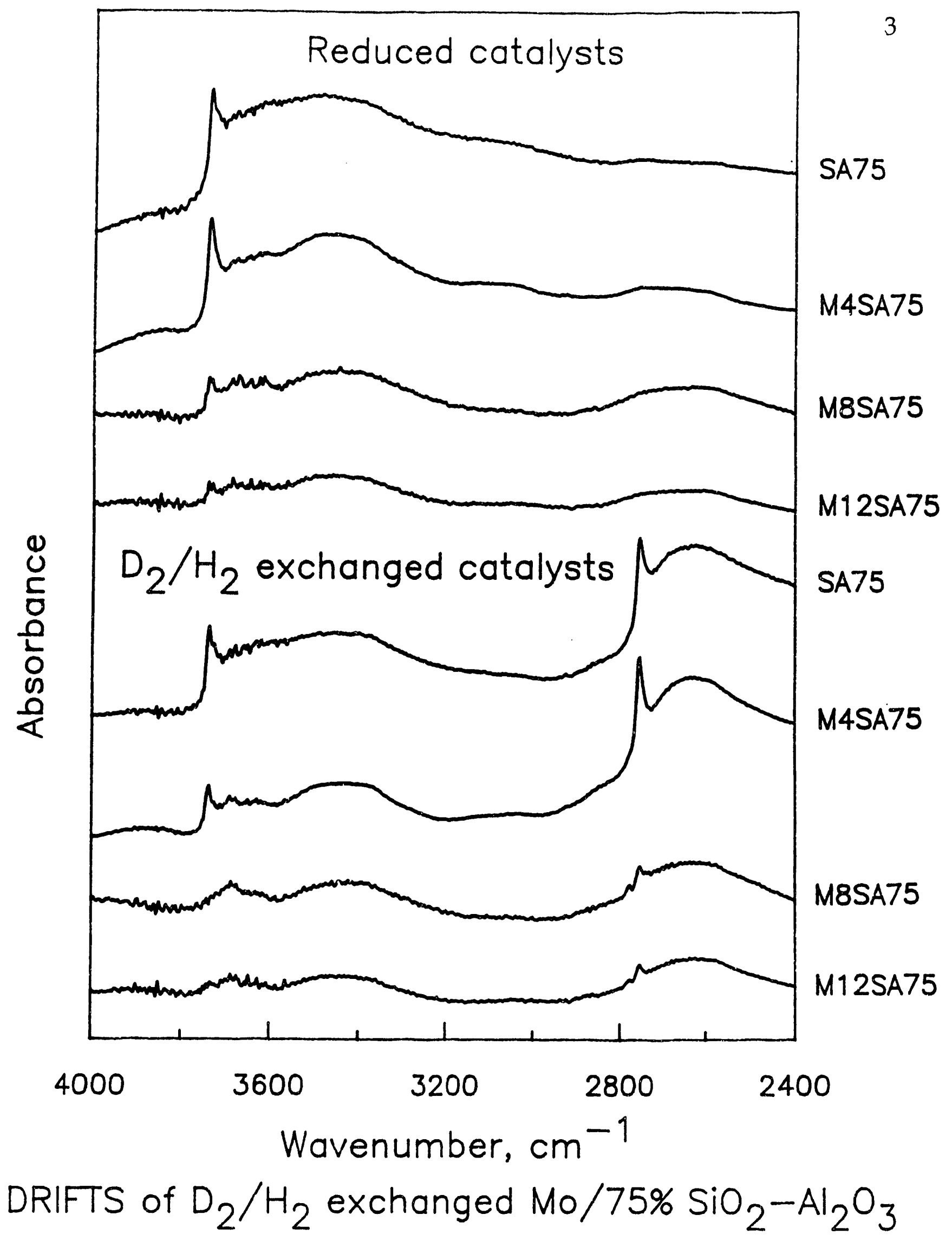


Report DOE/PC/89771-13

\title{
Part 10: ADSORPTION OF PIPERIDINE ON REDUCED MOLYBDENUM CATALYSTS
}

\begin{abstract}
Diffuse reflectance ir spectroscopy of adsorbed piperidine was done to study the interaction of highly basic cyclic amines with $\mathrm{OH}$ on various surfaces. The silanol groups on pure silica do not interact strongly with piperidine, as shown by their inability to promote the exchange of deuterium from OD with hydrogen from piperidine. After supporting molybdena on such silica, however, the silanol groups associated with interfacial sites become more acidic and are able to exchange $\mathrm{D}$ with piperidine, which is also adsorbed more strongly. The $\mathrm{OH}$ groups on pure alumina do not interact with adsorbed piperidine because of their high basicity. Upon supporting molybdena, however, new acidity and probably new OH groups are generated that interact and exchange $D$ with piperidine.
\end{abstract}

\section{INTRODUCTION}

Recently we utilized DRIFTS of deuterium-exchanged catalysts to follow the depletion of OH on the support and the simultaneous regeneration of $\mathrm{OH}$ due to molybdena addition. It was found that silica hydroxyls react partially with deposited molybdena. The new species formed do not lead to regeneration of hydroxyls on the catalyst. On the other hand, the interaction of molybdena with alumina or silica-alumina leads to the generation of interfacial $\mathrm{OH}$ groups, that compensate for the hydroxyls lost to reaction.

The HDN reaction of pyridine was utilized to assess the variation in activity and selectivity produced by the nature of the support. The results revealed that for silica-alumina supports (>50 wt\% silica) the optimum loading of molybdena is $4 \mathrm{wt} \%$. At this loading, the selectivity for denitrogenation was maximum, in coincidence with a substantial portion of the support (containing acidic sites) being exposed. The possible role of Lewis acid sites produced on the molybdena surface by coordinative unsaturation is the strong adsorption of aromatic and saturated cyclic amines, while the weak-strong acidic Bronsted sites, present on the support as well as on the molybdena, interact with those amines. It is not clear at this point the nature of such interaction. In principle, $\mathrm{H}+$ would add to $\mathrm{NH}$ to form a stable quaternary $\mathrm{N}+$ ion, as is known to occur in solution chemistry.

To answer the question of the nature of the interaction between adsorbed cyclic amines and supported reduced molybdena phases, we used the deuterium-exchange technique we have described above. Exchange of surface $\mathrm{OH}$ with deuterium produces an isotopic shift in the IR spectra of the $\mathrm{OH}$ region, placing the new bands in a more sensitive IR region. Adsorption of piperidine on the exchanged catalysts leads to a perturbation of the spectra in a manner that is characteristic of the interaction of cyclic saturated amine with surface $\mathrm{OH}$. 
Report DOE/PC/89771-13

\section{EXPERIMENTAL}

\section{Synthesis of Supports and Supported Molybdena}

Pure silica and gamma-alumina were synthesized as described before. The supports were characterized by BET surface area, ammonia chemisorption and TPD, and IR of adsorbed pyridine.

Supported molybdena ( $8 \mathrm{wt} \%$ ) was prepared by incipient impregnation method from ammonium heptamolybdate, and was dried and calcined according to the technique described previously. The oxidic catalysts were prereduced in $50 \mathrm{ml} / \mathrm{min} \mathrm{H}_{2}$ at $400^{\circ} \mathrm{C}$ for 4 hours in a fixed-bed microreactor. Subsequently the powder was lightly compressed into a $13 \mathrm{~mm}$ pellet and rereduced in situ in the DRIFT cell, by flowing $\mathrm{H}_{2}$ at $400^{\circ} \mathrm{C}$ for 1 hour.

\section{Deuterium Exchange}

The exchange was effected with $D_{2}$ inside the DRIFTS cell equipped with environmental chamber and described above. A catalyst pellet was made with $100 \mathrm{mg}$ of powder compressed at about 200-500 psig for about $5 \mathrm{~min}$. No additive was used in these pellets. The pellet was rereduced and then evacuated at $400^{\circ} \mathrm{C}$ during 1 hour $\left(10^{-5} \mathrm{Torr}\right)$ to remove gas phase hydrogen.

For the exchange using $\mathrm{D}_{2}, 2 \mathrm{~atm}$ of gas was kept in the cell maintained at $400^{\circ} \mathrm{C}$ during 1 hour. The temperature was reduced to $150^{\circ} \mathrm{C}$ under pressure, followed by evacuation at $150^{\circ} \mathrm{C}$ during 1 hour. DRIFT spectra were recorded under $\mathrm{H}_{2}$ and $\mathrm{D}_{2}$ atmostpheres and under vacuum at 150 and $400^{\circ} \mathrm{C}$.

\section{Piperidine Adsorption and Desorption}

Piperidine was purified by distillation and was kept dry on a bed of molecular sieves and $\mathrm{KOH}$. A 0.5 microl pulse of piperidine was injected over the catalyst held under vacuum at $150^{\circ} \mathrm{C}$. Infrared peaks of the adsorbed species appeared immediately. After 30-60 min under vacuum at $150^{\circ} \mathrm{C}$ the spectrum was recorded. Then the temperature was raised quickly to $400^{\circ} \mathrm{C}$, and kept for 
Report DOE/PC/89771-13

$1 \mathrm{~h}$ before recording another spectrum. In some experiments (see figures) $\mathrm{H}_{2}$ was then flown over the catalyst at $400^{\circ} \mathrm{C}$.

\section{RESULTS AND DISCUSSION}

Fig. 1 shows the result of piperidine adsorption and desorption on pure silica support. The bands observed were previously assigned following Baumgarten et al. [1]: the band at $3744 \mathrm{~cm}^{-1}$ belongs to the terminal isolated silanol groups $\mathrm{Si}-\mathrm{OH}$ and the broad band between 3700 and 3300 $\mathrm{cm}^{-1}$ belongs to the $\mathrm{H}$-bonded silanols on the silica surface. After exchange, new bands at 2757 $\mathrm{cm}^{-1}$ and $2720-2400 \mathrm{~cm}^{-1}$ appear, and they correspond to the isolated and deuterium-bonded OD groups, respectively (Fig. 2).

The silanol groups remain unperturbed during $\mathrm{H}_{2}$ treatment at $400^{\circ} \mathrm{C}, 150^{\circ} \mathrm{C}$ and under vacuum at $150^{\circ} \mathrm{C}$, as seen in Fig. 1. Upon injection, and after removal of gas phase piperidine, new bands corresponding to adsorbed species appear. The observed bands are in agreement with previous experiments of Hirokawa et al. [2], who made most of the assignments given in Table 1.

\section{Table 1}

Adsorbed Piperidine

\begin{tabular}{lll} 
W-number (cm-1) & Assignment & Ref. \\
\hline $2430(w)$ & $\mathrm{N}-\mathrm{D}$ str. & 12 \\
$2760(\mathrm{w}) *$ & $\mathrm{OH}$-piperidine & 13 \\
$2864(\mathrm{~m})$ & $\mathrm{CH}_{2}$ asym. str. & 12 \\
$2944(\mathrm{~s})$ & $\mathrm{CH}_{2}$ sym. str. & 12 \\
$3290(\mathrm{w})$ & $\mathrm{N}-\mathrm{H}$ str. & 12
\end{tabular}

Our spectra (Fig. 1) show the presence of the 3290, 2944, 2864 and $2760 \mathrm{~cm}^{-1}$ bands. The $2760 \mathrm{~cm}^{-1}$ band is really originating from the $3740 \mathrm{~cm}^{-1}$ band after a frequency shift of 980 $\mathrm{cm}-1$ that occurs upon interaction of piperidine with $\mathrm{OH}$ on silica, according to Pukshtis et al. [3]. Observe that the intensity of the $3744 \mathrm{~cm}^{-1}$ band suffered a reduction after adsorption of piperidine, as a result of the interaction of $\mathrm{OH}$ with the amine. Also observe that a temperature increase to $400^{\circ} \mathrm{C}$ produces the complete desorption of piperidine and the regain of intensity of the $3744 \mathrm{~cm}-1$ band. A feasible conclusion at this point is that the interaction of the adsorbed piperidine with silanols on silica is weak, as expected from the basicity of such silanols.

Fig. 2 includes the exchange of some of the isolated silanols with deuterium, and the adsorption of piperidine on the deuterated surface. It must be observed that deuterium exchange occurs mainly with the isolated silanols and not the $\mathrm{H}$-bonded ones, and that piperidine interacts mainly with the exchangeable groups, and not with the unexchanged ones. This latter observation 
is derived from the relatively large reduction in intensity suffered by the $2757 \mathrm{~cm}^{-1}$ band, in comparison to the $3744 \mathrm{~cm}^{-1}$ band. After desorption of piperidine at $400^{\circ} \mathrm{C}$, both $\mathrm{OH}$ and OD isolated groups are restored. Thus, the extent of exchange of $D$ with piperidine seems to be limited by the weak interaction with the support.

Similar experiments were performed with supported molybdena. Figs. 3-4 shows the 8 wt \% molybdena results. As pointed out before molybdena loading on silica causes the loss of isolated $\mathrm{OH}$ groups from the support, without regeneration of new $\mathrm{OH}$ groups related to the molybdena phases, as seen by comparing Figs. 1 and 3 . The remaining silanol band $(3744 \mathrm{~cm}-1)$ is reduced further upon adsorption of piperidine (fourth spectrum in Fig. 3 and fifth in Fig. 4).

On supported molybdena catalyst, and in contrast to pure silica support, increase of temperature to $400^{\circ} \mathrm{C}$ is not enough to provoke the complete desorption of piperidine and the restoration of the $3744 \mathrm{~cm}^{-1}$ band. After flowing $\mathrm{H}_{2}$ at $150^{\circ} \mathrm{C}$ most or all of the $3744 \mathrm{~cm}-1$ band is restored, although some piperidine still remains adsorbed. Only after flowing $\mathrm{H}_{2}$ at $400^{\circ} \mathrm{C}$ is the compete desorption possible. The immediate conclusions from this experiment are that piperidine now interacts with both $\mathrm{OH}$ groups from the support and with the molybdena phases. The molybdena interaction is probably through coordinated unsaturated sites (cus) since no new $\mathrm{OH}$ are formed on molybdena. Both adsorbed species (OH..piperidine) and (cus..piperidine) are stronger than the original $\mathrm{OH}$..piperidine interaction on pure silica support.

An observation that is more clearly seen with the deuterated surface (Fig. 4) is that desorption of piperidine under vacuum, with no $\mathrm{H}_{2}$ flowing, is accompanied by the lack of substantial regeneration of OD (last spectrum, Fig. 4). It does appear that the piperidine that remains adsorbed (i.e. the strongly adsorbed piperidine) is interacting with both OD and cus, i.e. forming a OD..piperidine..cus species, which can only be desorbed by hydrogenolysis at $400^{\circ} \mathrm{C}$. Another explanation to the lack of OD $2757 \mathrm{~cm}^{-1}$ restoration after partial desorption of piperidine is that molybdena induces enough lability (acidity) on the $D$ of OD that $D$ is able to exchange with piperidine $\mathrm{H}$ and leave the surface together with piperidine. This point will be clarified a posteriori with mass spectrometry of the desorbed species.

Similar experiments were run with alumina support (Fig. 5), reduced molybdena on alumina (Fig. 6) and deuterated reduced molybdena on alumina (Fig. 7). The broadness of the bands observed for these materials is due to the existence of several types of surface hydroxyl groups on alumina, as shown by Knozinger and Ratnasamy [6] and others [4-5]. Isolated OH bands lie in the region of about 3700 to $3800 \mathrm{~cm}^{-1}$, whi'e the H-bonded bands lie between 3200 to $3600 \mathrm{~cm}^{-1}$. Corresponding bands appear in the $2600-2,300 \mathrm{~cm}^{-1}$ region upon deuterium exchange (Fig. 5), and typical $\mathrm{CH}_{2}$ stretching bands in the $2800-3000 \mathrm{~cm}^{-1}$ after adsorption of piperidine. In contrast to the silica $\mathrm{OH}$, the alumina $\mathrm{OH}$ seem not to interact at all with the adsorbed piperidine. Adsorption, however, is strong, as shown by the amount of residual piperidine not desorbing at $400^{\circ} \mathrm{C}$.

When molybdena is supported on alumina (Fig. 6), as noticed before, new $\mathrm{OH}$ are generated, probably as Al-OH-Mo, i.e. interfacial, groups. Fig. 7 shows that the extent of deuteration of the new $\mathrm{OH}$ groups is better than that of the bare alumina groups (Fig. 5), because of their reduced basicity (increased $\mathrm{H}$ lability). Likewise, the adsorption of piperidine affects now the OD bands more than before. Desorption of piperidine does not recompose the CD bands to 
their original levels, meaning that as in the case of silica-supported molybdena, $D$ has probably exchanged or reacted with the desorbing piperidine. Also as in the case of silica-supported molybdena, the strongly chemisorbed remaining piperidine may be the one interacting with the OD groups.

\section{CONCLUSIONS}

The adsorption of piperidine on silica, alumina and supported molybdena occurs on various types of sites. It is apparent that the high basicity of $\mathrm{OH}$ groups on alumina prevents their interaction with the strongly basic piperidine, even though adsorption on alumina is strong. Thus the most probable sites of adsorption on alumina are the Lewis acid sites ( $\mathrm{Al} \mathrm{cus).} \mathrm{The} \mathrm{lack} \mathrm{of}$ interaction of piperidine with $O H$ (OD) groups leads to little exchange of surface D with piperidine $\mathrm{H}$. As molybdena is supported on alumina, new, more acidic $\mathrm{OH}(\mathrm{OD})$ groups are generated which now are able to interact and exchange $D$ with piperidine. Thus piperidine seems to be adsorbed on $\mathrm{Mo}$ cus, $\mathrm{Al}$ cus and near $\mathrm{Al}-\mathrm{OH}-\mathrm{Mo}$ interfacial sites. The aliphatic ring vibrations, however, are not affected by the difference in adscrption modes. Differences of this type have not been reported in the literature.

Silica adsorbs piperidine weakly and the basic OH (OD) groups do not interact strongly with piperidine. On the other hand, when molybdena is adsorbed on silica, the acidity of the same silanols is greatly increased, so that interaction and exchange with piperidine now occurs. Piperidine seems to be adsorbed on Mo cus, which are also responsible for the higher acidity (and $\mathrm{H}$ lability ) of Si-OH-Mo groups.

\section{REFERENCES}

1. E. Baumgarten, C. Lentes-Wagner, R. Wagner, J. Molec. Catal. 50, 153-65 (1989)

2. T. Hirokawa, T. Kimura, K. Ohno, H. Murata, Spectrochimica Acta, 36A, 329-32 (1980)

3. E.A. Paukshtis, E.N. Yurchenko, Russ. Chemical Rev., 52, 242-58 (1983)

4. J.L. Carter, P.J. Lucchesi, P. Corneil, D.J.C. Yates, J.H. Sinfelt, J. Phys. Chem. 69, 3070-4 (1965)

5. Y. Amenomiya, J. Catal. 22, 109-22 (1971)

6. H. Knozinger, P. Ratnasamy, Catal. Rev. Sci. Eng. 17, 31 (1978) 


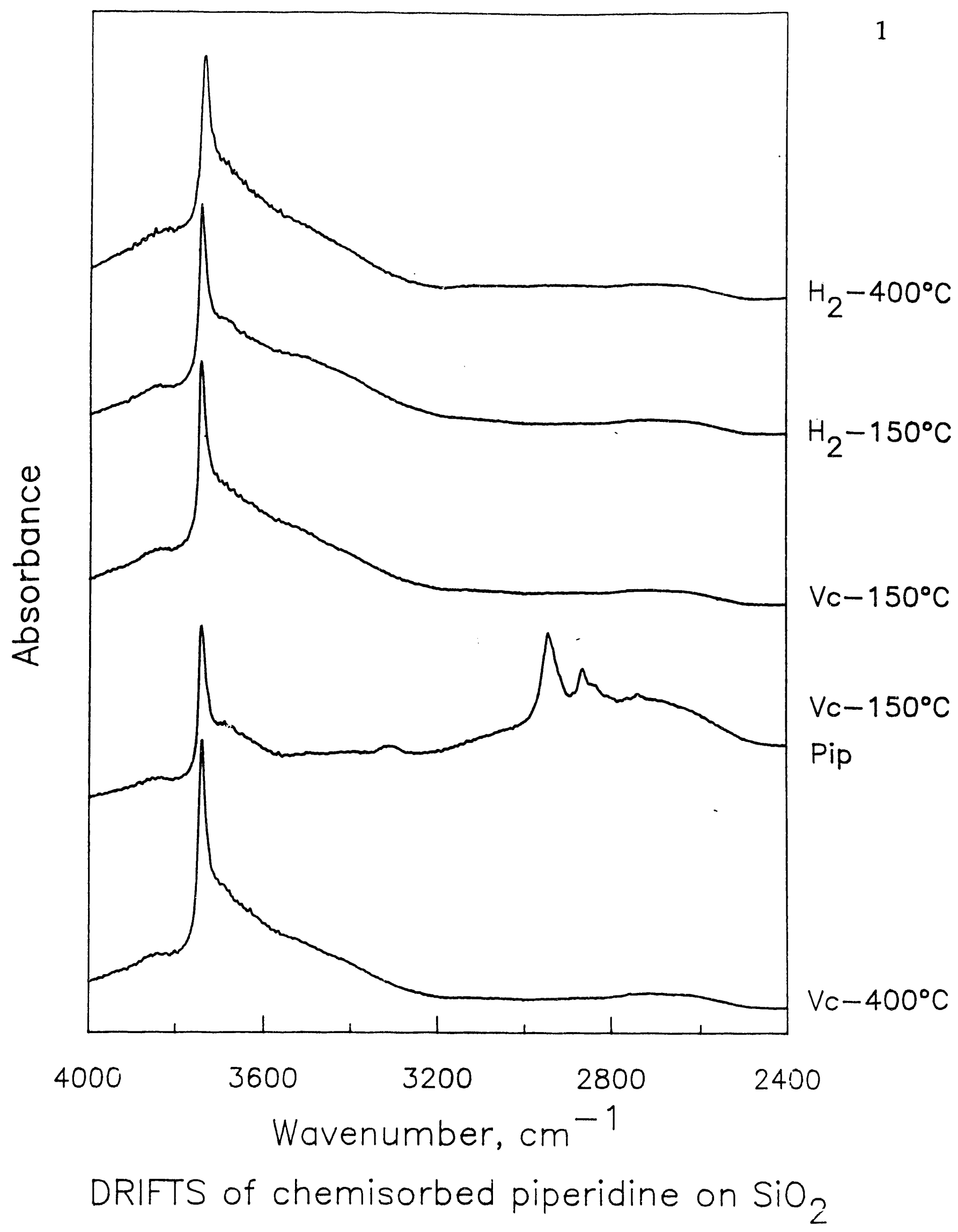




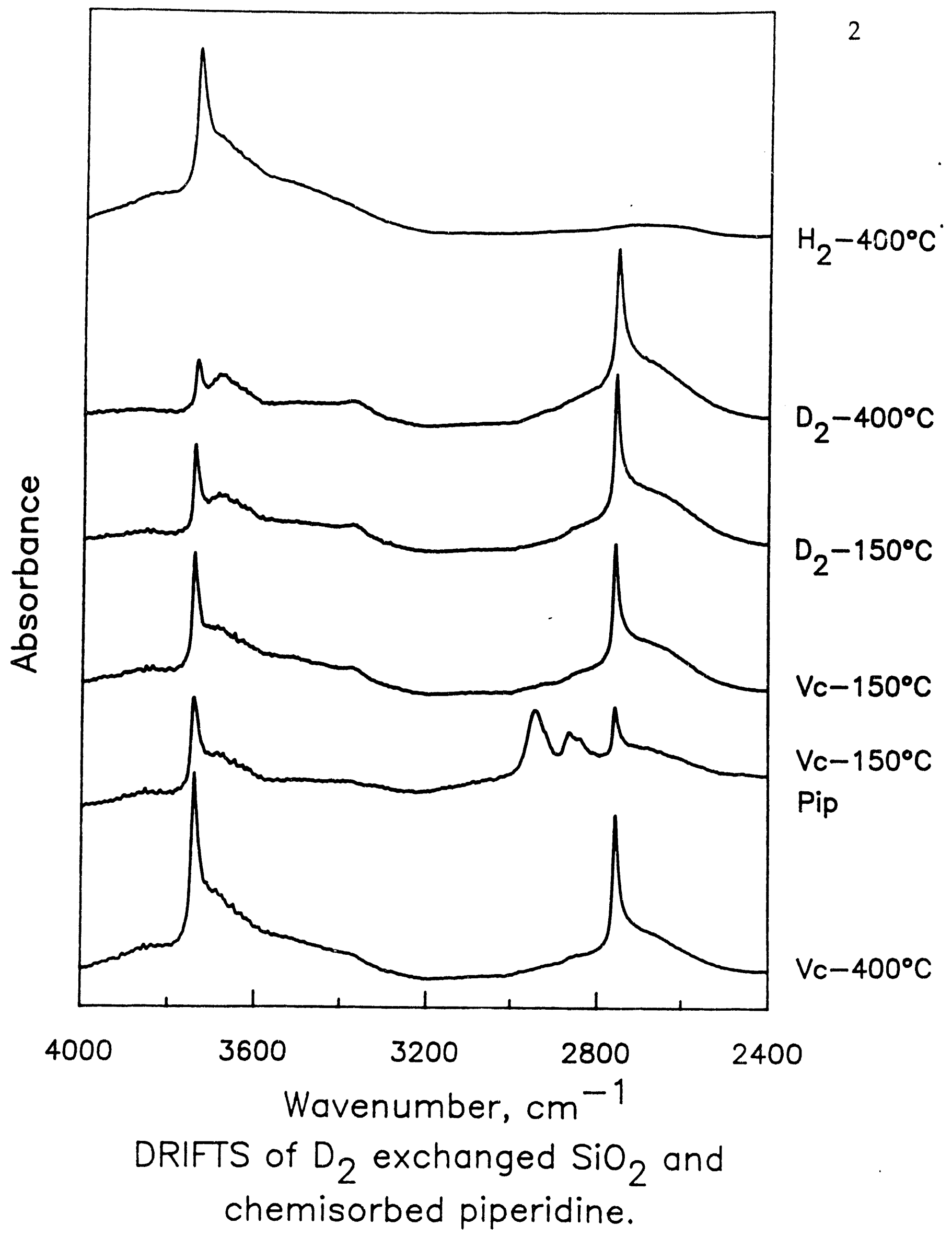




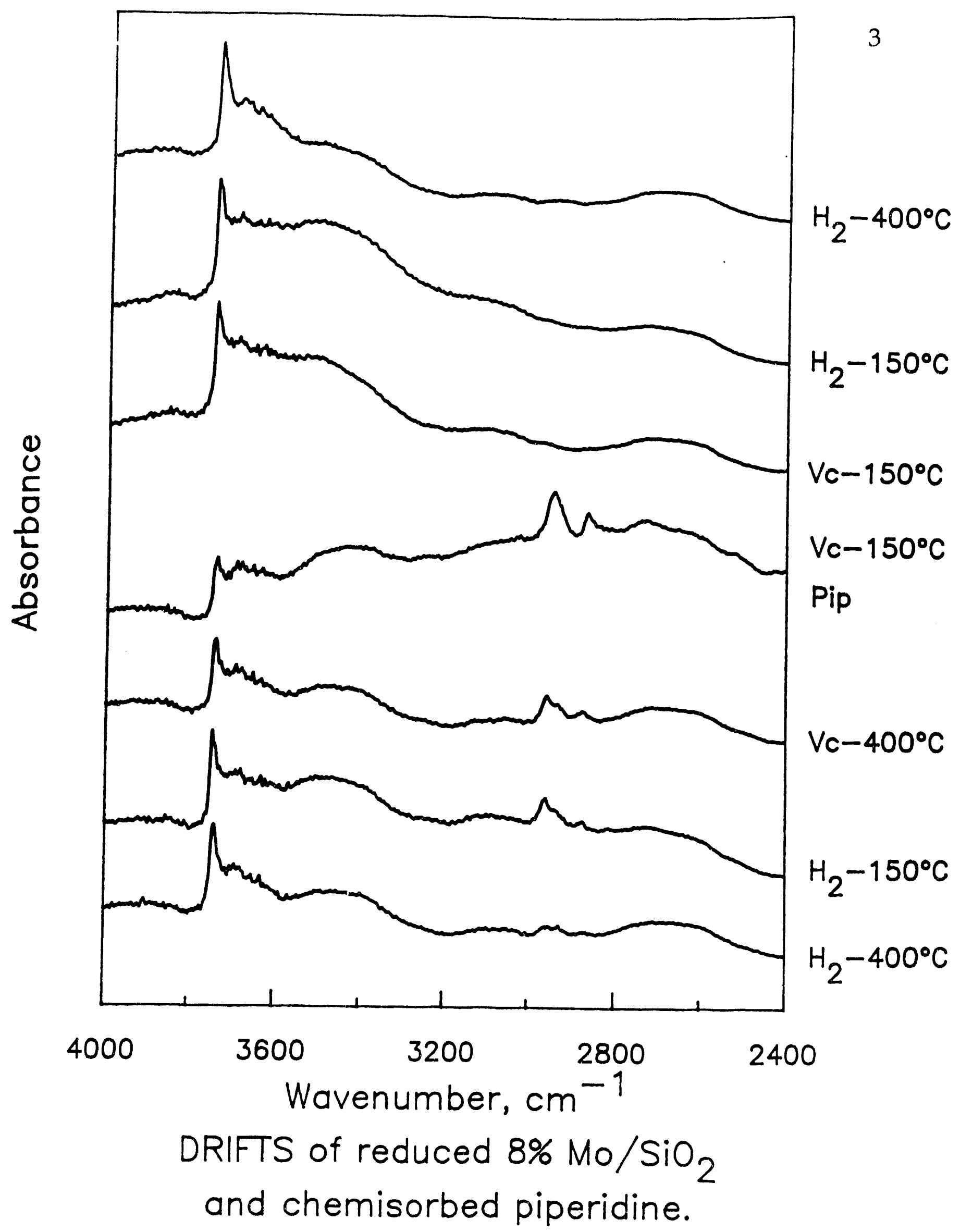




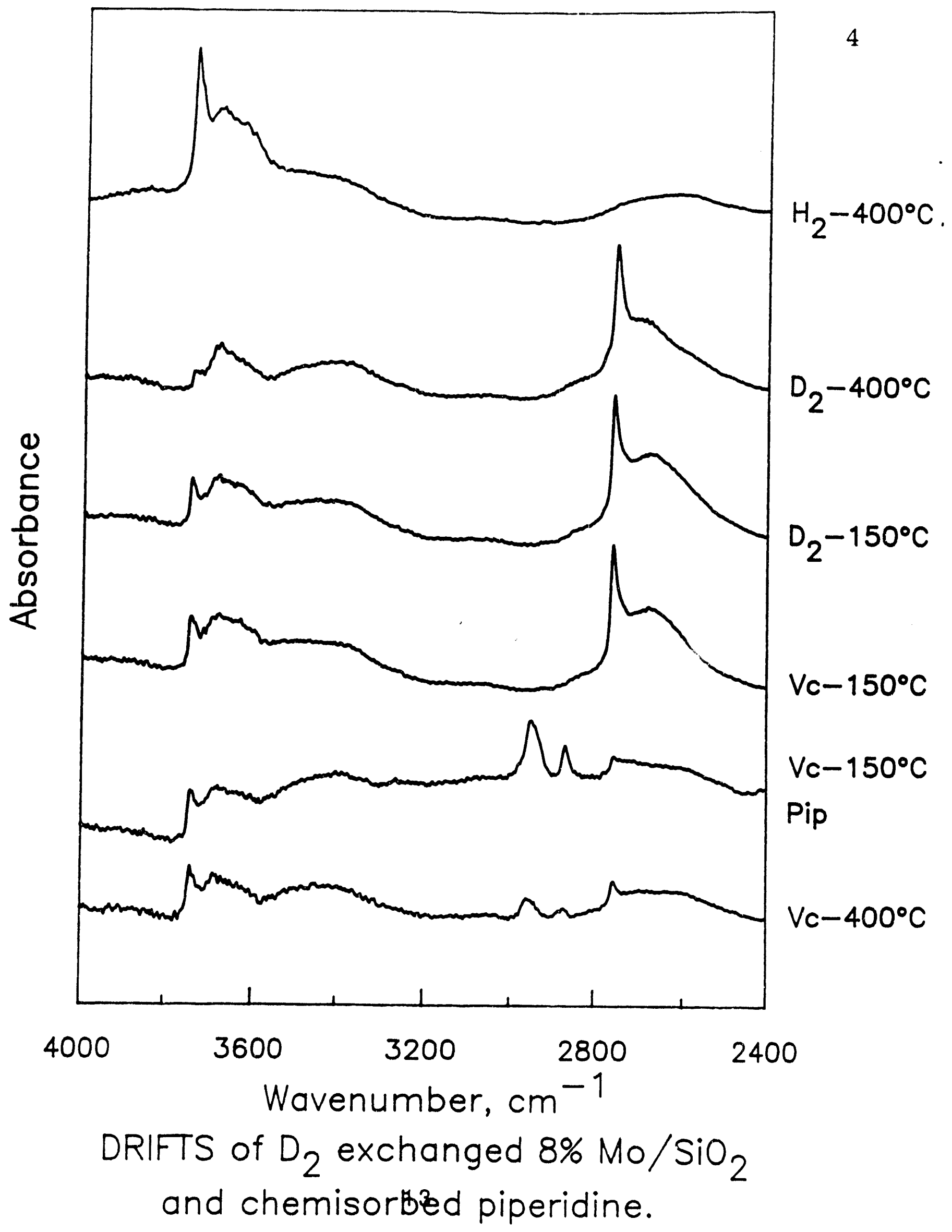




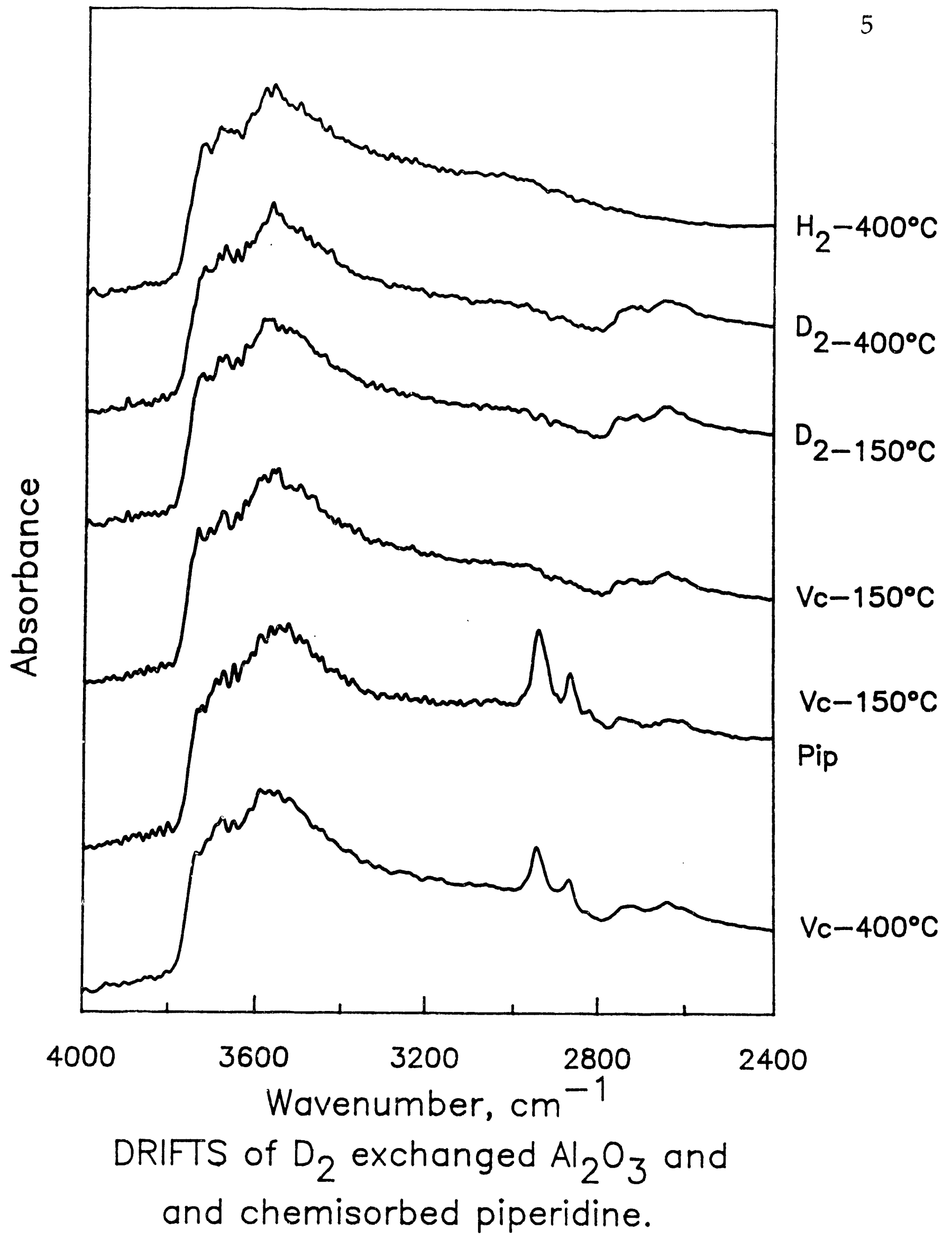




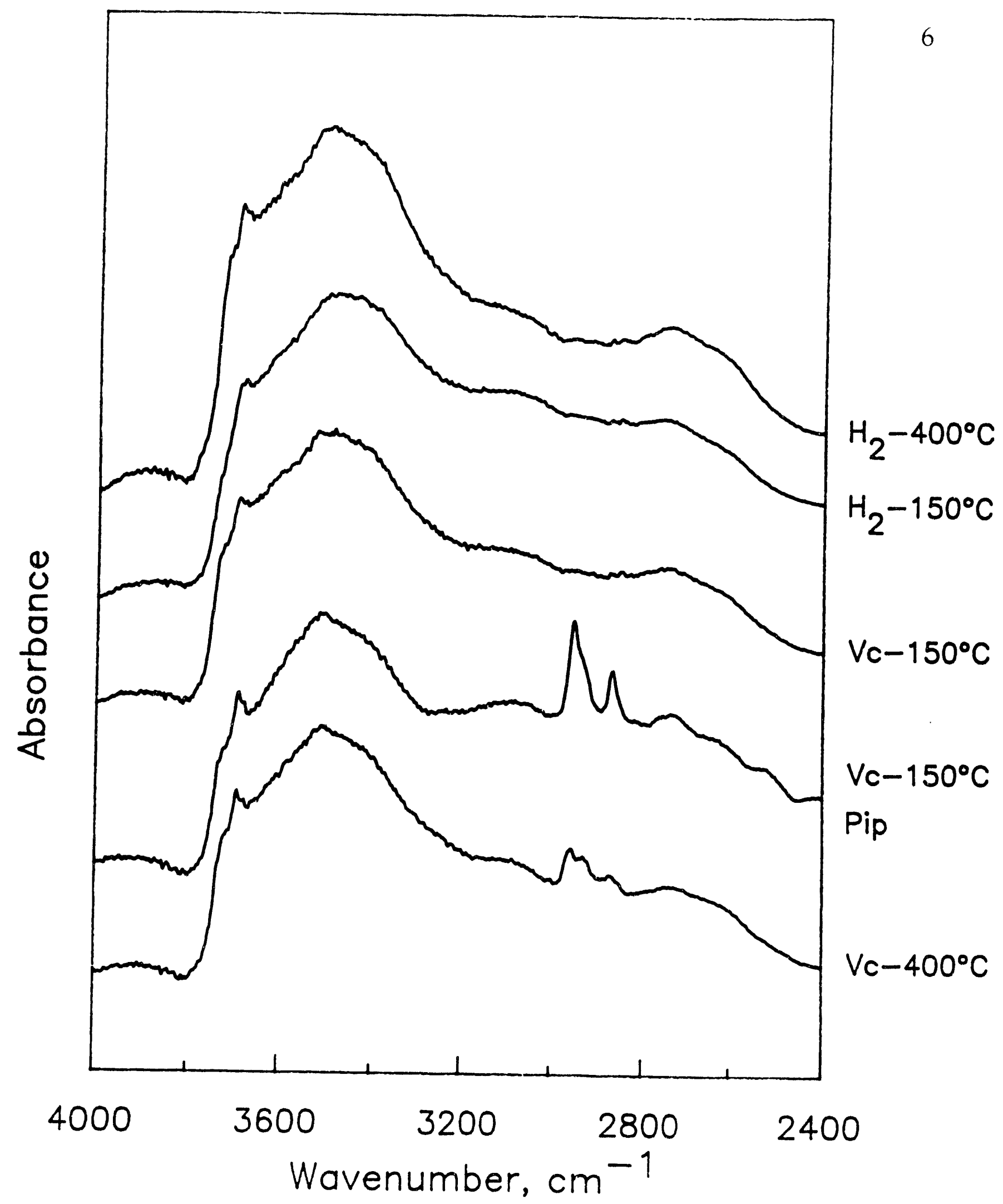

DRIFTS of reduced $8 \% \mathrm{Mo} / \mathrm{Al}_{2} \mathrm{O}_{3}$ and chemisorbed piperidine 


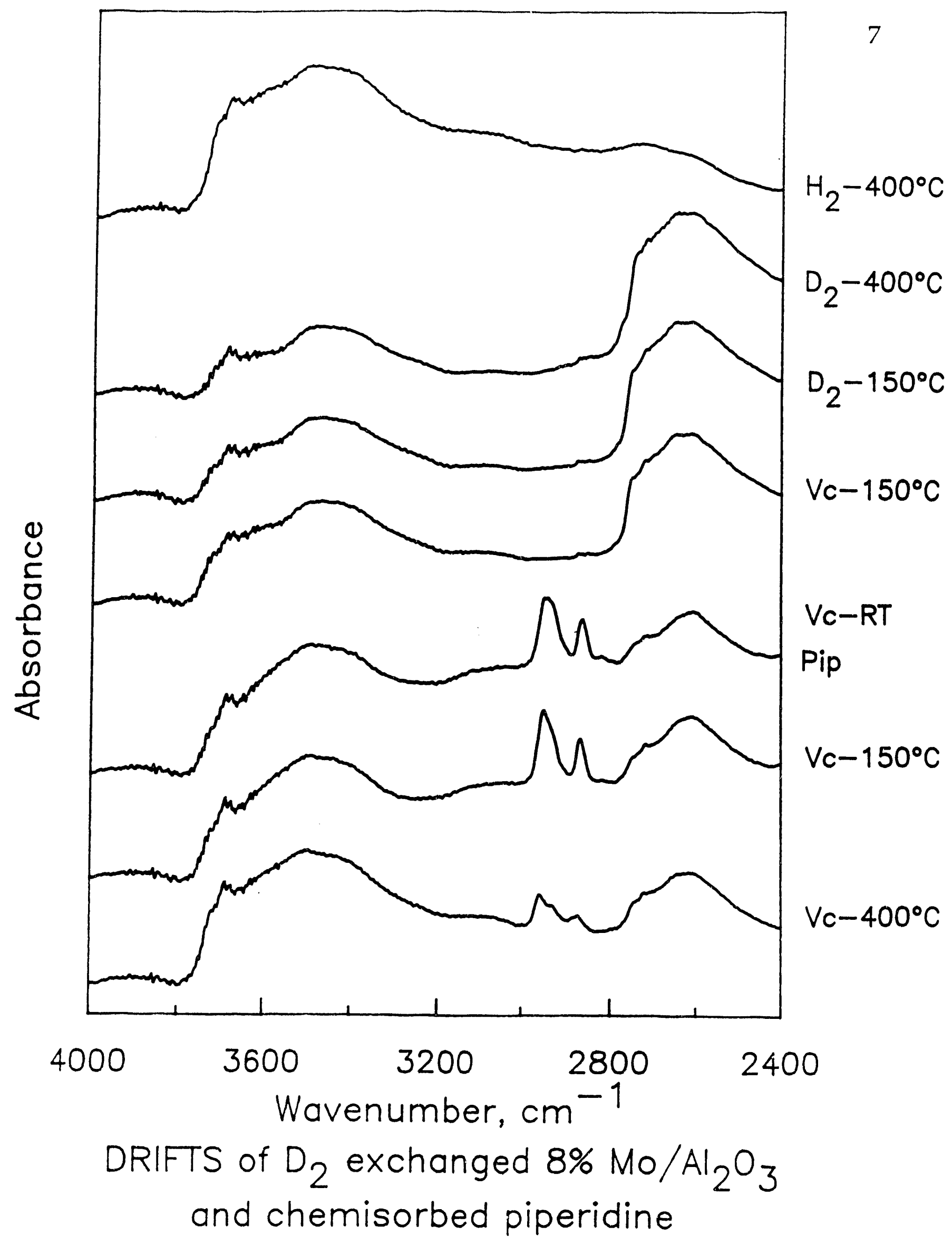


Report DOE/PC/89771-13

\title{
Part 11: BETA-HYDROGEN ELIMINATION
}

\begin{abstract}
Adsorption and thermal desorption of piperidine from catalysts exchanged with deuterium were studied by diffuse reflectance infrared spectroscopy of adsorbed piperidine and mass spectrometry of the desorption product. Thus the nature of the interaction between the adsorbed piperidine and the surface $\mathrm{OH}$ was elucidated. It was possible to conclude that piperidine exchanges only the beta$\mathrm{H}$ of its molecule with surface $\mathrm{OD}$. The lability of such hydrogen and its degree of interaction with surface sites are strong evidence that on acidic catalysts piperidine may undergo Hofmann elimination during the hydrodenitrogenation reaction.
\end{abstract}

\section{INTRODUCTION}

In retrospective three general types of mechanisms of HDN have survived the pass of time: a so called hydrogenolysis mechanism, a beta-elimination mechanism and a nucleophilic ring opening mechanism (Fig. 1). In the hydrogenolysis mechanism the saturated cyclic amine becomes a bidentate ligand of a coordinatively unsaturated metal site (cus). The metal has to expand its coordination sphere to accept the nitrogen lone pair and the alpha-carbon sp-electron. The strain in the cycle is removed by ring opening at the alpha-carbon. Gas phase hydrogen is probably dissociated in another metalic site before it provokes the desorption of the linear amine by hydrogenolytic addition. The elimination mechanism does not require the addition of hydrogen or of hydrogen dissociation sites. However, it requires the presence of a strong Bronsted acid site to provide proton addition to and quaternization of $\mathbf{N}$. Following Hofmann elimination rules, the alfa carbon-nitrogen bond weakens and a beta carbon loses a proton, so that the ring opens and alfabeta carbons become pi-bonded. The presence of a Lewis base promotes the elimination of the beta hydrogen, and thus further weakening of $\mathrm{N}$-alfa carbon bond, and the formation of the pi bond between alfa and beta carbons. The elimination described is of E2 or electrophilic type, requiring the presence of a Lewis base next to the adsorbed piperidinium ion. On the other hand, after $\mathrm{N}$ quaternization a nucleophilic attack may occur on the alfa carbon, provoking ring opening. This mechanism has been postulated to explain the enhanced denitrogenation activity displayed by Mo oxide catalysts in the presence of $\mathrm{H}_{2} \mathrm{~S}$ added to the feed.

In this section we describe the how piperidine interacts with deuterated Mo catalysts. The surface of acidic and non-acidic catalysts was deuterated to exchange surface $\mathrm{OH}$ with $\mathrm{D}$, piperidine was pulsed over the deuterated catalysts, and evidence of deuterium exchange or addition was sought in the products of desorption. 
Report DOE/PC/89771-13

\section{EXPERIMENTAL}

\section{Synthesis of Supports and Supported Molybdena}

Silica-aluminas, pure silica and gamma-alumina were synthesized as already described. Supported molybdena was prepared by incipient impregnation. Several loadings were generated of which only the $8 \mathrm{wt} \%$ molybdena will be discussed in this section. The oxidic catalysts were prereduced in $50 \mathrm{ml} / \mathrm{min} \mathrm{H}_{2}$ at $400^{\circ} \mathrm{C}$ for 4 hours in a fixed-bed microreactor. Subsequently the powder was lightly compressed into a $13 \mathrm{~mm}$ pellet and rereduced in situ in the DRIFT cell, by flowing $\mathrm{H} 2$ at $400^{\circ} \mathrm{C}$ for 1 hour.

\section{Deuterium Exchange}

The exchange was effected with $D_{2}$ inside the DRIFTS cell equipped with environmental chamber. A catalyst pellet was made and reduced as already specified. Finally, the sample was evacuated at $400^{\circ} \mathrm{C}$ during 1 hour (10-5 Torr) to remove gas phase hydrogen.

For the exchange using $\mathrm{D}_{2}, 2 \mathrm{~atm}$ of gas was kept in the cell maintained at $400^{\circ} \mathrm{C}$ during 1 hour. The temperature was reduced to $150^{\circ} \mathrm{C}$ under pressure, followed by evacuation at $150^{\circ} \mathrm{C}$ during 1 hour. DRIFT spectra were recorded under $\mathrm{H}_{2}$ and $\mathrm{D}_{2}$ atmostpheres and under vacuum at 150 and $400^{\circ} \mathrm{C}$.

\section{Piperidine Adsorption and Desorption}

Piperidine was purified by distillation and was kept dry on a bed of molecular sieves and $\mathrm{KOH}$. A 0.5 microl pulse of piperidine was injected over the catalyst held under vacuum at $150^{\circ} \mathrm{C}$. Infrared peaks of the adsorbed species appeared immediately. After 30-60 min under vacuum at $150^{\circ} \mathrm{C}$ the spectrum was recorded. Then the temperature was raised quickly to $400^{\circ} \mathrm{C}$, and kept for $1 \mathrm{~h}$ before recording another IR spectrum.

\section{Mass Spectrometry of Desorption Products}

The desorption products were sampled just above the catalyst pellet held inside the DRIFT cell, by means of a quartz capillary column that was directly connected to a mass spectrometer. The UTI $100 \mathrm{C}$ quadrupole mass spec was operated typically at a pressure of $10^{-7}$ Torr produced by an ion pump. About $1 \mathrm{ml} / \mathrm{min}$ of gas was sampled from the DRIFT cell which was maintained at about $10^{-3}$ Torr by a turbomolecular pump. The capillary tube fed the gas directly into the electron ionization chamber of the mass spectrometer. The electron ionization potential was kept at $70 \mathrm{eV}$. Continuous scanning of $\mathrm{m} / \mathrm{z}$ between 1 and 100 was performed at a rate of about $2 \mathrm{~m} / \mathrm{z}$ per second. Faster scanning rates were unnecessary because the desorption dynamics was very slow. In addition, this slow scanning allowed high sensitivity. The background was kept low by continuous baking of all the vacuum chamber at a temperature of $100^{\circ} \mathrm{C}$. 
Report DOE/PC/89771-13

\section{RESULTS AND DISCUSSION}

Fig. 2 gives the DRIFT spectra of $8 \mathrm{wt} \%$ molybdena supported on $75 \%$ silica-alumina and treated as indicated in the figure. The observed bands match those previously described [1]. The band at $3744 \mathrm{~cm}^{-1}$ belongs to the isolated silanol groups $\mathrm{Si}-\mathrm{OH}$ while the broad band between 3700 and $3300 \mathrm{~cm}^{-1}$ belongs to the H-bonded silanols. After exchange (Fig. 3), new bands at $2757 \mathrm{~cm}^{-1}$ and $2720-2400 \mathrm{~cm}^{-1}$ appear, and they correspond to the isolated and deuterium-bonded OD groups, respectively. The group of bands between 3600 and $3700 \mathrm{~cm}^{-1}$ are enhanced by the $\mathrm{OH}$ groups present on alumina. The broadness of the bands in these catalysts is due to the existence of several types of surface hydroxyl groups on the silica-alumina [2-4]. The bands between 3300 and $3600 \mathrm{~cm}^{-1}$ are themselves greatly enhanced by the appearance of new hydroxyl groups associated to molybdena, and probably present at the interface between support and molybdena. After the hydrogen and vacuum treatments indicated in Fig. 2, a pulse of piperidine provokes the appearance of the typical adsorbate bands at 2864 and $2944 \mathrm{~cm}^{-1}$ which belong to $\mathrm{CH}_{2}$ stretching vibrations. As seen before in the case of pure silica and silica-supported molybdena, piperidine interacts with the silanols of the silica-alumina surface. The interaction is strong as observed by the residual piperidine adsorbed even after desorption at $400^{\circ} \mathrm{C}$.

The nature of the interaction is more clearly seen in Fig. 3, which describes the adsorption and desorption of piperidine from D-exchanged silica-alumina surface. The sharp Si-OD band $\left(2757 \mathrm{~cm}^{-1}\right)$ is decreased after adsorption (fifth spectrum), and so is the broad band that we have assigned to OD groups at interfacial sites $\left(2600-2700 \mathrm{~cm}^{-1}\right)$. After desorption at $400^{\circ} \mathrm{C}$ (last spectrum) a minor restoration of the 2757, 2600-2700 (OD) and $3744 \mathrm{~cm}^{-1}$ (Si-OH) bands occur, while substantial amount of piperidine remains adsorbed. As shown before only $\mathrm{H}_{2}$ flow at $400^{\circ} \mathrm{C}$ is able to completely desorb the piperidine and restore the Si-OH bands. The piperidine that desorbs at $400^{\circ} \mathrm{C}$ under vacuum is possibly carrying with it the deuterium lost from the surface. This point was investigated next by monitoring the desorption products by mass spectrometry.

Fig. 4 is the mass spectrum of gas phase piperidine obtained by electron impact ionization at $70 \mathrm{eV}$. The parent peaks are at $\mathrm{m} / \mathrm{z}: 84$ and 85 , and there are main daughter peaks at 70, 55-57 and 39-44. Such distribution is shown qualitatively in Table 1.

Fig. 5 is the mass spectrum of the species desorbing at 150 and $400^{\circ} \mathrm{C}$ under vacuum (Fig. 3) after having exchanged the catalyst with deuterium and having pulsed piperidine at $150^{\circ} \mathrm{C}$. Both desorption products at 150 and $400^{\circ} \mathrm{C}$ are identical, and their mass spectrum corresponds closely to that of piperidine (Fig. 4). Qualitative comparison of the observed peaks is given in Table 1.

The major difference, and the one that deserves comment, is the appearance of 85-86 as the parent peaks in the desorbate as opposed to 84-85 in the piperidine feed. This result can be easily interpreted as the D-exchange of a single hydrogen in piperidine. Therefore, the loss of OD band in the infrared (Fig. 3) is actually due to exchange with piperidine. 
Table 1

Main Peaks in Gas-Phase and Desorbed Piperidine

\begin{tabular}{|c|c|}
\hline Gas Phase & Desorbed \\
\hline & 29 \\
\hline 39 & $\begin{array}{l}30 \\
39\end{array}$ \\
\hline 41 & 41 \\
\hline 42 & 42 \\
\hline 43 & 43 \\
\hline 44 & 44 \\
\hline 54 & 54 \\
\hline 55 & 55 \\
\hline 56 & 56 \\
\hline 57 & 57 \\
\hline 70 & 70 \\
\hline 84 & 84 \\
\hline 85 & 85 \\
\hline & 86 \\
\hline
\end{tabular}

A question arises as to where in the molecule has the exchange occurred. Since under the conditions of the experiment nnlly a single exchange is fast, it is expected that the location of the exchange will indicate which wom in piperidine has a labile hydrogen and has also the possibility of interacting with surface $\mathrm{OH}(\mathrm{OD})$. For such reason we examined the mechanism of piperidine fragmentation by electron impact, as described by Duffield et al. [5], and shown in Fig. 6.

The possible exchange locations are four: $N$, and $\alpha, \beta, \gamma-C$. According to Fig. 6 it is possible to discriminate the location of the exchange by identifying the unique $\mathrm{m} / \mathrm{z}$ that would be observed under each possible exchange. Such unique masses and the actually observed masses are given in Table 2.

Table 2

Fragment Masses for Possible Locations of Deuterium Exchange in Piperidine

\begin{tabular}{lllll}
$\alpha-C$ & $\beta-C$ & $\gamma-C$ & $N$ & Observed \\
\hline 86 & 86 & 86 & 86 & yes \\
71 & 85 & 85 & 85 & yes \\
58 & & 71 & 71 & no \\
31 & & & 58 & no \\
45 & & & 31 & no \\
\hline
\end{tabular}


As Table 2 indicates only $\beta-C$ exchange agrees with the observed fragmentation pattern. Thus the hydrogen that is most labile in adsorbed piperidine is located at the beta position. Furthermore, this is the location that is able to interact efficiently with surface OD.

Further experiments similar to the one described for silica-alumina/supported molybdenum were performed for silica, alumina, molybdena/silica and molybdena/alumina. Only the supported molybdena on silica and silica-alumina catalysts are able to exchange deuterium into piperidine under the conditions described here. As previously discussed the supported molybdena catalysts (including the alumina-supported) chemisorb piperidine strongly and show (in the infrared) interaction between $\mathrm{OH}(\mathrm{OD})$ and adsorbed piperidine. However, only the silica-supported and silica-alumina-supported catalysts show the characteristic 3744 (2757) $\mathrm{cm}^{-1} \mathrm{OH}(\mathrm{OD})$ that is drastically depleted upon desorption of piperidine. These observations afford the conclusion that the $\mathrm{D}$-exchanging piperidine is strongly adsorbed on Mo cus that are located in proxinity to SiOD, such as the interfacial sites Si-OD-Mo.

\section{CONCLUSIONS}

Diffuse reflectance infrared spectroscopy of adsorbed piperidine and mass spectrometry of the desorption product were applied to study the nature of the interaction between the adsorbed piperidine and the surface $\mathrm{OH}$. It was possible to conclude that piperidine exchanges a single $\mathrm{H}$ of its molecule with surface $\mathrm{OD}$, and that that $\mathrm{H}$ is the beta-hydrogen. This happens only on catalysts that contain strong adsorption sites for piperidine, such as Mo cus, located in proximity to Si-OH sites, such as those present on silica and silica-alumina at the interface with molybdena. The betahydrogen exchange indicates that such hydrogen is labile and is in close contact with surface sites, thus it may be eliminated according a Hofmann elimination mechanism.

\section{REFERENCES}

1. E. Baumgarten, C. Lentes-Wagner, R. Wagner, J. Molec. Catal. 50, 153-65 (1989)

2. J.L. Carter, P.J. Lucchesi, P. Corneil, D.J.C. Yates, J.H. Sinfelt, J. Phys. Chem. 69, 3070-4 (1965)

3. Y. Amenomiya, J. Catal. 22, 109-22 (1971)

4. H. Knozinger, P. Ratnasamy, Catal. Rev. Sci. Eng. 17, 31 (1978)

5. A.M. Duffield, H. Budzikiewicz, D.H. Williams, C. Djerassi, JACS, 87, 810-816 (1965) 
Report DOE/PC/89771-13

\section{FIGURES}

Fig. 1 Classically Postulated Mechanisms of Ring Opening of Cyclic Aliphatic Amines.

Fig. 2 Diffuse reflectance $\mathbb{R}$ spectra of reduced $8 \mathrm{wt} \%$ molybdena/75\% silica-alumina. Adsorption and desorption of piperidine.

Fig. 3 Diffuse reflectance IR spectra of reduced and deuterium-exchanged $8 \mathrm{wt} \%$ molybdena $/ 75 \%$ silica-alumina. Adsorption and desorption of piperidine.

Fig. 4 Mass spectrum of pure piperidine, obtained by electron impact ionization.

Fig. 5 Mass spectrum of piperidine desorbed at two temperatures from deuteriumexchanged $8 \mathrm{wt} \%$ molybdena $/ 75 \%$ silica-alumina.

Fig. 6 Mechanism of mass fragmentatior [5]. 
Hydrogenolysis

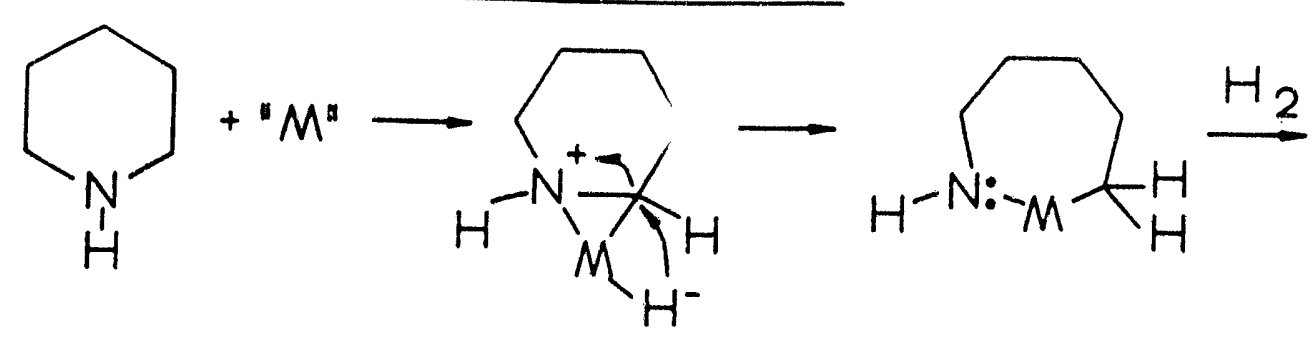

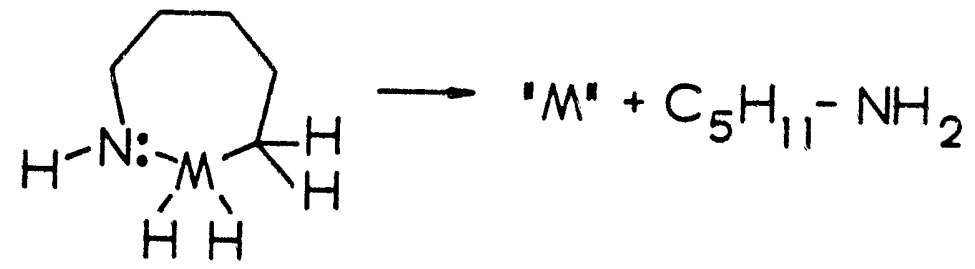

Elimination

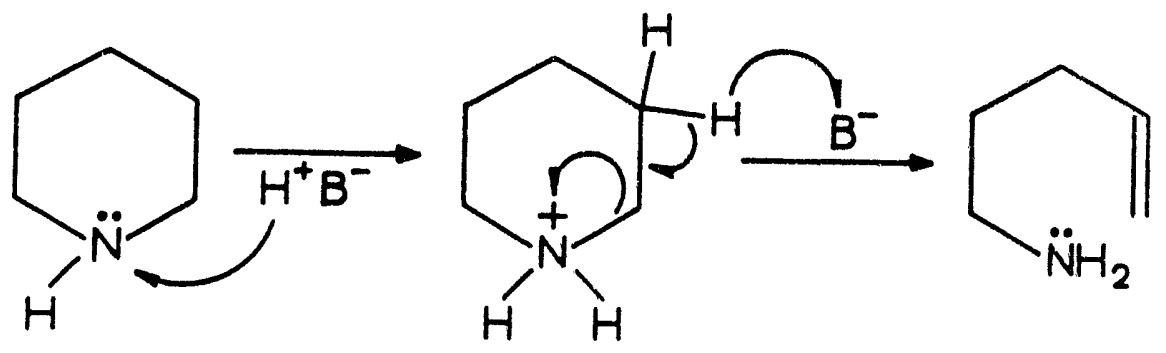

Nucleophilic ring opening

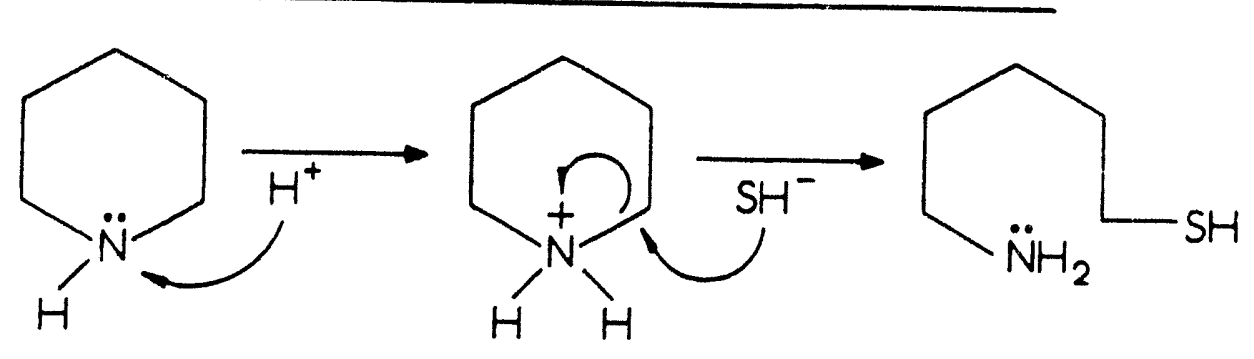




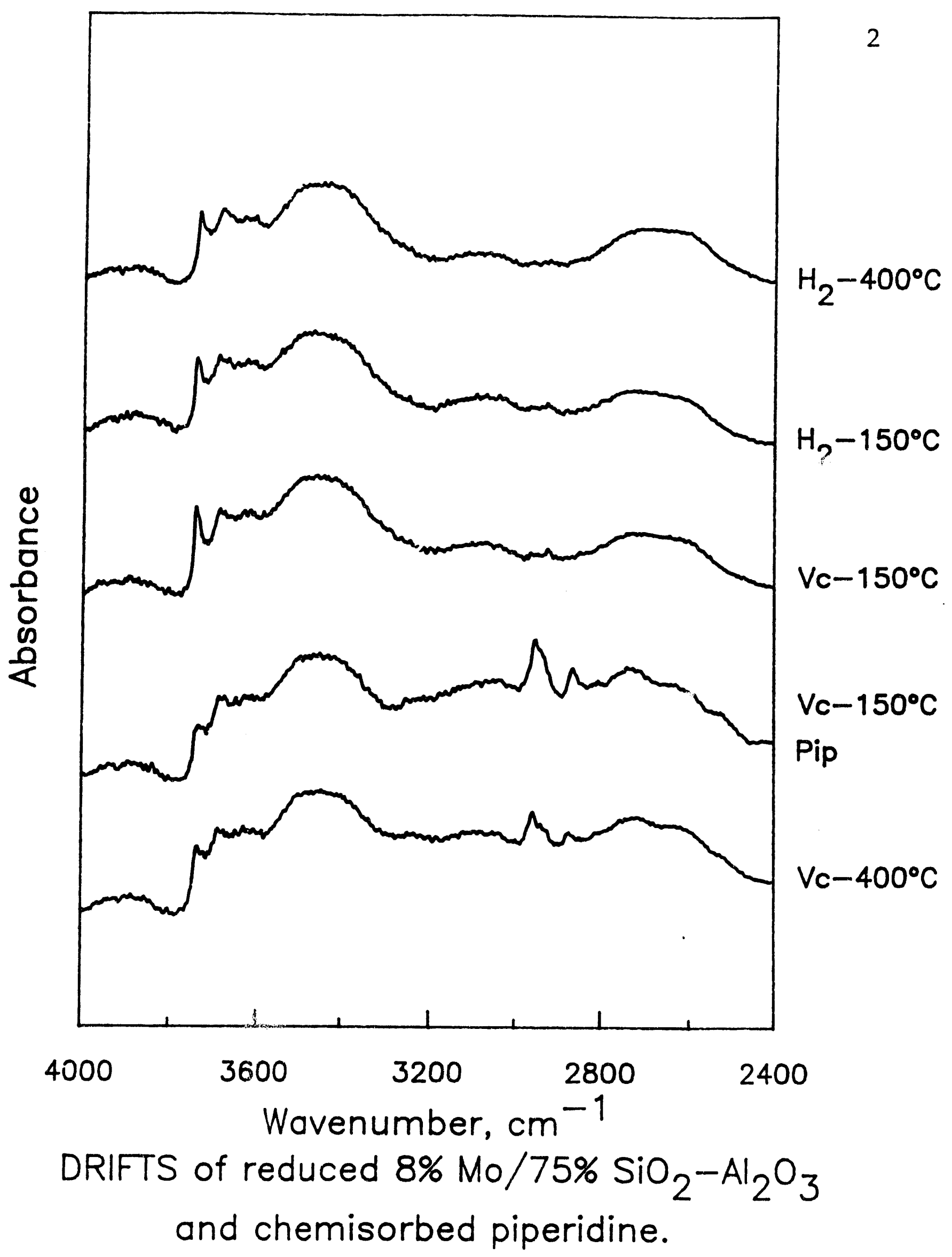




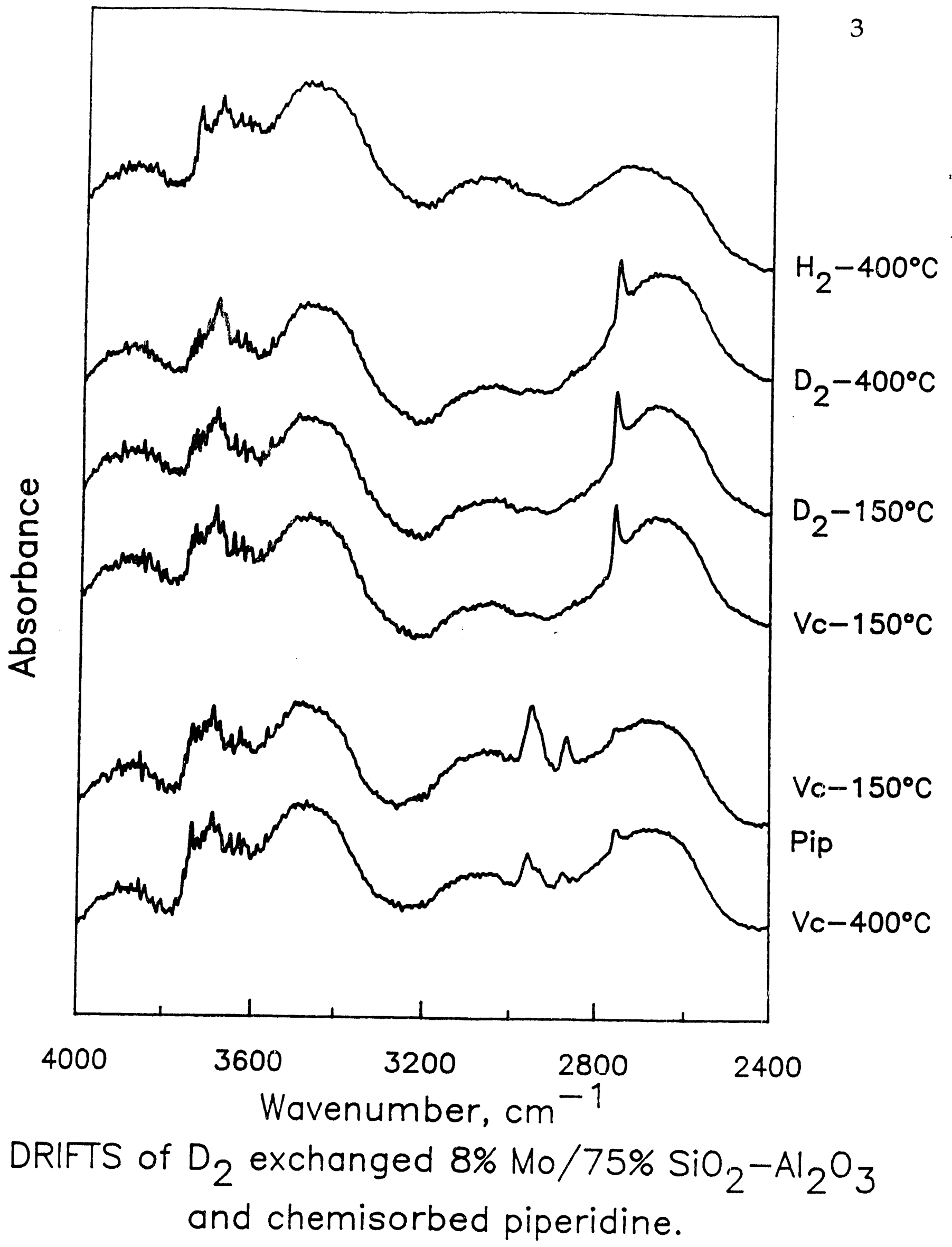




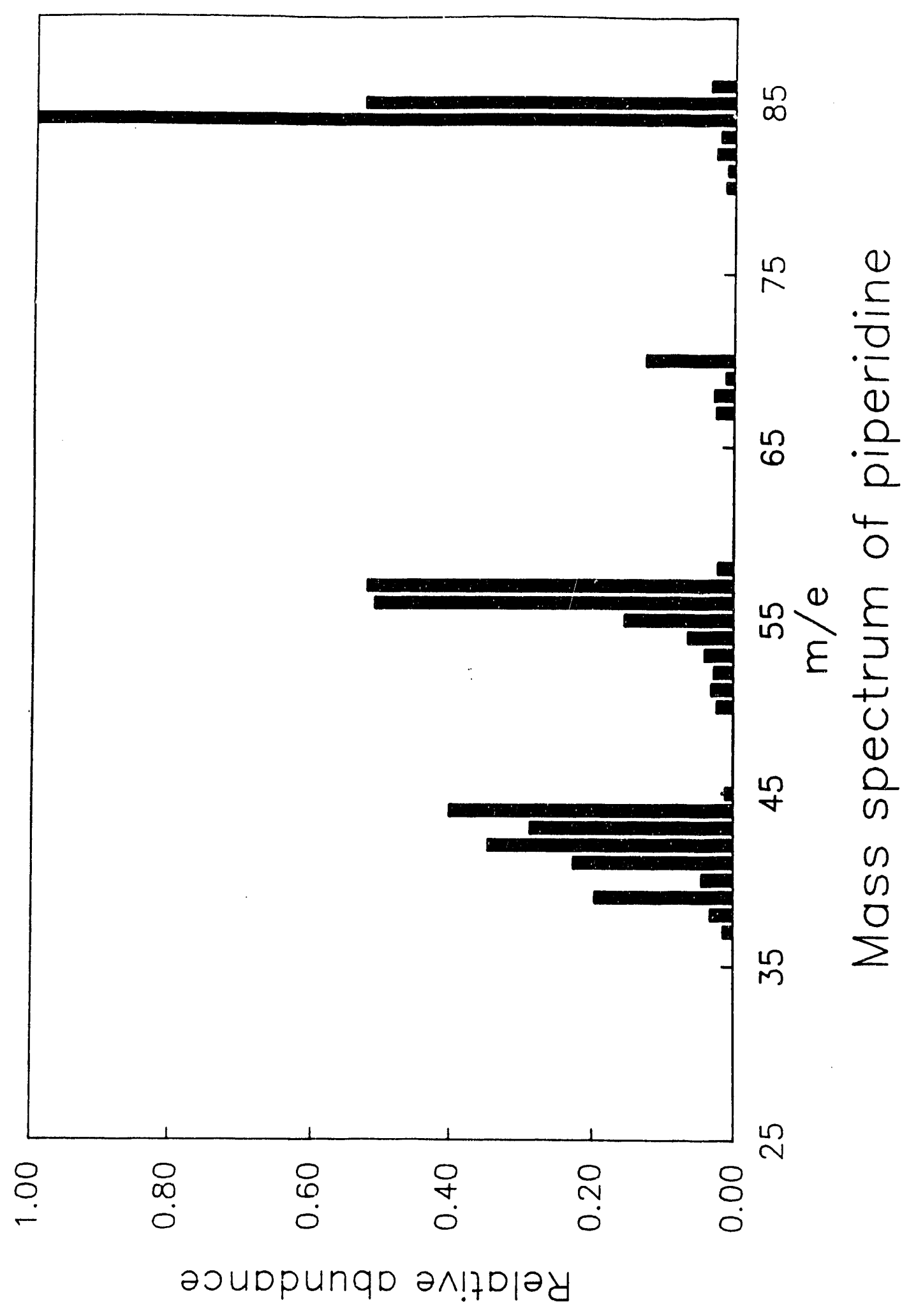




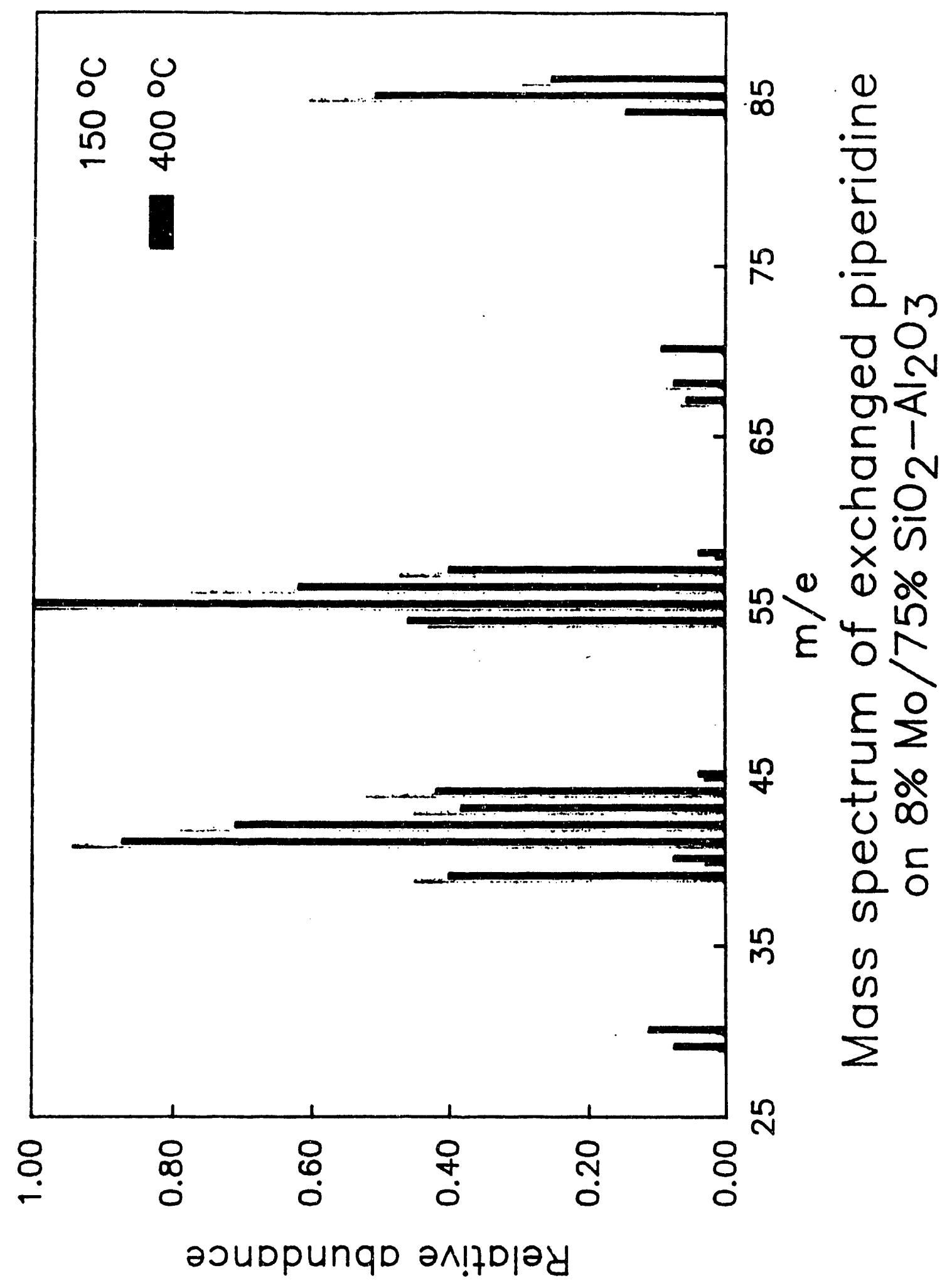




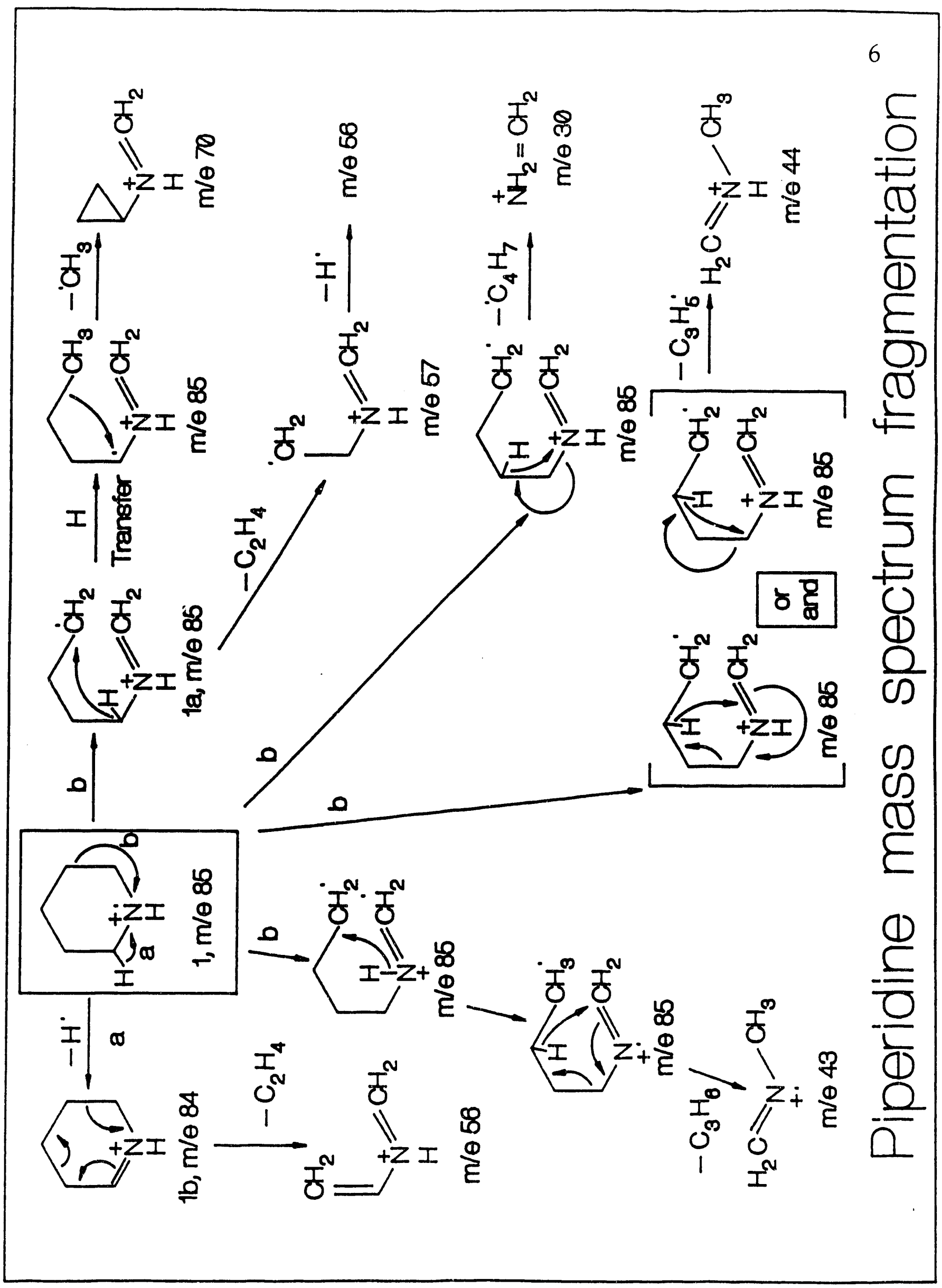


Report DOE/PC/89771-13

\title{
Part 12: PREPARATION OF SUPPORTED Ru CATALYSTS
}

\begin{abstract}
A series of Ru oxide catalysts has been prepared and partially characterized. Starting from $\mathrm{Ru}(\mathrm{NO})\left(\mathrm{NO}_{3}\right)_{3}$ to avoid residual $\mathrm{Cl}$ in the catalysts, $\mathrm{Ru}+3$ oxides have been prepared in loadings of 1,4 and $8 \mathrm{wt} \%$, over silica, gamma-alumina and silica-aluminas of controlled acidity. The highiy dispersed oxides are produced in order to study the controllability of the various types of catalytic functionalities present on HDN catalysts.
\end{abstract}

\section{INTRODUCTION}

In spite of the significance of an acidic pathway leading to pyridine and piperidine denitrogenation, it is important to emphasize that aromatic molecules must be hydrogenated to some extent before acid sites are able to quaternize the nitrogen hetero-atom and remove the piperidine beta-hydrogen. It is thus important to notice that the high hydrogenation activity that is needed necessarily leads to high hydrogenolysis activity in the case of Mo catalysts, and hence to high production of smaller alkanes.

In view of this difficulty in controlling the reaction selectivity, it becomes apparent that to balance the population of various sites (hydrogenation, hydrogenolysis and acidic sites), an additional or alternate catalyst component is needed. Such component may provide, for example, high hydrogenation but low hydrogenolysis activity, thus leading to high acidic selectivity.

Reports of the high activity of Ru sulfide catalyst for HDN make Ru a good candidate for incorporation into acidic Mo catalysts. In principle, the high hydrogenation activity of reduced Ru oxide can be conveniently exploited without extensive reduction of the Mo oxide. The reducibility of Ru oxides is known to be higher than that of Mo oxides, thus milder reduction conditions could be used to obtain less reduction of Mo and thus less hydrogenolysis activity.

Various questions : $r_{i}$ ist be answered to assess the role of $\mathrm{Ru}$ addition in the overall mechanism of HDN, such as effect of Ku on acidity, and effect of the support composition on Ru oxide structure. Therefore during this period of the project, a series of silica-alumina supports has been prepared and characterized by BET, and Ru oxide has been supported in different loadings over these supports.

\section{EXPERIMENTAL}

\section{Synthesis of Supports and Supported Ruthenium Oxide}

Fresh batches of silica-aluminas were prepared with compositions of 25,50 and $75 \mathrm{wt} \%$ silica. Separately, pure silica and gamma-alumina were also synthesized from the same precursors as the 
silica-aluminas. The supports were characterized by BET surface area, and will be characterized in subsequent work by ammonia chemisorption and TPD, and IR of adsorbed pyridine. Details of the support preparation have been given above.

Supported Ru oxide was prepared by incipient impregnation method from $\mathrm{Ru}(\mathrm{NO})\left(\mathrm{NO}_{3}\right)_{3}$, as described in reference 1 . The support pore volume was measured by water absorption. Appropriate amount of Ru salt was dissolved in acidified distilled water to produce catalysts with loadings of 1 , 4 and $8 \mathrm{wt} \%$ of $\mathrm{Ru}_{2} \mathrm{O}_{3}$. After impregnation, the solids were dried for $24 \mathrm{~h}$ at room temperature and $4 \mathrm{~h}$ in air at $383 \mathrm{~K}$. The catalysts were then loaded in the BET adsorption cell and heated to $573 \mathrm{~K}$ under vacuum to decompose the nitrates and remove $\mathrm{N}$ oxides. BET surface area was then measured following standard techniques. A total of 15 different sample compositions were produced with BET surface areas between 250 and $300 \mathrm{~m}^{2} / \mathrm{g}$, in agreement with our previous work on supported Mo.

\section{DISCUSSION}

The control of the different types of functionalities present on supported oxides allows in principle the design of catalysts with optimized selectivity. In the case of HDN catalysis we have learned that it is relevant to control the number and density of hydrogenation, hydrogenolysis and acidic scission sites. While in our recent work with Mo we were able to vary the amount and type of acid sites and the amount of reduced Mo sites, we were not able to control the hydrogenation activity without altering the hydrogenolysis activity. Both functions depend upon the state of oxidation of the Mo, which is mostly a function of support composition and Mo oxide loading. The introduction of a second, more reducible transition metal, Ru, provides us with another degree of freedom to alter the ratio of hydrogenation to hydrogenolysis activity.

It is pertinent to observe that the use of Ru sulfide in HDN has been practically demonstrated [2] after various authors showed that the volcano plot for HDS catalysis has a maximum on $\mathrm{Ru}$ sulfide. It is also pertinent to observe that the optimum HDN catalyst in that work consisted of Ru sulfide supported on Y-zeolite, a strongly Bronsted acidic support, although high temperature was required for good selectivity. At lower temperature (about $300^{\circ} \mathrm{C}$ ) the high hydrogenation and low hydrogenolysis activities which are characteristic or $\mathrm{Ru}$, were observed. Therefore, the strategy proposed in this work, that is, to control hydrogenation activity by means of Ru sites, hydrogenolysis activity by means of Mo sites, and acidic scission activity by means of Bronsted/Lewis sites, has some empirical support. Likely important is to consider the lifetime of $\mathrm{Ru}$ catalysts. It is well known that deactivation of Ru sulfide in HDS reactions has prevented its use. However, at least in the case of HDN it has been demonstrated that addition of Ru to Mo catalysts results in $\mathrm{Ru}$ species that are resistant to deactivation [3].

Following the style of our previous work, we have initially prepared supports with variable amount and type of acidity, from pure Lewis acidic gamma-alumina, to increasingly Bronsted acidic silica-aluminas. On these supports, we have deposited Ru oxide to various loading levels, altering the overall acidity of the catalysts. There is no systematic work on the effect of Ru oxide coverage on the acidity of supports, thus that question will be answered by this research. There are works, however, on the role of Ru precursors on the resulting properties of catalysts. In particular, highly interacting Ru with supports produced better HDN catalysts than less interacting ones [2]. High interaction with zeolitic supports was obtained by ion exchange with $\left[\mathrm{Ru}\left(\mathrm{NH}_{3}\right)_{6}\right]^{3+}$, as 
opposed to impregnation with $\mathrm{Ru}$ chloride or deposition from $\mathrm{Ru}$ carbonyls. Such result is not as relevant for our work since we are not attempting to produce Ru metal but Ru oxides in strong interaction with the supports. Of more importance is the result obtained by various authors that $\mathrm{Cl}$ is hard to remove by reduction and interferes with hydrogen chemisorption [4]. Additionally, in our work, $\mathrm{Cl}$ would interfere with the control of the acidic functionalities. Thus, to completely avoid the presence of $\mathrm{Cl}$ in the preparation, and to produce supported $\mathrm{Ru}$ oxide, the precursor salt chosen here is $\mathrm{Ru}(\mathrm{NO})\left(\mathrm{NO}_{3}\right)_{3}$.

The degree of dispersion of the oxide, and thus its degree of interaction with the support and its reducibility, is affected by the extent of precursor reaction with the support $\mathrm{OH}$, and by the conditions of drying, calcination and reduction. The reaction with the support is hereby controlled by the $\mathrm{pH}$ of the impregnating solution. Acidic $\mathrm{pH}$ have been observed to produce more uniform, sheet-like, distribution of nxide than neutral or basic $\mathrm{pH}$ [5]. Drying is performed under mild conditions (room temperature, followed by heating to $373 \mathrm{~K}$ ) and calcination is performed at $573 \mathrm{~K}$ in the absence of oxygen, since oxygen leads to oxidation and sintering of $\mathrm{Ru}^{+}$. The final treatment, reduction, is performed in situ prior to reaction, at $573 \mathrm{~K}$ with $10 \%$ hydrogen-helium mixture. The acidity, reduced Ru oxide dispersion, and catalytic activity for pyridine HDN will be tested in subsequent work.

\section{REFERENCES}

1. X. Wu, B.C. Gerstein, T.S. King, J. Catal. 118, 238-254 (1989)

2. T.G. Harvey, T.W. Matheson, J. Catal. 101, 253-261 (1986)

3. A.S. Hirschon, R.B. Wilson, R.M. Laine, Appl. Catal. 34, 311-316 (1987)

4. T. Narita, H. Miura, K. Sugiyama, T. Matsuda , R.D. Gonzalez, J. Catal. 103, 492-495

(1987); K. Lu, B.J. Tatarchuk, J. Catal. 106, 166-175 (1987); ibid., 106, 176-187 (1987)

5. A. Bossi, F. Garbassi, A. Orlandi, G. Petrini, L. Zanderighi 


\section{ACKNOWLEDGEMENTS \\ Funding}

This work was carried out with funds from DOE (Grant DE-FG22-89PC89771), partial support from NSF (Grant No. RII-8610671) and from the Commonwealth of Kentucky (EPSCoR Program).

\section{PUBLICATIONS}

Portions of the work here described have been presented at National Meetings of the American Institute of Chemical Engineers (San Francisco 1991, Miami 1992), and have appeared in Analytical Chemistry Letters (1990), and in Journal of Catalysis (1992). Several other manuscripts have been submitted.

\section{PERSONNEL}

Rajagopal Sakamuri, Post Doctoral Research Associate.

Jorge Marzari, PhD student.

Thomas Grimm, MEng student. 

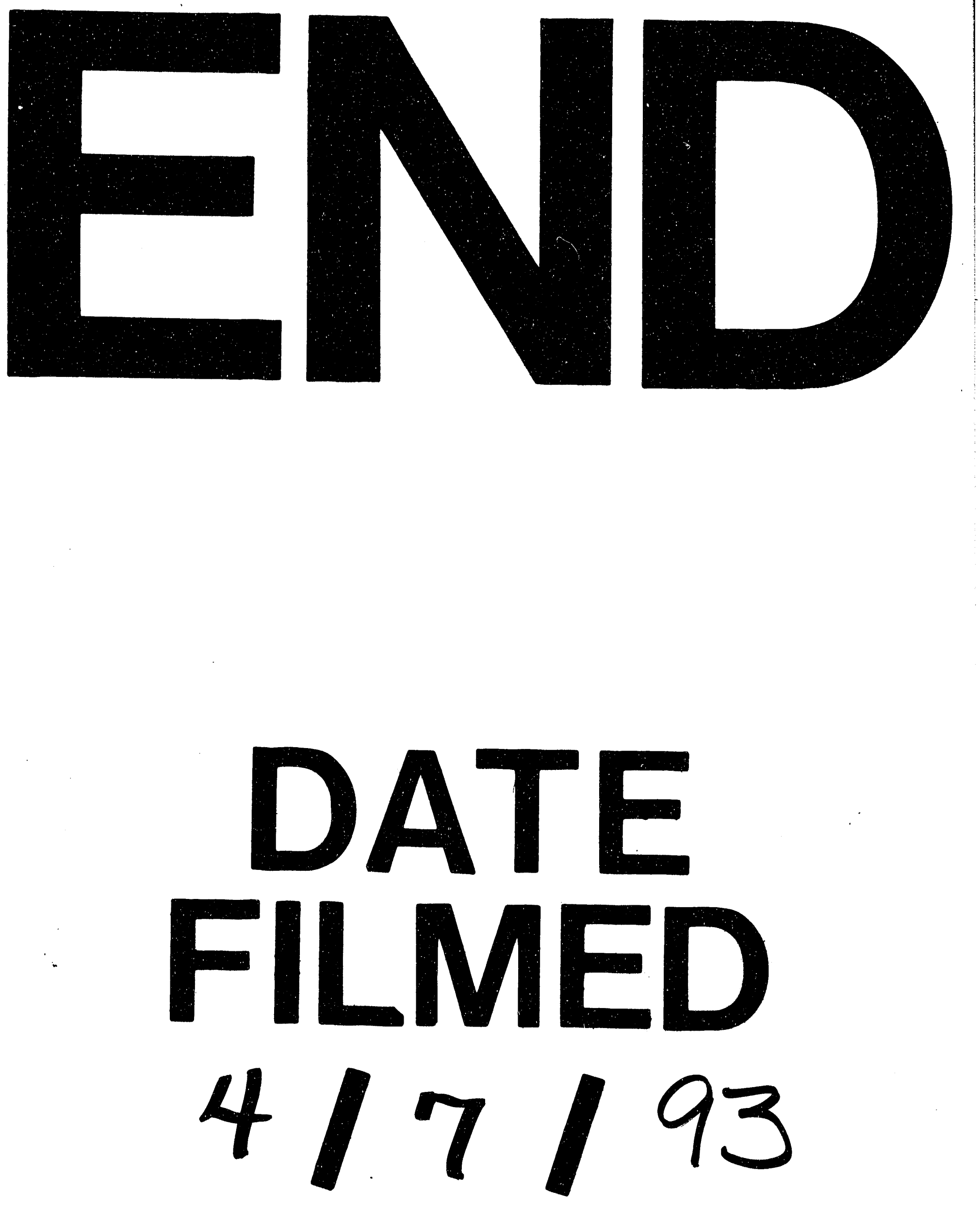
